\title{
VARIAÇÃO DA QUALIDADE DA MADEIRA EM CLONES DE Eucalyptus urophylla S.T. BLAKE DA ILHA DE FLORES, INDONÉSIA
}

\section{OSMAR FRANCISCO RUY}

Orientador: Prof. Dr. Mário Ferreira

Dissertação apresentada à Escola Superior de Agricultura "Luiz de Queiroz ", da Universidade de São Paulo, para obtenção do título de Mestre em Ciências, Área de Concentração: Ciência e

Tecnologia de Madeira

\section{PIRACICABA}

Estado de São Paulo - Brasil

Maio - 1998 
Dados Internacionais de Catalogação na Publicação (CIP) DIVISÃo DE BIBLIOTECA E DOCUMENTAÇÃO - Campus "Luiz de Queiroz"/USP

Ruy, Osmar Francisco

Variação da qualidade da madeira em clones de Eucalyptus urophylla S.T. Blake da llha de Flores, Indonésia / Osmar Francisco Ruy. - - Piracicaba, 1998.

$69 \mathrm{p}$. : il.

Dissertação (mestrado) - - Escola Superior de Agricultura Luiz de Queiroz, 1998. Bibliografia.

1. Casca 2. Clone de eucalipto 3. Densidade 4. Fibra de madeira 5. Madeira de eucalipto 6. Qualidade 7. Tecnologia de madeira I. Título

CDD 634.9734 


\section{ERR A T A}

Página vii. Onde se lê fenorípico, leia-se fenotípico.

Página ix. Onde se lê 6 anos, leia-se 9 anos.

Página xi. Onde se lê 6 years-old, leia-se 9 years-old.

Página 13. Onde se lê parâmentros, leia-se parâmetros.

Página 37. Onde se lê 6,18, leia-se $6,88 \mu \mathrm{m}$.

Página 39. Onde se lê $0,61-0,69,0,60-0,68,0,54-0,65 \mathrm{~g} / \mathrm{cm}^{3}$, leia-se $0,61-0,69$, $0,60-0,68,0,54-0,65,0,57-0,63 \mathrm{~g} / \mathrm{cm}^{3}$.

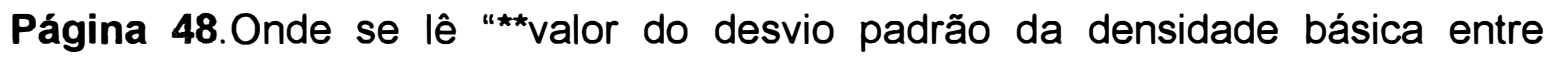
estacas", leia-se **valor do desvio padrão da percentagem de casca média entre estacas.

Página 49. Onde se lê " "valor do desvio padrão da densidade básica entre estacas", leia-se **valor do desvio padrão do comprimento médio da fibra entre estacas.

Página 51.Onde se lê "**valor do desvio padrão da densidade básica entre estacas", leia-se **valor do desvio padrão da largura média da fibra entre estacas.

Página 52. Onde se lê "**alor do desvio padrão da densidade básica entre estacas", leia-se **valor do desvio padrão do diâmetro do lume médio da fibra entre estacas.

Página 53. Onde se lê "**valor do desvio padrão da densidade básica entre estacas", leia-se *kalor do desvio padrão da espessura média da parede da fibra entre estacas.

Página 61. Onde se lê OLIVEIRA, T. da S., leia-se OLIVEIRA, J. T. S

Página 69. Onde houver ( ), entenda-se como número de identificação da parcele no banco clonal. 


\title{
Dedicatória
}

À Deus pelo dom da vida.

\begin{abstract}
À minha esposa Carina e aos meus filhos Renato e Victória pela compreensão, estímulo e carinho dedicados durante toda a vida, em especial durante a execução deste trabalho.
\end{abstract}

Aos meus pais Oswaldo e Maria, pela formação moral $e$ intelectual que permitiram meu desenvolvimento pessoal e profissional. 


\section{AGRADECIMENTOS}

Aos professores do Departamento de Ciências Florestais da ESALQ/USP pelo apoio, em especial aos amigos: Prof. Dr. Mário Ferreira, Prof. Dr. Mário Tomazello Filho e Prof. Dr. José Otávio Brito.

Aos funcionários do Departamento de Ciências Florestais da ESALQ/USP, em especial, Maria Ap. Bermudes, Maria Regina Buch, Udemilson Luis Ceribelli, Luis Eduardo Facco e Milton Ribeiro.

À Champion Celulose e Papel Ltda pelo apoio e oportunidade.

Ao CNPq ( Conselho Nacional de Desenvolvimento Científico e Tecnológico ) pelo suporte financeiro.

À todos os amigos que incentivaram este trabalho. 


\section{SUMÁRIO}

Página

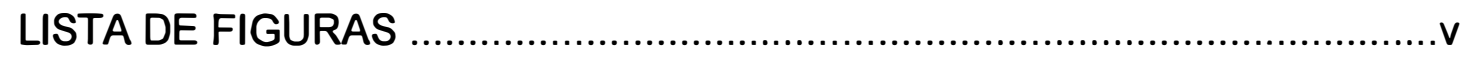

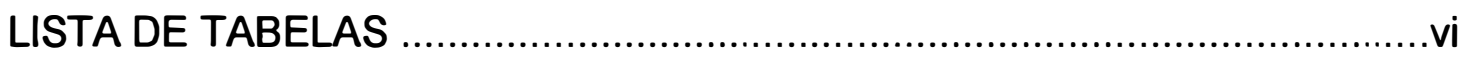

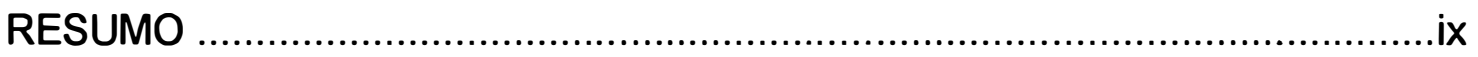

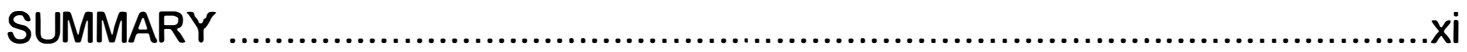

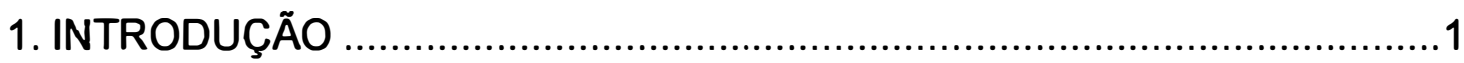

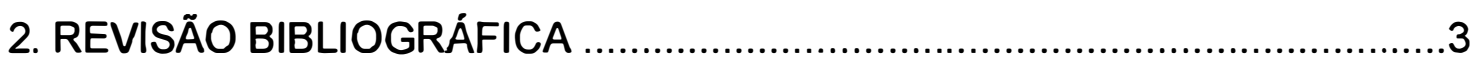

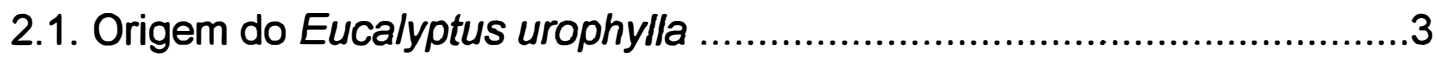

2.2. Importância do Eucalyptus urophylla no Brasil .......................................5

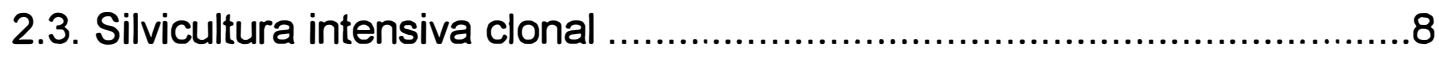

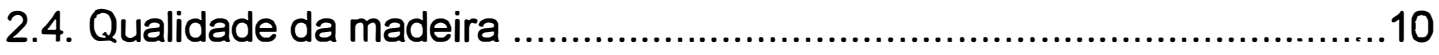

2.5. Densidade básica e características anatômicas .................................14

2.6. Amostragem tecnológica da madeira .................................................15

2.7. Característica da madeira de Eucalyptus urophylla ............................17

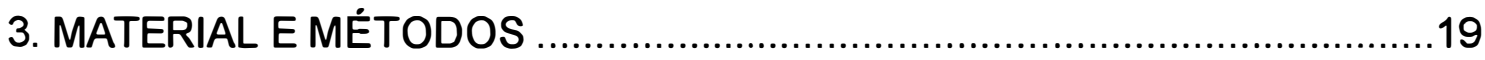

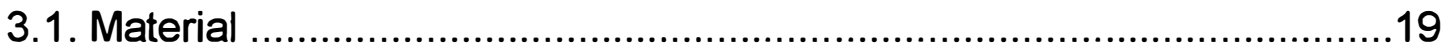

3.1.1. Caracterização da população clonal ..........................................19

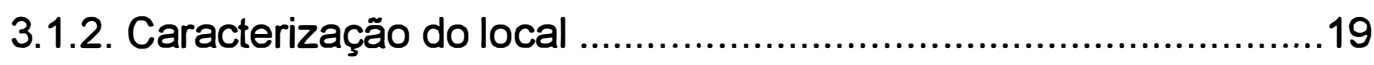

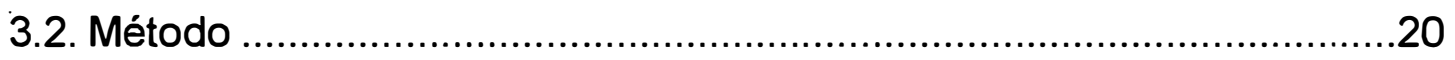

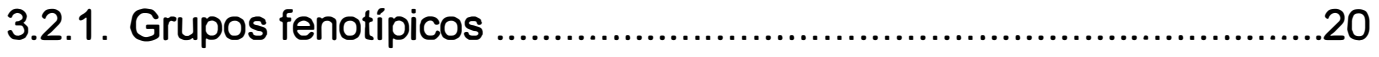

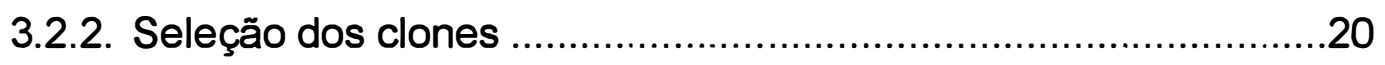

3.2.3. Avaliação dos parâmetro da qualidade da madeira ....................21

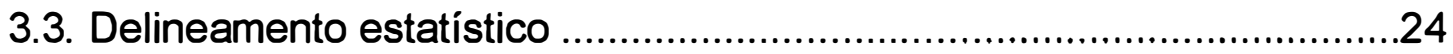

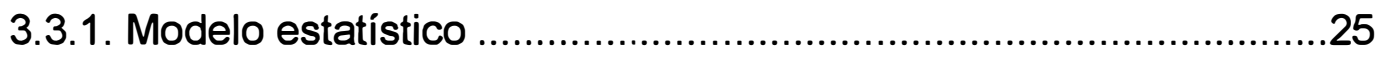

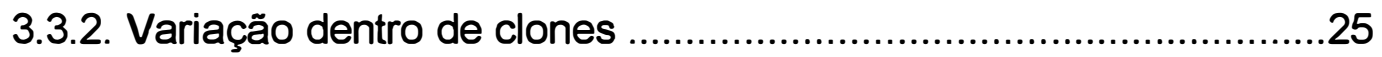

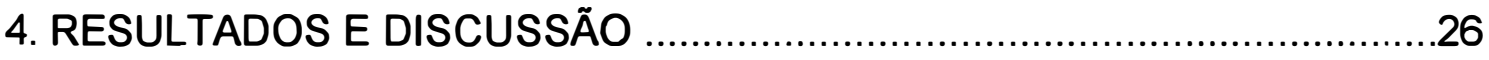

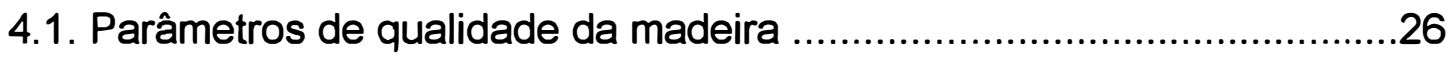

4.2. Teste de comparação de médias entre grupos fenotípicos ...................32

4.3. Teste de comparação de médias dentro de grupos fenotípicos ............38

4.4. Variação dos parâmetros tećnológicos dentro de clones ......................46 


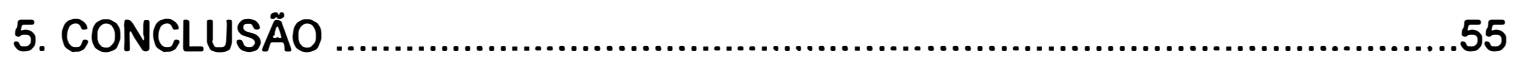

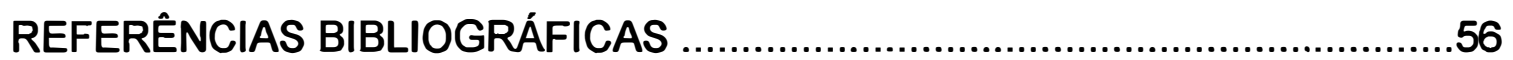

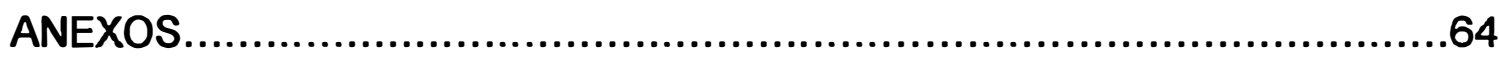




\section{LISTA DE FIGURAS}

FIGURAS

Páginas

1.Coleta das amostras para análise dos parâmetros de qualidade da madeira

2.Desvio padrão da densidade da madeira para grupos fenotípicos e clones de E. urophylla

3.Desvio padrão da percentagem de casca para grupos fenotípicos e clones de $E$. urophylla

4.Desvio padrão do comprimento das fibras para grupos fenotípicos e clones de $E$. urophylla..

5.Desvio padrão da largura das fibras para grupos fenotípicos e clones de E. urophylla 51

6.Desvio padrão do diâmetro do lume das fibras para grupos fenotípicos e clones de E. urophylla

7.Desvio padrão da espessura da parede das fibras para grupos fenotípicos e clones de E. urophylla 


\section{LISTA DE TABELAS}

TABELAS

Páginas

1.Parâmetros de qualidade da madeira analisados para os 3 clones de $E$. urophylla, pertencentes ao grupo fenorípico 1.

2. Parâmetros de qualidade da madeira analisados para os 3 clones

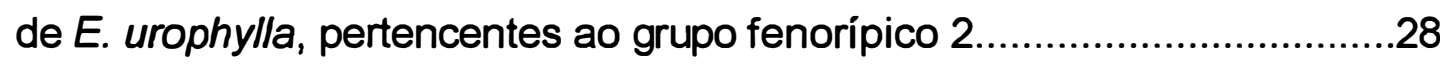

3.Parâmetros de qualidade da madeira analisados para os 3 clones de $E$. urophylla, pertencentes ao grupo fenorípico 3

4.Parâmetros de qualidade da madeira analisados para os 3 clones de $E$. urophylla, pertencentes ao grupo fenorípico 4

5.Análise da variância (teste F) para os parâmetros de qualidade da madeira: dados de valores de quadrado médio

6.Resultado do teste de Tukey para parâmetros de qualidade da madeira: densidade básica.

7.Correlação entre parâmetros de qualidade da madeira e características fenotípicas quantitativas de clones de $E$. urophylla, segundo LOPEZ (1992).

8.Resultados do teste Tukey para parâmetros de qualidade da madeira: comprimento das fibras.

9.Resultados do teste Tukey para parâmetros de qualidade da madeira: diâmetro do lume das fibras.

10.Resultados do teste Tukey para parâmetros de qualidade da madeira: densidade básica da madeira.

11.Resultados do teste Tukey para parâmetros de qualidade da madeira: percentagem de casca.

12.Resultados do teste Tukey para parâmetros de qualidade da madeira: comprimento das fibras

13.Resultados do teste Tukey para parâmetros de qualidade da madeira: diâmetro do lume das fibras. 
14. Resultados do teste Tukey para parâmetros de qualidade da madeira: espessura da parede das fibras..............................................43

15.Densidade básica da madeira dos clones de E. urophylla e

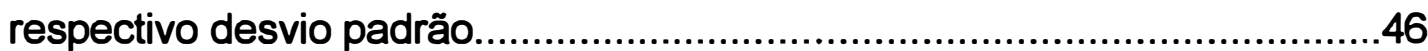

16.Percentagem de casca média da madeira dos clones de $E$. urophylla e respectivo desvio padrão.

17. Comprimento da fibra médio da madeira dos clones de $E$. urophylla e respectivo desvio padrão.

18.Largura da fibra da madeira dos clones de E. urophylla e respectivo desvio padrão.

19.Diâmetro do lume da fibra da madeira dos clones de $E$. urophylla e respectivo desvio padrão.

20. Espessura da parede da fibra média da madeira dos clones de $E$. urophylla e respectivo desvio padrão. 


\title{
VARIAÇÃO DA QUALIDADE DA MADEIRA EM CLONES DE Eucalyptus urophylla S.T. BLAKE DA ILHA DE FLORES, INDONÉSIA
}

\author{
Autor: OSMAR FRANCISCO RUY \\ Orientador: PROF.DR. MÁRIO FERREIRA
}

\section{RESUMO}

O objetivo do presente trabalho, foi de estudar os parâmetros de qualidade da madeira ( densidade básica, comprimento, largura, diâmetro do lume e espessura da parede das fibras ), em clones de Eucalyptus urophylla, procedentes da llha de Flores, Indonésia, agrupados pelas suas características silviculturais e botânicas.

A população base constitui-se de um banco clonal da espécie, com 6 anos de idade, instalado no município de Aguaí - SP., no Horto Florestal Nossa Senhora Aparecida, de propriedade da Champion Papel e Celulose Ltda. Nesse banco clonal, os clones foram agrupados em 5 grupos fenotípicos, de acordo com LOPEZ ( 1992 ), considerando suas características silviculturais ( produtividade, altura, desrama, sobrevivência, forma, etc. ) e botânicas (tronco, casca, folha, fruto, etc. ). Foram selecionados 3 clones para cada grupo fenotípico, com um total de 12 clones, excluindo-se o grupo fenotípico 5, por não atender aos critérios de seleção. Para cada clone foram selecionadas as estacas (árvores) em 3 classes de diâmetro ( pequena, média e grande), compreendendo um total de 108 estacas. Após o corte dessas estacas foram obtidos discos de madeira e casca, em 5 posições do tronco, que foram analisados para: espessura de casca, densidade básica da madeira e dimensões das fibras.

Os resultados das análises dos parâmetros de qualidade da madeira, obtidos para os 4 grupos fenotípicos, mostraram não haver diferenças significativas entre 
os grupos fenotípicos, sendo observadas maiores variações dentro do que entre os grupos fenotípicos. Com base nos resultados recomenda-se que nos ensaios de seleção, sejam incluídos conjuntamente parâmetros de qualidade da madeira e fenotípicos, para a seleção de clones superiores de E. urophylla. 


\title{
WOOD QUALITY VARIATION IN Eucalyptus urophylla S.T. BLAKE CLONES FROM FLORES ISLAND, INDONÉSIA
}

\author{
Author: OSMAR FRANCISCO RUY \\ Adviser: PROF. DR. MÁRIO FERREIRA
}

\section{SUMMARY}

The main objectives of this research were to analyse the wood quality parameters (wood basic, fiber length, width, diameter and wall thickness) in $E$. urophylla clones from Flores Island, Indonesia, grouped by silvicultural and botanical characteristics.

The clonal bank of the specie - the basic population - was a 6 years-old plantation located in Aguai - SP, Brazil. The clones were classified in to 5 phenotypic groups, according LOPEZ (1992), considering the silvicultural (yield, height, natural prunning, surviral, tree form, etc,) and botanical (trunk, bark, leaf, fruit, etc.) characteristics. Theree clones were selected for each phenotype group, with a total of 12 clones, excluding the group 5, for not attending the selection criterion. The trees (ramets) of 3 different diameters (small, medium, large) in a total of 108 were selected form each clone. After felling the trees, wood samples including bark were obtained in 5 positions of the trunk. The wood samples were analysed for bark thickness, wood basic density and fiber dimensions.

The results obtained from the 4 phenotypic groups, regarding the wood parameters quality, showed that there is no significative differences among groups. Its was observed that the largest variations were within groups than among groups. Considering the results of this research it is recommended that, during further 
genetic selection programm, wood quality parameters have to be included together with phenotypic parameters, in order to select superior clones of $E$. urophylla. 


\section{INTRODUÇÃO}

O gênero Eucalyptus ocorre quase que exclusivamente na Austrália, com mais de 600 espécies e inúmeras procedências e variedades. Sendo que das espécies que ocorrem fora da Austrália, em número de seis, três ocorrem no arquipélago da Indonésia, quais sejam: E. urophylla, E.alba, E. deglupta. O Eucalyptus urophylla ocorre naturalmente neste arquipélago, nas ilhas de Timor, Flores, Andora, Lomblen, Pantar, Alor e Wetar. (VIEIRA \& BUCSAN, 1980).

Na maior parte de sua área de ocorrência, o Eucalyptus urophylla é a única espécie do gênero, que se apresenta isoladamente, com exceção para determinadas áreas das ilhas de Timor, Alor, Lomblen, Wetar e Flores, onde encontra-se geralmente associado ao Eucalyptus alba, em altitudes de até $500 \mathrm{~m}$. (LOPEZ, 1992)

$\mathrm{Na}$ ilha de Flores, a ocorrência de Eucalyptus urophylla segundo MARTIN \& COSSALTER (1975), se dá a partir da cidade de Maumere, localizada na parte leste da ilha.

O Eucalyptus urophylla, foi introduzido no Brasil em 1919 por Edmundo Navarro de Andrade, no município de Rio Claro-SP, sendo erroneamente identificado como Eucalyptus alba. A descrição da espécie só foi oficialmente adotada a partir de 1977 , após os estudos feitos por S. T. Blakely.(PÁSZTOR, 1990)

O Eucalyptus urophylla é uma das espécies de maior importância para países tropicais do mundo, especificamente aqueles do hemisfério sul. No Brasil até o ano de 1966, a espécie, juntamente com o Eucalyptus saligna e E. grandis, era uma das mais plantadas nas regiōes típicas de cerrado, estações secas pronunciadas. A partir de 1966, passou a ser substituída pelo Eucalyptus grandis, para a produção de madeira para celulose e papel, e pelo Eucalyptus citriodora, E. tereticornis e E. camaldulensis para fins energéticos. Estima-se que hoje existam acima de 600.000 ha plantados com a espécie e seus híbridos no Brasil, face aos problemas surgidos nos plantios de $E$. grandis nas zonas tropicais. A susceptibilidade ao cancro do eucalipto, aliada a baixa capacidade de rebrota em climas sujeitos a deficiências hídricas, limitaram a utilização extensiva do $E$. 
grandis. Como conseqüência, a síntese do híbrido $E$. grandis $X E$. urophylla, passou a ser a base da silvicultura intensiva clonal brasileira. (FERREIRA, 1996).

Sendo o E. urophylla uma espécie de grande potencialidade para regiões de clima quente e de elevados déficits hídricos, autores como PÁSZTOR (1975), citam que a espécie e seus híbridos, tem sido bastante utilizada no Brasil em programas de reflorestamento, em razão do seu bom desenvolvimento em regiões tropicais, da boa qualidade de sua madeira para carvão, celulose, serraria e, principalmente, pela sua resistência ao Cryphonectria cubensis.

Tendo como base essas considerações, justifica-se a importância do melhor conhecimento da espécie quanto a sua alta variabilidade genética, adaptação a diferentes condições ecológicas, a ocorrência da interação genótipo $X$ ambiente e as suas implicações nas características da madeira, a fim de aproveitar o seu grande potencial adaptativo às áreas brasileiras. Podendo assumir uma posição estratégica nos programas de melhoramento genético de Eucalyptus spp. em áreas que apresentem vocação para a silvicultura intensiva clonal. Pois possui grande variedade fenotípica e silvicultural que pode ser observadas inclusive ao nivel de clone, permitindo a sua exploração em diversos ambientes. A utilização de clones vigorosos, resistentes a doenças e déficits hídricos, com alta produtividade e grande homogeneidade qualitativa da madeira, está sendo a base dos novos povoamentos florestais.

Pelo exposto o presente trabalho tem como objetivo estudar os parâmetros de qualidade da madeira ( densidade básica, percentagem de casca, comprimento, largura, diâmetro do lume e espessura das paredes das fibras), em clones de Eucalyptus urophylla, procedentes da llha de Flores, Indonésia, agrupados pelas suas características silviculturais e botânicas. 


\section{REVISÃO BIBLIOGRÁFICA}

\subsection{Origem do Eucalyptus urophylla}

De acordo com VIEIRA \& BUCSAN (1980), o gênero Eucalyptus ocorre quase que exclusivamente na Austrália, com mais de 600 espécies e inúmeras procedências e variedades. Sendo que das espécies que ocorrem fora da Austrália, em número de seis, três ocorrem no arquipélago da Indonésia, quais sejam: E. urophylla, E.alba, E. deglupta. O Eucalyptus urophylla ocorre naturalmente neste arquipélago, nas ilhas de Timor, Flores, Andora, Lomblen, Pantar, Alor e Wetar. Estando localizadas entre as coordenadas geográficas $119^{\circ}-128^{\circ} \mathrm{E}$ de longitude e $6^{\circ}-11^{\circ} \mathrm{S}$ de latitude, em altitudes que variam de 300 a $3000 \mathrm{~m}$. A precipitação média na região varia de 1000 a 1500 mm/ano, com maior concentração de chuvas no verão, a estação seca varia de 3 a 6 meses, com temperatura média das máximas de $29^{\circ} \mathrm{C}$ e a média das minímas entre 8 a $12^{\circ} \mathrm{C}$.

Segundo LOPEZ (1992), na maior parte de sua área de ocorrência, o Eucalyptus urophylla é a única espécie do gênero, que se apresenta isoladamente, com exceção para determinadas áreas das ilhas de Timor, Alor, Lomblen, Wetar e Flores, onde encontra-se geralmente associado ao Eucalyptus alba, em altitudes de até $500 \mathrm{~m}$.

$\mathrm{Na}$ ilha de Flores, a ocorrência de Eucalyptus urophylla segundo MARTIN \& COSSALTER (1975), se dá a partir da cidade de Maumere, localizada na parte leste da ilha. Os povoamentos naturais ocorrem sobre cinco regiões determinadas pelos montes Egon, Wukoh, Lewotobi (1700 m), Mandiri (1500 m) e Leworanhang (1120 m ).

BRASIL (1983), relata que na ilha de Timor o Eucalyptus urophylla ocorre em altitudes que variam de 800 a $2700 \mathrm{~m}$ e o Eucalyptus alba entre 80 e 1300m. Nas regiões onde as associações aparecem, o Eucalyptus urophylla é a espécie dominante. Em Flores, o Eucalyptus alba aparece entre 400 a $450 \mathrm{~m}$ e o Eucalyptus urophylla de 450 a $1350 \mathrm{~m}$ de altitude. Nas demais ilhas o Eucalyptus urophylla cresce em povoamentos puros a partir de 550 a $600 \mathrm{~m}$ e o $E$. alba em altitudes menores. 
Em geral, as populações de Eucalyptus urophylla ocupam os sítios mais férteis, enquanto que as populações de Eucalyptus alba ocupam sítios de menor fertilidade e com exposição montanhosa ( MARTIM \& COSSALTER, 1975).

VIEIRA (1983), relata que nas áreas de contato é comum encontrar indivíduos hibridos, com características intermediárias entre as espécies. Entretanto, morfológicamente, há diferenças fundamentais entre as mesmas. O Eucalyptus urophylla uma árvore de grande porte, sem tortuosidade, com forte dominância apical, casca do tipo rugosa e folhas do tipo afiladas e o Eucalyptus alba uma árvore de pequeno porte, tortuosa, sem dominância apical, folhas largas e com casca lisa.

PÁSZTOR et alii (1990), citam, em trabalhos efetuados com a espécie, a constatação de grande variabilidade existente dentro da zona de distribuição natural, com base em resultados de altura, diâmetro e caracteres morfológicos, que variam de acordo com as altitudes das procedências. O Eucalyptus urophylla de uma faixa altitudinal baixa (300 a $1200 \mathrm{~m}$ ) apresenta uma taxa de crescimento em altura e diâmetro e de sobrevivência, superior àquelas apresentadas por procedências de altitudes acima de $1500 \mathrm{~m}$, sendo que esta variação ocorre gradualmente ao longo da escala altitudinal.

MARTIN \& COSSALTER (1975), descrevem que o Eucalyptus urophylla da ilha de Flores é bastante diferente do encontrado na ilha de Timor. Em Timor, apresenta características uniformes de folhagem, casca e frutos, enquanto que em Flores existe uma grande desuniformidade destas características. Em Timor o tronco apresenta-se recoberto por uma casca rugosa até a extremidade dos galhos, enquanto que em Flores a casca rugosa às vezes inexiste, ou existe em proporções variadas.

Isto, segundo os autores, leva a pensar que a proporção de casca rugosa seria uma variação clinal em função do aumento de altitude. Chegam, os autores, a admitir a presença de duas variedades separadas pela altitude: a variedade com casca fibrosa (em altitudes mais elevadas), e a variedade de casca lisa ( em altitudes médias). A variedade com casca fibrosa é chamada, por alguns, de Eucalyptus urophylla, ao passo que a variedade com casca fina é conhecida, no Brasil, impropriamente como Eucalyptus urophylla var. platyphylla, e apresenta potencial para regiões de clima tropical. 
Em relação a denominação para o Eucalyptus urophylla com casca lisa MARTIM (1987) citado por LOPES (1992), explica a possibilidade dessas árvores serem híbridas, com características semelhantes ao Eucalyptus urophylla e ao Eucalyptus alba, portanto o autor admite que as árvores de casca lisa possam ser um híbrido de Eucalyptus alba $x$ Eucalyptus urophylla.

De maneira geral, podemos dizer que a casca de eucalipto assume grande importância industrial, pois varia suas características de acordo com a espécie, idade, altura no tronco e "site". No caso do $E$. urophylla, as árvores oriundas de altitude acima de $1000 \mathrm{~m}$ apresentam o tronco recoberto com casca fibrosa sendo a sua madeira, portanto, não desejável nas indústrias de celulose e papel o uso da sua madeira. A casca fibrosa apresenta uma série de desvantagens no processo, desde o descascamento até a qualidade da polpa branqueada produzida. As árvores com casca fibrosa apresentam cerne mais duro, susceptibilidade ao ataque da broca do tronco (Platypus sp) e a susceptibilidade ao fungo Cryphonectria cubensis, causador do cancro do eucalipto, quando os plantios são em regiões ecologicamente não adequadas.

A ampla diversidade fenotípica das populações de Eucalyptus urophylla tem levado diversos autores a lançarem diferentes propostas para tentar explicá-la. Assim, MARTIN \& COSSALTER (1975) destacam também a hipótese de uma possível introgressão do Eucalyptus alba.

\subsection{Importância do Eucalyptus urophylla no Brasil.}

Segundo PÁSZTOR et alii (1990), o Eucalyptus urophylla, foi introduzido no Brasil em 1919 por Edmundo Navarro de Andrade, no município de Rio Claro-SP, sendo erroneamente identificado como Eucalyptus alba. A descrição da espécie só foi oficialmente adotada a partir de 1977, após os estudos feitos por S. T. Blakely.

Segundo FERREIRA (1996), o Eucalyptus urophylla é uma das espécies de maior importância para países tropicais do mundo, especificamente aqueles do hemisfério sul. No Brasil até o ano de 1966, a espécie, juntamente com o Eucalyptus saligna e $E$. grandis, era uma das mais plantadas nas regiões típicas de cerrado, estações secas 
pronunciadas. A partir de 1966, passou a ser substituída pelo Eucalyptus grandis, para a produção de madeira para celulose e papel, e pelo Eucalyptus citriodora, E. tereticornis e E. camaldulensis para fins energéticos.

Estima-se que hoje existam acima de 600.000 ha plantados com a espécie e seus híbridos no Brasil, face aos problemas surgidos nos plantios de $E$. grandis nas zonas tropicais. A susceptibilidade ao cancro do eucalipto, aliada a baixa capacidade de rebrota em climas sujeitos a deficiências hídricas, limitaram a utilização extensiva do $E$. grandis. Como conseqüência, a síntese do híbrido $E$. grandis $X E$. urophylla, passou a ser a base da silvicultura intensiva clonal brasileira.

Sendo o E. urophylla uma espécie de grande potencialidade para regiões de clima quente e de elevados déficits hídricos, autores como PÁSZTOR (1975), cita que a espécie e seus híbridos, tem sido bastante utilizada no Brasil em programas de reflorestamento, em razão do seu bom desenvolvimento em regiões tropicais, da boa qualidade de sua madeira para carvão, celulose, serraria e, principalmente, pela sua resistência ao Cryphonectria cubensis.

Segundo CAPITANI et alii (1987), sua introdução no Brasil foi bem sucedida, pois em sua origem ocorre naturalmente em diferentes condições climáticas e edáficas, possuindo grande plasticidade de adaptação a esses locais.

Graças a isso podemos notar trabalhos realizados, com esta espécie, nas mais diferentes regiões brasileiras, contribuindo para o desenvolvimento do setor florestal em áreas onde os reflorestamentos comerciais tornam-se limitantes face as condições desfavoráveis do local.

SANTOS et alii (1990), citam que o Eucalyptus urophylla é uma espécie de grande importância econômica para as zonas tropicais úmidas, sendo que as procedências de maior interesse são as mais tropicais. Os diversos ensaios de procedências instalados em diferentes países de clima tropical úmido revelam uma grande estabilidade de respostas da procedência.

CANEVA et alii (1993), cita o Eucalyptus urophylla como uma das principais espécies para celulose na região de Três Lagoas-MS, em solos extremamente arenosos. 
Em pesquisa com híbrido de E. grandis $\times$ E. urophylla no Estado de São Paulo, ODA \& FERREIRA (1982) observaram que, aos 14 meses, o hibrido apresentou uma superioridade em relação ao $E$. grandis, tendo ainda maior retidão de fuste e melhores características de ramificação.

Analisando a variação no comportamento silvicultural das populações de $E$. urophylla testadas, em diferentes condições ecológicas, autores como, PRODEPEF, (1976); CAPITANI et alii, (1987), concluiram que as procedências que apresentaram melhores crescimentos foram aquelas que na sua origem ocorrem em altitude abaixo de $1200 \mathrm{~m}$.

ZANI F. et alii (1990), citando os estudos de MOURA (1981), realizados com a espécie, na região centro-leste brasileira ( Estados de Minas Gerais e Espirito Santo), em diferentes condições climáticas e de solos, os quais revelaram que os melhores comportamentos silviculturais foram obtidos com procedências 9008 (M. Egon - Flores) com 410 m de altitude, 9016 (Dili - Timor) com 580 m e 1014 (N. Aileu - Timor) com 1210 $\mathrm{m}$ de altitude.

GOLFARI (1982), confirma estes resultados e relata que, em algumas localidades, as procedências ainda competem em igualdade ou, às vezes, superam o $E$. grandis e o E. tereticornis, além de possuir a vantagem de serem resistentes ao fungo causador do cancro.

Para as regiões de Bebedouro e Luiz Antonio-SP e Ribas do Rio Pardo-MS, FERREIRA et alii (1983) também confirmam o bom comportamento silvicultural das procedências de baixa altitude.

HIGA \& STURION (1991), em trabalho de avaliação da capacidade e crescimento de brotação de 13 espécies de eucalipto na região de Uberaba-MG, concluíram que o Eucalyptus urophylla, juntamente com o E. pilularis e E. camaldulensis apresentaram $100 \%$ de brotação e maior rapidez de crescimento.

Tendo como base essas considerações, justifica-se a importância do melhor conhecimento da espécie quanto a sua alta variabilidade genética, adaptação a diferentes condições ecológicas, a ocorrência da interação genótipo $X$ ambiente $e$ as 
suas implicações nas características da madeira, a fim de aproveitar o seu grande potencial adaptativo às áreas brasileiras. Podendo assumir uma posição estratégica nos programas de melhoramento genético de Eucalyptus spp. em áreas que apresentem vocação para a silvicultura intensiva clonal. A utilização de clones vigorosos, resistentes a doenças e déficits hídricos, com alta produtividade e grande homogeneidade qualitativa da madeira, está sendo a base dos novos povoamentos florestais.

\subsection{Silvicultura intensiva clonal.}

Os trabalhos desenvolvidos nas duas últimas décadas com melhoramento florestal, conseguiram elevar o nivel tanto produtivo como qualitativo das florestas comerciais.

Primeiro com trabalho via sexuada, melhorando a qualidade das sementes e consequentemente as características silviculturais das espécies e procedências utilizadas. $\mathrm{E}$, mais recentemente, utilizando técnicas de reprodução assexuada, está alcançando avanços sem precedentes na produtividade e na homogeneização da qualidade da madeira produzida, ultrapassando barreiras de ocupação de novas áreas, através da síntese de clones adaptados às mais diferentes condições bioclimáticas.

Essa nova silvicultura procura melhorar, segundo FERREIRA (1992), a adaptação das espécies/procedências e estabelecer bases genéticas mais sólidas para a silvicultura intensiva clonal. Apresentando opções que, combinadas com a silvicultura tradicional, abrirão um novo horizonte na eucaliptocultura.

Segundo BERTOLUCCI \& PERCHEL (1993), no Brasil a propagação vegetativa do eucalipto por enraizamento de estacas começou a ser desenvolvida no ínicio da década de 70 .

No ano de 1974 pesquisadores brasileiros começaram no desenvolvimeto de métodos de propagação vegetativa de estacas retiradas de brotações de cepas de eucalipto e em 1979, a primeira plantação clonal era estabelecida em uma área de 1000 ha no Estado do Espiríto Santo, obtendo-se ganhos expressivos em produtividade e qualidade da madeira. 
Segundo FERREIRA (1992), a silvicultura clonal baseia-se na seleção de árvores dentro de populações de espécies/procedências e pela utilização de técnicas de reprodução assexuada dessas árvores procurando-se utilizar toda a variação genética existente, em bases seguras e com os ganhos genéticos sucessivos não interrompidos, propiciando maior produção com melhor qualidade, no menor lapso de tempo por unidade de área.

Dentro deste contexto cabe dizer que os estudos dos métodos de seleção, bem como a variabilidade natural e a adequação ao uso da madeira (qualidade da madeira), tornam-se fundamentais na silvicultura intensiva clonal. Atualmente, o melhoramento genético florestal visa selecionar como genótipos superiores, não apenas indivíduos com excelentes características silviculturais, mas também tecnológicas, tais como: densidade básica da madeira, teor de lignina, rendimento em celulose, teor de extrativos e características da polpa.

Como exemplo desta nova metodologia FERREIRA (1992), cita que na Aracruz Florestal S/A, das 13 características selecionadas, 3 referem-se a qualidade da madeira, a densidade básica, porcentagem de casca e rendimento da polpa. E na República Popular do Congo, na seleção dos clones são incluídas a densidade básica da madeira e percentagem de casca. Nos testes clonais incluem-se o rendimento em pasta para celulose, número de $\mathrm{m}^{3}$ de madeira verde por tonelada de polpa, produção de toneladas de polpa/ha/ano e propriedades físicas da polpa.

No Brasil, além da Aracruz Florestal S/A, grandes projetos florestais utilizando a silvicultura clonal vem sendo instalados como base da expansão da industria de celulose e papel, principalmente nos Estados da Bahia, Maranhão e Amapá. Os excelentes resultados obtidos com o híbrido $E$. grandis $\times$ E. urophylla propagado clonalmente vem sendo, hoje, a principal justificativa para países como a China, Venezuela, África do Sul e Indonésia, introduzirem a silvicultura clonal em seus programas de abastecimento industrial de madeira (FERREIRA, 1996).

Segundo CAMPINHOS Jr. \& SILVA Jr. (1990), para produzir "super hibridos" para produção de madeira para celulose no Estado do Espírito Santo, são selecionadas 
árvores de $E$. grandis e $E$. urophylla, que apresentam excepcionais qualidades fenotípicas e genotípicas, principalmente para volume, plasticidade para "sites", qualidade da madeira para polpeamento, rendimento de polpa e qualidade de fibra e que são cruzadas para programas futuros de propagação vegetativa. E, simultâneamente, os pomares de sementes para produção de híbridos por polinização aberta também são instalados, utilizando-se as combinações de clones de E. grandis e E. urophylla e de $E$. grandis e E. pellita, com o objetivo de produzir sementes hibridas que satisfaçam as exigências tanto da área florestal como industrial: volume, resistência a doenças, adaptação ao meio ambiente e qualidade da madeira para produção de polpa branqueada.

GRIFFIN \& RIVELLI (1993) citam que, em 1991, aproximadamente 20 empresas brasileiras já operavam programas de plantios clonais. Sendo que $65 \%$ da produção, das 25 maiores empresas, eram de eucalipto e destes $29 \%$ oriundos de estacas enraizadas.

É importante ressaltar que a silvicultura intensiva clonal vem adquirindo grande importância, pois propicia a redução na idade de exploração, maior produção de madeira de melhor qualidade, no menor tempo por unidade de área; racionalização das atividades operacionais e redução nos custos de exploração e transporte tornando o setor florestal brasileiro ainda mais competitivo a nível mundial.

\subsection{Qualidade da madeira.}

Uma definição consagrada por vários autores diz que "a qualidade da madeira está associada ao tipo de uso e ao processo empregado para sua transformação em produto industrializado." Quanto mais homogênea for a matéria-prima, mais rápida e econômicamente será atingida a otimização do processo industrial.

A densidade básica da madeira, definida como uma medida da quantidade da substância madeira por unidade de volume (grama por centímetro cúbico ou tonelada por metro cúbico), é um dos mais importantes fatores a serem considerados dentre as 
diversas físicas da madeira, por ser complexa e resultante da combinação de diversos fatores.

Como parâmetro de aferição da qualidade, a densidade básica da madeira possui ampla aceitação pelo fato de estar correlacionada com diversas características e propriedades de uso do produto final e pela simplicidade de sua determinação. Além disso, é uma característica passível de melhoramento por apresentar alto valor de herdabilidade e variabilidade entre indivíduos.

Entre as propriedades físicas da madeira a densidade básica é a mais utilizada como parâmetro de seleção, pois é influenciada pela base genética, ambiental, e resultado da interação desses dois fatores.

DEMUNER \& BERTOLUCCI (1994), relatam, a importância do estudo do efeito de fatores genéticos e ambientais sobre as características de interesse. Sendo a densidade básica o parâmentro de estudo mais utilizado dentro do gênero Eucalyptus para se avaliar essas características. Citam o exemplo da Aracruz Florestal S/A que, utilizando dados de densidade básica da madeira para seleção de matrizes para plantios clonais, obteve aumento significativo na produtividade e na uniformidade da floresta, consequentemente, produzindo pasta celulósica mais homogênea de melhor qualidade.

Desta forma, a densidade básica da madeira afeta diretamente os produtos originários da madeira tornando-se de fundamental importância o seu conhecimento para um melhor resultado de trabalho.

RIBEIRO \& ZANI (1983), citam que de todas as fontes de variação da densidade básica da madeira, (entre espécies, entre procedências, entre árvores, dentro de árvores nos sentidos radial e longitudinal, com a idade e com o ambiente), para fins de melhoramento genético, a variação entre árvores de uma mesma população é a mais importante, pois permite a seleção para altas e baixas densidades, orientando os trabalhos de qualidade da madeira para produção de celulose.

A partir de estudos sobre o uso adequado da densidade básica como índice de qualidade da madeira de eucalipto para produçāo de celulose, FOELKEL et ali (1990), alerta que o componente espécie é muito importante no processo, pois madeiras de 
espécies diferentes e que apresentam o mesmo valor de densidade não são tecnológicamente e/ou anatomicamente semelhantes.

Segundo HILLIS (1978), a densidade básica da madeira é a característica mais simples e um útil índice para a avaliação da qualidade, estando altamente correlacionada com a produção de polpa e com as propriedades mecânicas da madeira.

Para a indústria de celulose e papel, a densidade da madeira deve ser vista sob vários aspectos, sendo que muitas considerações podem ser feitas em torno dela.

Segundo BUSNARDO et alii (1983) a avaliação adequada da densidade básica da madeira, proporciona uma indicação de rendimento do processo empregado, como também indica o comportamento de algumas propriedades físico-mecânicas da polpa.

Para BARRICHELO \& BRITO (1976), a fabricação de celulose química, semiquímica ou mesmo termo-mecânica a densidade ideal fica em torno de 0,500 g/cm3. Sendo esta um importante fator a ser considerado na produção da celulose obtida de uma determinada madeira em termos de rendimento por unidade de volume. Acrescenta ainda, que a velocidade de impregnação da madeira pelo licor de cozimento, e consequente rítmo de deslignificação, são influenciados pela densidade, sendo de se esperar que dentro de uma mesma espécie, madeiras menos densas sejam mais facilmente deslignificadas.

Ela é também importante na determinação da qualidade do carvão vegetal, pois quanto mais denso o carvão, maior é a quantidade de carbono utilizável como redutor, ou maior a quantidade de energia por unidade de área, segundo BRITO \& BARRICHELO, (1976) e JUVILLAR, J.B, (1980).

Segundo BARRICHELO \& BRITO (1980), existem estudos na literatura mostrando a influência da densidade básica sobre várias características da madeira. Para o carvão vegetal observa-se que a densidade básica da madeira exerce influência direta sobre a sua densidade aparente. Portanto, a escolha de espécies de eucaliptos que apresentem densidades elevadas é altamente vantajoso para os principais usos do carvão por elas produzido. 
SHIMOYAMA \& BARRICHELO (1989), comentam sobre a herdabilidade como um indicador do grau de controle genético que é exercido sobre uma determinada característica. De maneira geral, as características da madeira são de moderada a fortemente herdáveis, possibilitando a seleção para a direção desejada, sendo a densidade básica a principal característica.

ALMEIDA et alii (1981), estudando 79 famílias de meio irmãos de $E$. citriodora, aos 4 meses de idade, chegou a estimativas de 0,91 para herdabilidade da densidade básica média das famílias. Valores acima de 0,90 também foram encontrados por OLIVEIRA (1981) em Eucalyptus grandis.

FERNANDES et alii (1989), encontrou diferenças significativas para densidade básica da madeira entre 5 procedências de $E$. grandis estudadas aos 13,5 anos de idade.

Os trabalhos indicam, portanto, a confiabilidade do uso da densidade básica da madeira em programas de melhoramento que visem o estudo de parâmentros de qualidade da madeira como critério de seleção.

Portanto, esta importante ferramenta de trabalho deve ser muito bem manejada, pois FOELKEL et alii (1990), alerta para o fato da densidade básica ser uma consequência da distribuição, tipos e composição química dos elementos anatômicos que compõem a madeira, e não a causa.

A qualidade ideal da madeira para um determinado processo pode ser atingida após a identificação dos parâmetros que caracterizam sua variabilidade. Em termos gerais, podemos dizer que as variações da densidade básica da madeira estão relacionadas com muitas características anatômicas e químicas da madeira. E estas por sua vez sobre influências dos fatores ambientais.

BRASIL (1983), afirma ser o estudo da densidade básica um reflexo das características da madeira. Sendo, assim, importantíssima na avaliação de programas de melhoramento genético.

Para FONSECA et allii (1996), a densidade básica da madeira tem sido a principal característica tecnológica para seleção, influenciando tanto no custo da madeira produzida, quanto no rendimento do processo industrial e principalmente na qualidade do 
produto produzido. Relação entre as características da madeira com as propriedades da polpa e papel produzidas a densidade básica da madeira é destacada como sendo a de maior importância pela sua forte relação direta com a espessura da parede celular da fibra (VASCONCELOS e SILVA JR. 1985; CAMPINHOS JR e SILVA JR., 1990; SHIMOYAMA, 1990 ).

\subsection{Densidade básica e características anatômicas}

SHIMOYAMA (1990), em revisão bibliográfica cita controversias entre vários autores com relação a existência de uma correlação entre o comprimento da fibras e a densidade básica da madeira.

Segundo CARPIM et alii (1985), muitas vezes, as correlações positivas citadas para ambos os parâmetros mostram apenas que os mesmos possuem um comportamento similar dentro da árvore, onde somente o comprimento não é capaz de alterar o valor da densidade.

Em relação a espessura da parede das fibras SHIMOYAMA (1990), diz que essa é uma característica que está relacionada a fatores genéticos e ambientais e a idade da árvore. Os carboidratos são depositados na parede da fibra, e por possuirem alto grau de polimerização, podem tornar a madeira mais densa.

DAVIDSON, (1972); BARRICHELO \& BRITO,(1976); BARRICHELO, (1979) e VASCONCELLOS DIAS \& CLAUDIO DA SILVA Jr.,(1985); ao estudarem a madeira de espécies de eucaliptos, concluíram que a densidade básica pode dar indicações da espessura da parede da fibra.

A largura das fibras é uma característica que deixa dúvidas quanto a sua relação com a densidade básica. Pois, se as fibras possuirem diâmetros grandes e paredes espessas, serão observadas correlações positivas. Porém, se as mesmas forem largas, mas com paredes finas, o resultado será o inverso.

O diâmetro do lúme depende da largura e da espessura da parede das fibras. Quanto maior o seu valor, mais espaços vazios serão encontrados na madeira e, 
consequentemente, esta apresentará menor densidade básica da madeira, SHIMOYAMA (1990).

Quanto maior o diâmetro e o número de vasos encontrados na madeira, maior a área de espaços vazios existente. Dessa forma, geralmente suas correlações com a densidade básica, quando encontradas, mostram-se negativas (DAVIDSON, 1972).

Em termos gerais, podemos dizer que as características anatômicas da madeira, tais como comprimento da fibra espessura da parede, diâmetro do lúme, proporção dos vários tipos de celulas e tecidos, como vasos e parênquimas, possuem certa relação com a densidade. Pois assim como a densidade exerce sua influência na característica final da madeira, ela também sofre influência dos elementos que a compõem.

Porém, muitas vezes as dimensões das fibras, isoladamente, podem não mostrar correlações significativas com a densidade, conforme verificado por ANDRADE (1987). Porém, ao agrupá-las, podem ser constatados resultados satisfatorios. Esses agrupamentos, sob diversas formas, resultam em índices que auxiliam na interpretação da qualidade da madeira. São eles o índice de Runkel, definido como sendo a relação entre 2 vezes a espessura da parede celular e o respectivo diâmetro do lúme; o índice de enfeltramento, relação entre o comprimento e a largura da fibra; o coeficiente de flexibilidade, expresso pela relação entre o diâmetro do lúmen e a largura da fibra, em porcentagem; e a fração parede, definida como sendo a relação percentual entre a espessura da parede da fibra e a metade de sua largura. BARRICHELO (1979), observou que o índice de Runkel é a relação que exerce maior influência sobre a densidade da madeira.

\subsection{Amostragem tecnológica da madeira}

Num programa de melhoramento florestal o ponto principal é a perfeita integração dos critérios de seleção entre a pesquisa florestal e a pesquisa industrial. Pois a qualidade da madeira produzida deve satisfazer as exigências das duas áreas. 
Para FONSECA et allii (1996), a amostragem para caracterização tecnológica da árvore deverá levar em conta as variações que ocorrem com as propriedades da madeira em função da idade e da posição da amostragem na árvore.

Variações para a densidade básica da madeira ao longo do tronco, sentido basetopo têm sido constatadas, porém não têm obedecido a um padrão bem definido, enquanto no sentido transversal tem mostrado tendência de aumento no sentido medúlacasca.

Em face das variações da madeira ao longo do tronco, a prática mais utilizada de amostragem da árvore é a retirada de discos de 2,5 a $3 \mathrm{~cm}$ de espessura ou toretes de $30 \mathrm{~cm}$ de comprimento nas posições referentes a $0 \%$ (base), $25 \%, 50 \%, 75 \%, 100 \%$ da altura comercial do tronco para determinação das características tecnológicas da madeira. Tendo assim, uma boa representatividade da madeira tando no sentido transversal como longitudinal, sem a necessidade da utilização integral do tronco comercial, facilitando o manuseio e as operações laboratoriais (FONSECA et allii, 1996).

Com o melhoramento florestal é obtido significativos ganhos na qualidade da madeira em termos de variabilidade e rendimento do processo. CAMPINHOS JR e SILVA JR (1990), acreditam que ganhos adicionais poderão ser obtidos com o uso de critérios de seleção fundamentados em aspectos relacionados ao ganho estimado de produção. Sendo que os fatores considerados no programa de seleção de árvores são, cozimentos laboratoriais similares ao industrial, obtenção de cavacos utilizando todo o volume comercial da árvore e em equipamento industrial e procedimentos padronizados de lavagem e depuração, comparando os resultados das árvores individuais com os valores médios de produção obtidos na operação industrial. Desse modo, discussões sobre possiveis correlações entre a rendimento do cozimento com a densidade básica da madeira e composição química, deixam de ter importância prática para a seleção das árvores, seguindo o critério de produtividade nas fábricas. 


\subsection{Características da madeira do Eucalyptus urophylla.}

As características da madeira dentro do gênero Eucalyptus apresenta-se bastante diversificada, sendo um vasto campo de pesquisas visando a seleção e maximização das características desejadas.

O Eucalyptus urophylla, apresenta uma alta variabilidade natural. As sementes produzidas no Brasil, com base na introdução feita em 1919 por Edmundo Navarro de Andrade, são em sua maioria hibridógenas FERREIRA, (1996), originando uma variação não controlada. Com a expansão dos reflorestamentos para áreas de maior déficit hídrico, reintroduziu-se a espécie aumentando assim sua base genética e ampliou-se a produção de sementes melhoradas. Como consequência a espécie apresenta-se como uma das mais promissoras fontes de matéria-prima para a indústria brasileira, despertando o interesse ao estudo das características de sua madeira.

Estudos realizados por FERREIRA et alii (1979), com E. urophylla, E. saligna e E. grandis em Mogi-Guaçu-SP não demostram efeito significativo da taxa de crescimento na densidade básica da madeira

BRASIL (1986), trabalhando com densidade básica da madeira de E. urophylla, observou que as procedências da llha de Flores aos 48 meses de idade, tinham suas madeiras 2,5\% mais densas em média que as procedências da ilha de Timor.

VITAL \& DELLA LUCIA (1987), estudando o efeito do espaçamento na produção e na qualidade da madeira de $E$. grandis e $E$. urophylla aos 52 meses de idade, verificaram que para $\circ E$. urophylla até a idade estudada, o espaçamento não afetou a densidade básica média da madeira das árvores, bem como os seus elementos anatômicos, sendo que o coeficiente de correlação de - 0,31, mostrou uma tendência de redução da densidade básica da madeira com altura do tronco, sendo que na região próxima a casca a densidade básica da madeira foi maior, consequência do aumento na parede das fibras nesta região.

STURION et alii (1987) em avaliação da densidade básica da madeira em 12 espécies de eucaliptos relaciona o $E$. urophylla como uma das espécies de menor densidade. 
RIBEIRO \& ZANI $F^{\circ}$ (1993) estudando a variação da densidade básica entre espécies/procedências de eucalipto concluiram que para o $E$. urophylla a densidade básica da madeira foram em média superiores a $0,510 \mathrm{~g} / \mathrm{cm}^{3}$ sendo que das procedências a de ilha de Flores apresentou maior densidade básica e que existe potencial de seleção para aumentar ou diminuir a densidade básica dentro das procedências analisadas. 


\section{MATERIAL E MÉTODOS}

\subsection{Material}

\subsubsection{Caracterização da população clonal}

Para realização do presente trabalho, foram utilizados clones de uma população de Eucalyptus urophylla, originária da liha de Flores, Indonésia, implantada com sementes de uma coleta efetuada em árvores de diferentes procedências, pela Florestas Rio Doce S/A, de maio a agosto de 1977.

As mudas produzidas a partir desta coleta foram plantadas em de 1980, na Estação Experimental de Ciências Florestais de Anhembi, pertencente ao Departamento de Ciências Florestais da ESALQ/USP, formando uma população de ampla base genética. Nesta população podem ser identificadas diferentes padrões fenotípicos, principalmente quanto ao tipo de casca, sugerindo inclusive uma denominação para destacar tais diferenças. Esse material genético altamente potencial para as regiões tropicais brasileiras, denominado "Eucalyptus urophylla var. platyphylla" (casca lisa) e E. urophylla. (casca rugosa), FERREIRA (1995).

Em junho de 1985 foram selecionadas 55 árvores no talhão T8A32, que apresentaram predominância de casca lisa e que foram a seguir clonadas, utilizando-se o método da macropropagação vegetativa.

A partir desses clones foi instalado um banco clonal em janeiro/fevereiro de 1986, no município de Aguaí-SP, no espaçamento $3 \times 3 \mathrm{~m}$ em um delineamento inteiramente casualizado com número variado de repetições para cada clone, totalizando 317 parcelas, com o número de estacas por parcela variando de 10 a 40.

\subsubsection{Caracterização do local}

O local de instalação do banco clonal foi o Horto Florestal Nossa Senhora Aparecida (talhão 87), em área da Champion Papel e Celulose Ltda., no municipio de Aguaí-SP, localizado em uma altitude de $580 \mathrm{~m}$, latitude $22^{\circ} 11^{\prime} \mathrm{S}$ e longitude de $47^{\circ} 07^{\prime} \mathrm{W}$. 
O clima é do tipo CWA, com inverno seco. A temperatura média do mês mais frio é inferior a $18^{\circ} \mathrm{C}$, e a do mês mais quente ultrapassa os $22^{\circ} \mathrm{C}$. A precipitação média anual situa-se em torno de $1500 \mathrm{~mm}$, sendo o total de chuvas do mês mais seco inferior a 30 $\mathrm{mm}$. A estação seca ocorre entre os meses de abril e setembro, sendo o período mais chuvoso oscilando entre dezembro, janeiro e fevereiro.

\subsection{Métodos}

\subsubsection{Grupos fenotípicos}

Através do agrupamento de variáveis silviculturais e botânicas dos clones, com base no fruto ( comprimento, diâmetro, tipo, forma do cálice, espessura do pedicelo ), tronco ( diâmetro do DAP, bifurcação, forma, inclinação), casca ( textura, altura de casca fibrosa no tronco), copa (largura, comprimento ), folha ( relação comprimento / largura, comprimento do peciolo), altura total, sobrevivência (\%), desrama e aspecto geral permitiu, aos 6 anos de idade, a divisão dessa população em 5 grupos fenotípicos, por LOPEZ (1992). No presente trabalho foi obedecido o critério de classificação dos grupos fenotípicos estabelecidos por LOPEZ (1992), (Anexos 1 e 2).

\subsubsection{Seleção dos clones}

Para efeito do presente trabalho foram estabelecidos critérios para seleção de clones dentro dos grupos fenotípicos, sendo que o objetivo básico para tal, foi o de se obter o mais alto grau possivel de representatividade do material a ser analisado.

Desse modo, foram estipulados:

3.2.2.1. Seleção dos grupos fenotípicos: foram selecionados os grupos fenotípicos que possuissem pelo menos 3 clones representativos, o que provocou a exclusão do grupo fenotípico 5 .

3.2.2.2. Seleção dos clones dentro dos grupos fenotípicos: dentro de cada grupo fenotípico, procurou-se selecionar o maior número possível de clones, tendo como 
restrições: i ) $O$ número mínimo de 3 parcelas dentro do delineamento inteiramente casualizado; ii ) clones com maior produtividade dentro de cada grupo.

Tal procedimento permitiu selecionar 3 clones para cada grupo fenotípico amostrado, totalizando 12 clones selecionados.

3.2.2.3. Seleção das parcelas dentro de clones: nas parcelas que apresentavam 30 ou 40 estacas, foi realizado um inventário florestal para o conhecimento da produtividade de madeira, expressa em volume cilindrico. Sendo selecionadas as 3 melhores parcelas para cada clone. (Anexo 03 e 04)

3.2.2.4. Seleção das estacas dentro de clones: com base nos dados dendrométricos de cada parcela, foram estabelecidas 3 classes de diâmetro baseadas na distribuição dos valores de DAP dentro de cada parcela. As classes foram: i ) DAP (médio); ii ) DAP+1,5 s (grande); iii ) DAP-1,5 s (pequeno)

Portanto, foram selecionados 12 clones sendo 3 para o grupo fenotípico1, 3 para o grupo fenotípico 2, 3 para o grupo fenotípico 3 e 3 para o grupo fenotípico 4. Foram selecionadas 3 parcelas para cada clone, sendo 3 estacas por parcela, uma para cada classe diametral, totalizando 9 estacas para cada clone. Totalizando, assim, 108 estacas selecionadas para os estudos dos parâmetros de qualidade da madeira ( Tabelas de 1 a 4 ).

\subsubsection{Avaliação do Parâmetro da Qualidade da Madeira.}

\subsubsection{Coleta das amostras}

A fim de se ter uma amostragem mais homogênea de cada estaca (árvore), em decorrência das variações de padrão indefinido das propriedades da madeira ao longo do tronco, retirou-se 5 discos/estaca, com aproximadamente $3 \mathrm{~cm}$ de espessura e faces paralelas, no sentido longitudinal do tronco referentes à $0 \%$ (base), $25 \%, 50 \%, 75 \%$ e $100 \%$ da altura onde situasse o diâmetro mínimo comercial com casca $(6 \mathrm{~cm})$ Figura $1(a)$. 


\subsubsection{Densidade básica da madeira}

Cada disco foi subdividido em 4 partes, sendo escolhidas as 2 partes opostas, para a determinação de densidade básica da madeira na forma de cunhas, através do método da balança hidrostática, conforme norma TAPPI PRESS (1995) (T 258 om - 94) Figura 1 (b).

De posse da média das 2 densidades básicas da madeira de cada um dos 5 discos amostrados por estaca e da média de duas leituras perpendiculares do diâmetro sem casca de cada disco, utilizou-se a formúla abaixo para o cálculo da densidade básica média ponderada da árvore, conforme BARRICHELO et alii (1983).

$D b m p=\frac{1}{2} * \frac{\left(D^{2} s c 1+D^{2} s c 2\right)^{*}(D b 1+D b 2)+\left(D^{2} s c 2+D^{2} s c 3\right) *(D b 2+D b 3)+\ldots+\left(D^{2} s c 4+D^{2} s c 5\right) *(D b 4+D b 5)}{D^{2} s c 1+D^{2} s c 2+2^{*}\left(D^{2} s c 2+D^{2} s c 3+D^{2} s c 4\right)}$

onde;

- $\mathrm{Db}_{\mathrm{mp}}=$ Densidade básica média ponderada da estaca $\left(\mathrm{g} / \mathrm{cm}^{3}\right)$

- $\mathrm{D}^{2}{ }_{\mathrm{sc} 1,2,3,4,5}=$ Diâmetro médio ao quadrado ao nível $1=(0 \%)$, $2=(25 \%), 3=(50 \%), 4=(75 \%), 5=(100 \%)$ da altura comercial.

- $\mathrm{Db}_{1,2,3,4,5}=$ Densidade básica média ao nível $1=(0 \%)$,

$$
2=(25 \%), 3=(50 \%), 4=(75 \%), 5=(100 \%)
$$

\subsubsection{Percentagem de casca em volume}

Tomando-se os resultados da determinação de densidade básica da casca de cada disco, calculou-se a percentagem de casca em volume para todas as árvores através da equação abaixo, conforme metodologia desenvolvida no Laboratório de Química da Madeira do Departamento de Ciências Florestais da ESALQ/USP : 


$$
\% \text { Casca }=\left(\frac{1-\text { PUM }- \text { PIM }}{\text { PUT }- \text { PIT }} * 100\right.
$$

onde:

-\% casca $(\mathrm{vol})=$ Percentagem de casca em volume;

-PUM = Peso úmido da madeira

-PIM = Peso imerso da madeira

-PUT = Peso úmido total da madeira com casca

-PIT = Peso imerso total da madeira com casca

\subsubsection{Mensuração das dimensões das fibras}

De cada cunha dos 5 discos que representam uma estaca (árvore), retirou-se uma faixa no sentido medúla casca e desta foram retirados vários pedaços de madeira na forma de pequenos palitos, os quais macerados em um único tubo de ensaio, formou uma amostra composta dos discos para cada estaca. Figura 1 (c)

Cada estaca (árvore) foi macerada através do processo nitríco - acético conforme BARRICHELO \& FOELKEL (1983) para a dissociação das fibras.

Para cada amostra foram montadas 2 lâminas cujas fibras foram coradas com safranina, onde foram medidos o comprimento $(\mathrm{mm})$, através de um projetor, a largura e o diâmetro do lúme $(\mu \mathrm{m})$ através de um microscópio óptico. Para cada lâmina foram medidas 20 fibras, totalizando 360 fibras para cada clone sendo calculadas as médias do comprimento, largura, diâmetro do lume e espessura da parede ( largura menos o diâmetro do lume, dividido por 2) de cada estaca. 


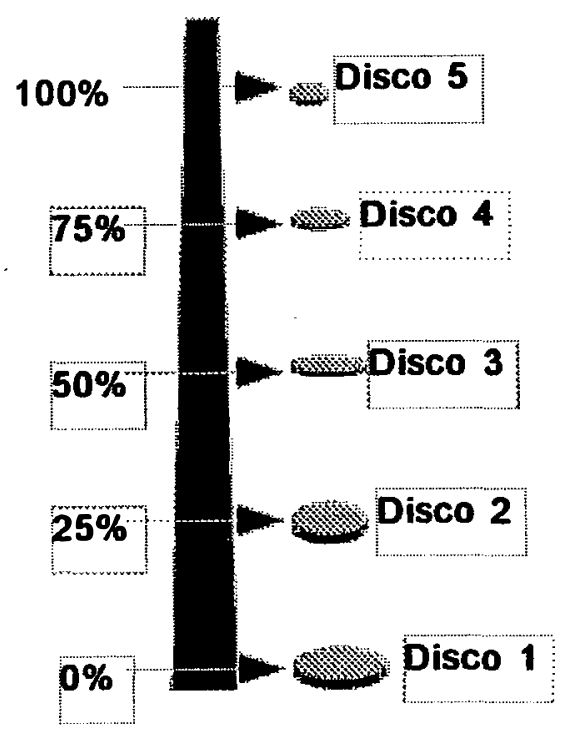

Fig.1a

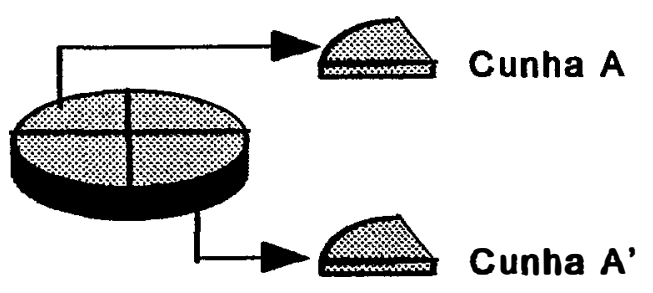

Fig.1b

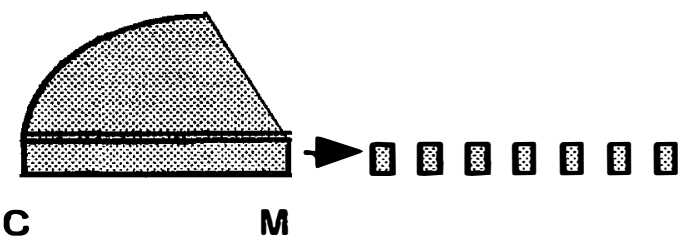

Fig.1c

Figura 1. Coleta das amostras para análise de parâmetros de qualidade da madeira

(a) amostragem em diferentes percentagens da altura comercial do tronco;

(b) amostragem dos discos para determinação da densidade básica da madeira;

(c) amostragem das cunhas para mensuração das fibras.

\subsection{Delineamento estatístico}

Os dados foram analisados pelo pacote estatístico SAS (Statistical Analysis System), seguindo delineamento estatístico com estrutura hierárquica para as variáveis: percentagem de casca, densidade básica da madeira, comprimento das fibras, largura das fibras, diâmetro do lume e espessura da parede das fibras, analisados estatísticamente conforme o modelo abaixo para os efeito de grupo e clones dentro de grupo: 


\subsubsection{Modelo Estatístico}

$$
Y_{i j k l}=\mu+G_{i}+C_{j(i)}+e_{k(i)}
$$

onde:

- $Y_{i k t}=$ variável dependente analisada

- = média geral dos dados, constante inerente a todas as observações

- $\mathrm{G}_{i}=$ é o efeito do i-ésimo grupo; sendo $i=1,2,3,4$

- $\mathrm{C}_{j}=$ é o efeito do j-ésimo clone do i-ésimo grupo; sendo $j=1,2,3$

- $e_{k}=$ erro experimental

Após a análise de variância realizada utilizando o procedimento "proc glm", foi realizado teste para comparação de médias, ou seja, teste Tukey ao nivel de significância de $5 \%$ de probabilidade, para as causas de variação onde as variáveis estudadas apresentaram diferenças significativas.

\subsubsection{Variação dentro de Clones}

Para a variação dentro de clones, foi realizado o estudo do desvio padrão para as mesmas variáveis citadas acima. 


\section{RESULTADOS E DISCUSSÃO}

\subsection{Parâmetros de qualidade da madeira}

Os parâmetros de qualidade da madeira analisados para os 4 grupos fenotípicos, compreendendo 12 clones de $E$. urophylla, são apresentados nas Tabelas 1 a 4.

Com relação à produtividade das parcelas ( $\mathrm{m}^{3} / \mathrm{ha}$ ), foram verificadas variações nos 4 grupos fenotípicos, entre e dentro de clones desses grupos.

Podem ser citados, como exemplo, os clones 28 e 18 dos grupos fenotípicos 1 e 2 , respectivamente, como os de maior produtividade; e os clones 11 e 23 do grupos fenotípicos 3 e 4 como os de menor produtividade. As maiores variações de produtividade foram observadas nos clones 46 e 43 dos grupos fenotípicos 1 e 4 , respectivamente; e as menores variações nos clones 18 e 11 dos grupos fenotípicos 2 e 3. Essas variações de produtividade entre e dentro de grupos fenotípicos para os diferentes clones devem ser devidas à variação genética existente na população base de E. urophylla da liha de Flores, implantada na E.E. de Anhembi. As variações de produtividade verificadas nos clones 46 e 43 dos grupos fenotípicos 1 e 4 devem estar

relacionadas com a origem do material e a metodologia de agrupamento dos clones na população base. Além da produtividade são apresentados nas Tabelas 1 a 4, os valores de diâmetro para as árvores das 3 classes selecionadas com base nesse parâmetro, nas parcelas, para os diferentes clones e grupos fenotípicos, das quais foram coletadas amostras de madeira para as análises de qualidade. 


\begin{tabular}{|c|c|c|c|c|c|c|c|c|c|c|c|c|}
\hline \multirow[t]{2}{*}{$\begin{array}{c}\text { Grupo } \\
\text { Fenotípico }\end{array}$} & \multirow[t]{2}{*}{ Clone } & \multirow[t]{2}{*}{ Parcela } & \multirow{2}{*}{$\begin{array}{c}\text { Produt da } \\
\text { Parcela } \\
\left(\mathrm{m}^{3} / \mathrm{ha}\right)\end{array}$} & \multirow[t]{2}{*}{$\begin{array}{l}\text { Ànv. } \\
\left(n^{\circ}\right)\end{array}$} & \multirow[t]{2}{*}{$\begin{array}{l}\text { Classe de } \\
\text { Diâmetro }\end{array}$} & \multirow{2}{*}{$\begin{array}{c}\text { Valor de } \\
\text { Diâmetro } \\
\text { (cm) }\end{array}$} & \multirow[t]{2}{*}{$\begin{array}{c}\text { Casca } \\
(\%)\end{array}$} & \multirow{2}{*}{$\begin{array}{c}\text { Densidade } \\
\text { da Madeira } \\
\left(\mathrm{g} / \mathrm{cm}^{3}\right)\end{array}$} & \multicolumn{4}{|c|}{ Dimensōes das Fibras } \\
\hline & & & & & & & & & $\begin{array}{l}\text { Comp. } \\
(\mathrm{mm})\end{array}$ & $\begin{array}{l}\text { Larg. } \\
(\mu \mathrm{m})\end{array}$ & \begin{tabular}{|l|} 
Lume \\
$(\mu \mathrm{m})$
\end{tabular} & $\begin{array}{c}\text { Parede } \\
(\mu \mathrm{m})\end{array}$ \\
\hline \multirow{27}{*}{1} & \multirow{9}{*}{26} & \multirow{3}{*}{1} & \multirow{3}{*}{333,05} & 1 & $P$ & 10,00 & 15,94 & 0,67 & 1,00 & 17,67 & 7,17 & 5,25 \\
\hline & & & & 2 & $M$ & 14,00 & 16,24 & 0,69 & 0,97 & 16,50 & 5,67 & 5,42 \\
\hline & & & & 3 & G & 17,00 & 15,86 & 0,68 & 1,03 & 15,50 & 6,83 & 4,33 \\
\hline & & \multirow{3}{*}{2} & \multirow{3}{*}{671,54} & 4 & $P$ & 15,50 & 13,59 & 0,65 & 0,98 & 17,67 & 7,50 & 5,33 \\
\hline & & & & 5 & $M$ & 18,00 & 14,69 & 0,68 & 1,09 & 18,33 & 7,67 & 5,33 \\
\hline & & & & 6 & G & 21,50 & 14,04 & 0,71 & 1,00 & 18,17 & 7,50 & 5,33 \\
\hline & & \multirow{3}{*}{3} & \multirow{3}{*}{770,75} & 7 & $P$ & 15,00 & 11,90 & 0,69 & 0,94 & 16,33 & 7,00 & 4,67 \\
\hline & & & & 8 & M & 17,00 & 13,03 & 0,69 & 1,03 & 15,17 & 6,17 & 4,50 \\
\hline & & & & 9 & $\mathbf{G}$ & 19,00 & 14,06 & 0,68 & 1,01 & 17,33 & 8,17 & 4,58 \\
\hline & \multirow{9}{*}{28} & \multirow{3}{*}{1} & \multirow{3}{*}{792,10} & 1 & $P$ & 18,00 & 9,32 & 0,63 & 1,02 & 17,67 & 8,33 & 4,67 \\
\hline & & & & 2 & $M$ & 21,00 & 11,42 & 0,63 & 1,03 & 18,00 & 7,67 & 5,17 \\
\hline & & & & 3 & G & 24,00 & 10,53 & 0,63 & 1,08 & 15,00 & 5,33 & 4,83 \\
\hline & & \multirow{3}{*}{2} & \multirow{3}{*}{933,79} & 4 & $P$ & 17,50 & 9,93 & 0,60 & 1,11 & 17,50 & 7,67 & 4,92 \\
\hline & & & & 5 & $M$ & 19,50 & 10,00 & 0,64 & 1,10 & 17,17 & 7,83 & 4,67 \\
\hline & & & & 6 & G & 21,50 & 10,12 & 0,62 & 1,14 & 16,17 & 6,83 & 4,67 \\
\hline & & \multirow{3}{*}{3} & \multirow{3}{*}{1059,39} & 7 & $P$ & 17,50 & 9,95 & 0,62 & 1,14 & 14,33 & 5,50 & 4,42 \\
\hline & & & & 8 & $M$ & 21,50 & 9,33 & 0,60 & 1,14 & 17,17 & 7,83 & 4,67 \\
\hline & & & & 9 & G & 24,50 & 9,57 & 0,61 & 1,06 & 14,67 & 6,67 & 4,00 \\
\hline & \multirow{9}{*}{46} & \multirow{3}{*}{1} & \multirow{3}{*}{335,17} & 1 & $P$ & 7,00 & 26,04 & 0,64 & 0,97 & 17,17 & 7,33 & 4,92 \\
\hline & & & & 2 & $M$ & 14,50 & 14,40 & 0,59 & 1,04 & 16,50 & 7,33 & 4,58 \\
\hline & & & & 3 & G & 20,50 & 14,02 & 0,61 & 1,07 & 16,50 & 8,00 & 4,25 \\
\hline & & & & 4 & $\bar{P}$ & 11,00 & 15,72 & 0,62 & 0,93 & 18,00 & 8,50 & 4,75 \\
\hline & & 2 & 660,07 & 5 & $M$ & 18,00 & 12,77 & 0,61 & 1,01 & 14,17 & 5,33 & 4,42 \\
\hline & & & & 6 & G & 21,50 & 14,17 & 0,62 & 1,02 & 15,17 & 5,33 & 4,92 \\
\hline & & & & 7 & $P$ & 14,00 & 12,61 & 0,59 & 1,07 & 15,33 & 6,50 & 4,42 \\
\hline & & 3 & 613,73 & 8 & $M$ & 18,00 & 12,85 & 0,63 & 1,09 & 17,50 & 7,83 & 4,83 \\
\hline & & & & 9 & G & 22,00 & 13,81 & 0,62 & 0,96 & 16,50 & 6.33 & 5,08 \\
\hline
\end{tabular}

Tabela 1. Parâmetros de qualidade da madeira analisados para os 3 clones de $E$. urophylla, pertencentes ao grupo fenotípico 1. 


\begin{tabular}{|c|c|c|c|c|c|c|c|c|c|c|c|c|}
\hline \multirow[t]{2}{*}{\begin{tabular}{|c|} 
Grupo \\
Fenotípico
\end{tabular}} & \multirow[t]{2}{*}{ Clone } & \multirow[t]{2}{*}{ Parcela } & \multirow{2}{*}{$\begin{array}{c}\text { Produt da } \\
\text { Parcela } \\
\text { ( } \mathrm{m}^{3} / \mathrm{ha} \text { ) }\end{array}$} & \multirow[t]{2}{*}{$\begin{array}{l}\text { Àrv. } \\
\left(n^{\circ}\right)\end{array}$} & \multirow[t]{2}{*}{$\begin{array}{l}\text { Classe de } \\
\text { Diâmetro }\end{array}$} & \multirow{2}{*}{$\begin{array}{c}\text { Valor de } \\
\text { Diâmetro } \\
(\mathrm{cm})\end{array}$} & \multirow[t]{2}{*}{$\begin{array}{c}\text { Casca } \\
(\%)\end{array}$} & \multirow{2}{*}{$\begin{array}{c}\text { Densidade } \\
\text { da Madeira } \\
\left(\mathrm{g} / \mathrm{cm}^{3}\right)\end{array}$} & \multicolumn{4}{|c|}{ Dimensōes das Fibras } \\
\hline & & & & & & & & & $\begin{array}{l}\text { Comp. } \\
(\mathrm{mm})\end{array}$ & $\begin{array}{l}\text { Larg. } \\
(\mu \mathrm{m})\end{array}$ & $\begin{array}{l}\text { Lume } \\
\text { (um) }\end{array}$ & $\begin{array}{c}\text { Parede } \\
(\mu \mathrm{m})\end{array}$ \\
\hline \multirow{9}{*}{2} & \multirow{3}{*}{12} & 1 & 628,78 & $\begin{array}{l}1 \\
2 \\
3\end{array}$ & $\begin{array}{l}P \\
M \\
G\end{array}$ & $\begin{array}{l}14,00 \\
16,50 \\
18,50 \\
\end{array}$ & $\begin{array}{l}13,120 \\
14,848 \\
12,287\end{array}$ & $\begin{array}{l}0,595 \\
0,623 \\
0,618 \\
\end{array}$ & $\begin{array}{l}0,875 \\
0,953 \\
0,935 \\
\end{array}$ & $\begin{array}{l}16,000 \\
17,167 \\
16,167\end{array}$ & $\begin{array}{l}8,166 \\
6,667 \\
7,667 \\
\end{array}$ & $\begin{array}{l}3,917 \\
5,250 \\
4,250 \\
\end{array}$ \\
\hline & & 2 & 703,06 & $\begin{array}{l}4 \\
5 \\
6 \\
\end{array}$ & $\begin{array}{l}P \\
M \\
G\end{array}$ & $\begin{array}{l}15,00 \\
17,50 \\
19,00\end{array}$ & $\begin{array}{l}15,021 \\
16,984 \\
14,430 \\
\end{array}$ & $\begin{array}{l}0,594 \\
0,654 \\
0,637\end{array}$ & $\begin{array}{l}1,086 \\
1,021 \\
1,007\end{array}$ & $\begin{array}{l}18,667 \\
17,666 \\
16,666 \\
\end{array}$ & \begin{tabular}{|l|}
8,000 \\
7,833 \\
6,667
\end{tabular} & $\begin{array}{l}5,333 \\
4,916 \\
5,000\end{array}$ \\
\hline & & 3 & 655,38 & $\begin{array}{l}7 \\
8 \\
9\end{array}$ & $\begin{array}{l} \\
M \\
G\end{array}$ & $\begin{array}{l}14,00 \\
17,00 \\
19,00\end{array}$ & $\begin{array}{l}12,673 \\
14,113 \\
13,057\end{array}$ & $\begin{array}{l}0,600 \\
0,622 \\
0,597\end{array}$ & $\begin{array}{l}1,033 \\
0,968 \\
1,004\end{array}$ & $\begin{array}{l}17,167 \\
17,000 \\
15,833\end{array}$ & \begin{tabular}{|l|}
8,333 \\
8,333 \\
7,500
\end{tabular} & \begin{tabular}{|l|}
4,167 \\
4,333 \\
4,166 \\
\end{tabular} \\
\hline & \multirow{3}{*}{18} & 1 & 930,77 & $\begin{array}{l}1 \\
2 \\
3\end{array}$ & $\begin{array}{l}P \\
M \\
G\end{array}$ & $\begin{array}{l}17,00 \\
19,50 \\
22,00 \\
\end{array}$ & $\begin{array}{l}11,856 \\
12,866 \\
13,330\end{array}$ & $\begin{array}{l}0,595 \\
0,595 \\
0,582 \\
\end{array}$ & $\begin{array}{l}0,994 \\
1,010 \\
1,040 \\
\end{array}$ & $\begin{array}{l}18,000 \\
17,000 \\
15,000\end{array}$ & \begin{tabular}{|l|}
8,500 \\
8,000 \\
7,333 \\
\end{tabular} & $\begin{array}{l}4,750 \\
4,500 \\
3,833 \\
\end{array}$ \\
\hline & & 2 & 776,88 & $\begin{array}{l}4 \\
5 \\
6\end{array}$ & $\begin{array}{l}P \\
M \\
G\end{array}$ & $\begin{array}{l}16,00 \\
18,00 \\
20,00\end{array}$ & $\begin{array}{l}12,237 \\
12,501 \\
12,031\end{array}$ & $\begin{array}{l}0,584 \\
0,604 \\
0,604\end{array}$ & \begin{tabular}{|l|}
0,981 \\
1,034 \\
0,985
\end{tabular} & $\begin{array}{l}18,330 \\
16,833 \\
17,667\end{array}$ & \begin{tabular}{|l}
8,833 \\
8,833 \\
8,833
\end{tabular} & $\begin{array}{l}4,750 \\
4,250 \\
4,417\end{array}$ \\
\hline & & 3 & 858,00 & $\begin{array}{l}7 \\
8 \\
9 \\
\end{array}$ & $\begin{array}{l}P \\
M \\
G\end{array}$ & $\begin{array}{l}16,00 \\
18,50 \\
21,50 \\
\end{array}$ & $\begin{array}{l}12,032 \\
11,913 \\
13,932 \\
\end{array}$ & $\begin{array}{l}0,568 \\
0,583 \\
0,585 \\
\end{array}$ & \begin{tabular}{|l|}
0,953 \\
0,977 \\
1,039 \\
\end{tabular} & $\begin{array}{l}16,333 \\
17,500 \\
17,000 \\
\end{array}$ & $\begin{array}{l}8,666 \\
8,333 \\
8,333 \\
\end{array}$ & $\begin{array}{l}, 833 \\
4,583 \\
4,333 \\
\end{array}$ \\
\hline & \multirow{3}{*}{40} & 1 & 489,57 & $\begin{array}{l}1 \\
2 \\
3 \\
\end{array}$ & $\begin{array}{l}P \\
M \\
G\end{array}$ & $\begin{array}{l}12,00 \\
15,00 \\
19,00\end{array}$ & $\begin{array}{l}14,505 \\
16,470 \\
14,092 \\
\end{array}$ & $\begin{array}{l}0,635 \\
0,667 \\
0,653\end{array}$ & $\begin{array}{l}0,943 \\
1,008 \\
1,047 \\
\end{array}$ & $\begin{array}{l}16,667 \\
15,000 \\
15,666\end{array}$ & \begin{tabular}{|l|}
7,500 \\
7,167 \\
6,000 \\
6,10
\end{tabular} & $\begin{array}{l}4,833 \\
3,917 \\
4,833 \\
\end{array}$ \\
\hline & & 2 & 606,21 & $\begin{array}{l}4 \\
5 \\
6\end{array}$ & $\begin{array}{l}P \\
M \\
G\end{array}$ & $\begin{array}{l}12,00 \\
16,50 \\
20,50\end{array}$ & $\begin{array}{l}12,374 \\
14,256 \\
13,063\end{array}$ & $\begin{array}{l}0,569 \\
0,633 \\
0,621\end{array}$ & $\begin{array}{l}1,092 \\
1,060 \\
0,969\end{array}$ & $\begin{array}{l}17,833 \\
15,833 \\
15,666\end{array}$ & \begin{tabular}{|l|}
8,167 \\
7,167 \\
6,666 \\
\end{tabular} & $\begin{array}{l}4,833 \\
4,333 \\
4,500\end{array}$ \\
\hline & & 3 & 577,56 & $\begin{array}{l}7 \\
8 \\
9\end{array}$ & $\begin{array}{l}P \\
M \\
G\end{array}$ & $\begin{array}{l}12,50 \\
15,00 \\
20,00\end{array}$ & $\begin{array}{l}10,533 \\
12,820 \\
13,208\end{array}$ & $\begin{array}{l}0,562 \\
0,605 \\
0,622\end{array}$ & $\begin{array}{l}1,105 \\
1,017 \\
1,044\end{array}$ & $\begin{array}{l}17,500 \\
17,000 \\
15,500\end{array}$ & \begin{tabular}{|l|}
8,333 \\
7,666 \\
7,000
\end{tabular} & $\begin{array}{l}4,583 \\
4,667 \\
4,250\end{array}$ \\
\hline
\end{tabular}

Tabela 2. Parâmetros de qualidade da madeira analisados para os 3 clones de $E$. urophylla, pertencentes ao grupo fenotípico 2 . 


\begin{tabular}{|c|c|c|c|c|c|c|c|c|c|c|c|c|}
\hline \multirow[t]{2}{*}{\begin{tabular}{|c|} 
Grupo \\
Fenotípico
\end{tabular}} & \multirow[t]{2}{*}{ Clone } & \multirow[t]{2}{*}{ Parcela } & \multirow{2}{*}{$\begin{array}{c}\text { Produt da } \\
\text { Parcela } \\
\left(\mathrm{m}^{3} / \mathrm{ha}\right)\end{array}$} & \multirow[t]{2}{*}{$\begin{array}{l}\text { Àrv. } \\
\left(n^{\circ}\right)\end{array}$} & \multirow[t]{2}{*}{$\begin{array}{l}\text { Classe de } \\
\text { Diâmetro }\end{array}$} & \multirow{2}{*}{\begin{tabular}{|c|} 
Valor de \\
Diâmetro \\
(cm)
\end{tabular}} & \multirow[t]{2}{*}{$\begin{array}{c}\text { Casca } \\
(\%)\end{array}$} & \multirow{2}{*}{\begin{tabular}{|c|} 
Densidade \\
da Madeira \\
$\left(\mathrm{g} / \mathrm{cm}^{3}\right)$
\end{tabular}} & \multicolumn{4}{|c|}{ Dimensōes das Fibras } \\
\hline & & & & & & & & & $\begin{array}{l}\text { Comp. } \\
\text { (mm) }\end{array}$ & $\begin{array}{l}\text { Larg. } \\
(\mu \mathrm{m})\end{array}$ & \begin{tabular}{|c|} 
Lume \\
$(\mu \mathrm{m})$
\end{tabular} & $\begin{array}{c}\text { Parede } \\
(\mu \mathrm{m})\end{array}$ \\
\hline \multirow{27}{*}{3} & \multirow{9}{*}{11} & \multirow{3}{*}{1} & \multirow{3}{*}{188,42} & 1 & $\mathbf{P}$ & 8,50 & 16,933 & 0,619 & 0,994 & 16,000 & 9,500 & 3,250 \\
\hline & & & & 2 & $\mathbf{M}$ & 12,00 & 16,018 & 0,645 & 0,645 & 17,666 & 9,000 & 4,333 \\
\hline & & & & 3 & $\mathbf{G}$ & 16,00 & 16,831 & 0,662 & 0,662 & 16,333 & 8,000 & 4,167 \\
\hline & & \multirow{3}{*}{2} & \multirow{3}{*}{170,75} & 4 & $P$ & 8,50 & 19,912 & 0,663 & 0,663 & 15,500 & 8,333 & 3,583 \\
\hline & & & & 5 & M & 11,50 & 16,413 & 0,666 & 0,666 & 15,333 & 8,000 & 3,666 \\
\hline & & & & 6 & G & 14,00 & 20,164 & 0,656 & 0,656 & 16,000 & 6,167 & 4,917 \\
\hline & & \multirow{3}{*}{3} & \multirow{3}{*}{159,65} & 7 & $\mathbf{P}$ & 9,50 & 18,480 & 0,626 & 0,626 & 16,833 & 8,333 & 4,250 \\
\hline & & & & 8 & M & 12,50 & 17,117 & 0,656 & 0,656 & 13,500 & 6,500 & 3,500 \\
\hline & & & & 9 & $\mathbf{G}$ & 13,50 & 17,531 & 0,658 & 0,658 & 16,000 & 7,000 & 4,500 \\
\hline & \multirow{9}{*}{32} & \multirow{3}{*}{1} & \multirow{3}{*}{627,09} & 1 & $\mathbf{P}$ & 14,00 & 11,605 & 0,660 & 0,660 & 18,000 & 6,833 & 5,583 \\
\hline & & & & 2 & M & 18,00 & 12,546 & 0,670 & 0,670 & 15,500 & 5,000 & 5,250 \\
\hline & & & & 3 & $\mathbf{G}$ & 22,00 & 10,864 & 0,640 & 0,640 & 16,666 & 6,833 & 4,917 \\
\hline & & \multirow{3}{*}{2} & \multirow{3}{*}{551,01} & 4 & $\mathbf{P}$ & 12,00 & 11,392 & 0,657 & 0,657 & 17,666 & 7,666 & 5,000 \\
\hline & & & & 5 & M & 16,00 & 12,247 & 0,668 & 0,668 & 16,666 & 7,333 & 4,666 \\
\hline & & & & 6 & G & 19,50 & 12,888 & 0,676 & 0,676 & 16,167 & 6,333 & 4,917 \\
\hline & & \multirow{3}{*}{3} & \multirow{3}{*}{752,03} & 7 & $P$ & 14,00 & 12,709 & 0,669 & 0,669 & 17,000 & 7,333 & 4,833 \\
\hline & & & & 8 & $M$ & 19,00 & 12,035 & 0,663 & 0,663 & 15,000 & 6,000 & 4,500 \\
\hline & & & & 9 & G & 25,00 & 13,167 & 0,662 & 0,662 & 17,833 & 7,833 & 5,000 \\
\hline & \multirow{9}{*}{36} & \multirow{3}{*}{1} & \multirow{3}{*}{446,18} & 1 & $P$ & 11,00 & 10,687 & 0,660 & 0,660 & 18,000 & 7,500 & 5,250 \\
\hline & & & & 2 & $M$ & 14,00 & 11,583 & 0,671 & 0,671 & 17,000 & 6,833 & 5,083 \\
\hline & & & & 3 & G & 17,00 & 10,097 & 0,699 & 0,699 & 16,500 & 6,500 & 5,000 \\
\hline & & & & 4 & $P$ & 13,00 & 9,772 & 0,636 & 0,636 & 16,666 & 6,667 & 5,000 \\
\hline & & 2 & 527,17 & 5 & $M$ & 16,00 & 16,692 & 0,613 & 0,613 & 16,333 & 7,833 & 4,250 \\
\hline & & & & 6 & G & 19,00 & 16,122 & 0,603 & 0,603 & 18,833 & 7,167 & 4,833 \\
\hline & & & & 7 & $P$ & 14,00 & 20,433 & 0,609 & 0,609 & 15,666 & 6,833 & 4,417 \\
\hline & & 3 & 573,94 & 8 & $M$ & 17,00 & 16,298 & 0,642 & 0,642 & 17,667 & 6,667 & 5,500 \\
\hline & & & & 9 & G & 19,00 & 18,564 & 0,647 & 0,647 & 17,167 & 8,000 & 4,583 \\
\hline
\end{tabular}

Tabela 3. Parâmetros de qualidade da madeira analisados para os 3 clones de $E$. urophylla, pertencentes ao grupo fenotípico 3. 


\begin{tabular}{|c|c|c|c|c|c|c|c|c|c|c|c|c|}
\hline \multirow[t]{2}{*}{\begin{tabular}{|c|} 
Grupo \\
Fenotípico
\end{tabular}} & \multirow{2}{*}{ Clone } & \multirow{2}{*}{ Parcela } & \multirow{2}{*}{$\begin{array}{l}\text { Produt da } \\
\text { Parcela } \\
\left(\mathrm{m}^{3} / \mathrm{ha}\right)\end{array}$} & \multirow[t]{2}{*}{$\begin{array}{l}\text { Àv. } \\
\left(n^{0}\right)\end{array}$} & \multirow[t]{2}{*}{$\begin{array}{l}\text { Classe de } \\
\text { Diâmetro }\end{array}$} & \multirow{2}{*}{$\begin{array}{c}\text { Valor de } \\
\text { Diâmetro } \\
\text { (cm) }\end{array}$} & \multirow[t]{2}{*}{$\begin{array}{c}\text { Casca } \\
(\%)\end{array}$} & \multirow{2}{*}{\begin{tabular}{|c|} 
Densidade \\
da Madeira \\
$\left(\mathrm{g} / \mathrm{cm}^{3}\right)$
\end{tabular}} & \multicolumn{4}{|c|}{ Dimensōes das Fibras } \\
\hline & & & & & & & & & $\begin{array}{l}\text { Comp. } \\
\text { (mm) }\end{array}$ & $\begin{array}{l}\text { Larg. } \\
(\mu \mathrm{m})\end{array}$ & \begin{tabular}{|l} 
Lume \\
$(\mu \mathrm{m})$
\end{tabular} & $\begin{array}{c}\text { Parede } \\
(\mu \mathrm{m})\end{array}$ \\
\hline \multirow{9}{*}{4} & \multirow{3}{*}{23} & 1 & 215,07 & $\begin{array}{l}1 \\
2 \\
3\end{array}$ & $\begin{array}{l}P \\
M \\
G\end{array}$ & $\begin{array}{l}11,00 \\
13,00 \\
16,00 \\
\end{array}$ & $\begin{array}{l}12,831 \\
12,677 \\
13,342 \\
\end{array}$ & $\begin{array}{l}0,616 \\
0,617 \\
0,624 \\
\end{array}$ & \begin{tabular}{|l|}
0,885 \\
0,914 \\
0,929 \\
\end{tabular} & $\begin{array}{l}15,500 \\
16,666 \\
15,500 \\
\end{array}$ & \begin{tabular}{|l|}
6,667 \\
6,667 \\
5,666 \\
\end{tabular} & \begin{tabular}{|l|}
4,417 \\
5,000 \\
4,916 \\
\end{tabular} \\
\hline & & 2 & 217,45 & $\begin{array}{l}4 \\
5 \\
6 \\
\end{array}$ & $\begin{array}{l} \\
M \\
G\end{array}$ & $\begin{array}{c}9,00 \\
12,00 \\
15,00 \\
\end{array}$ & $\begin{array}{l}15,503 \\
12,933 \\
12,855 \\
\end{array}$ & $\begin{array}{l}0,618 \\
0,602 \\
0,627 \\
\end{array}$ & \begin{tabular}{|l|}
0,937 \\
0,969 \\
1,007 \\
\end{tabular} & \begin{tabular}{|l|}
16,333 \\
16,000 \\
16,000 \\
\end{tabular} & \begin{tabular}{|l|}
6,833 \\
6,333 \\
5,833 \\
\end{tabular} & \begin{tabular}{|l|}
4,750 \\
4,833 \\
5,083 \\
\end{tabular} \\
\hline & & 3 & 320,00 & $\begin{array}{l}7 \\
8 \\
9 \\
\end{array}$ & $\begin{array}{l}P \\
M \\
G\end{array}$ & $\begin{array}{c}9,00 \\
13,00 \\
15,00 \\
\end{array}$ & $\begin{array}{l}13,844 \\
12,990 \\
14,644 \\
\end{array}$ & $\begin{array}{l}0,604 \\
0,617 \\
0,614 \\
\end{array}$ & \begin{tabular}{|l|}
0,998 \\
0,914 \\
0,932 \\
\end{tabular} & \begin{tabular}{|l|}
15,333 \\
16,333 \\
15,333 \\
\end{tabular} & \begin{tabular}{|l|}
5,666 \\
6,167 \\
7,167 \\
\end{tabular} & $\begin{array}{l}4,833 \\
5,083 \\
4,083 \\
\end{array}$ \\
\hline & \multirow{3}{*}{34} & 1 & 421,51 & $\begin{array}{l}1 \\
2 \\
3 \\
\end{array}$ & $\begin{array}{l}P \\
M \\
G\end{array}$ & $\begin{array}{l}11,00 \\
15,00 \\
19,00 \\
\end{array}$ & $\begin{array}{l}16,291 \\
18,538 \\
15,790 \\
\end{array}$ & $\begin{array}{l}0,572 \\
0,592 \\
0,597 \\
\end{array}$ & \begin{tabular}{|l|}
1,042 \\
0,991 \\
0,994 \\
\end{tabular} & $\begin{array}{l}16,500 \\
16,000 \\
16,666 \\
\end{array}$ & \begin{tabular}{|l|}
7,333 \\
7,500 \\
8,333 \\
\end{tabular} & $\begin{array}{l}4,583 \\
4,250 \\
4,167 \\
\end{array}$ \\
\hline & & 2 & 248,02 & $\begin{array}{l}4 \\
5 \\
6 \\
\end{array}$ & $\begin{array}{l}P \\
M \\
G\end{array}$ & $\begin{array}{c}8,50 \\
12,50 \\
17,50 \\
\end{array}$ & \begin{tabular}{|l|}
15,383 \\
17,738 \\
15,697 \\
\end{tabular} & $\begin{array}{l}0,572 \\
0,626 \\
0,591 \\
\end{array}$ & \begin{tabular}{|l|}
0,942 \\
0,904 \\
0,958 \\
\end{tabular} & $\begin{array}{l}16,667 \\
17,000 \\
15,666 \\
\end{array}$ & $\begin{array}{l}8,000 \\
7,000 \\
7,666 \\
\end{array}$ & $\begin{array}{l}4,333 \\
5,000 \\
4,000 \\
\end{array}$ \\
\hline & & 3 & 357,64 & $\begin{array}{l}7 \\
8 \\
9\end{array}$ & $\begin{array}{l}P \\
M \\
G\end{array}$ & $\begin{array}{l}12,50 \\
15,00 \\
16,50\end{array}$ & \begin{tabular}{l|}
13,622 \\
13,385 \\
14,008 \\
\end{tabular} & $\begin{array}{l}0,554 \\
0,490 \\
0,585\end{array}$ & $\begin{array}{l}0,903 \\
0,987 \\
0,923\end{array}$ & $\begin{array}{l}16,666 \\
16,000 \\
15,833\end{array}$ & $\begin{array}{l}8,000 \\
7,500 \\
8,333\end{array}$ & $\begin{array}{l}4,333 \\
4,250 \\
3,750\end{array}$ \\
\hline & \multirow{3}{*}{43} & 1 & 198,76 & $\begin{array}{l}1 \\
2 \\
3\end{array}$ & $\begin{array}{l}P \\
M \\
G\end{array}$ & $\begin{array}{c}8,00 \\
13,00 \\
17,50 \\
\end{array}$ & $\begin{array}{l}18,419 \\
16,785 \\
15,585 \\
\end{array}$ & $\begin{array}{l}0,578 \\
0,635 \\
0,600 \\
\end{array}$ & \begin{tabular}{|l|}
0,952 \\
0,940 \\
1,024 \\
\end{tabular} & \begin{tabular}{|c|}
17,0000 \\
15,666 \\
16,167 \\
\end{tabular} & $\begin{array}{l}8,167 \\
6,167 \\
6,167 \\
\end{array}$ & $\begin{array}{l}4,417 \\
4,750 \\
5,000 \\
\end{array}$ \\
\hline & & 2 & 404,67 & $\begin{array}{l}4 \\
5 \\
6\end{array}$ & $\begin{array}{l}P \\
M \\
G\end{array}$ & $\begin{array}{l}14,00 \\
16,00 \\
18,00\end{array}$ & $\begin{array}{l}15,655 \\
16,455 \\
16,191\end{array}$ & $\begin{array}{l}0,659 \\
0,658 \\
0,651\end{array}$ & \begin{tabular}{|l|}
0,946 \\
1,055 \\
0,995 \\
\end{tabular} & $\begin{array}{l}16,167 \\
17,167 \\
16,167\end{array}$ & $\begin{array}{l}5,833 \\
6,333 \\
7,167 \\
\end{array}$ & $\begin{array}{l}5,167 \\
5,417 \\
4,500\end{array}$ \\
\hline & & 3 & 485,20 & $\begin{array}{l}7 \\
8 \\
9\end{array}$ & $\begin{array}{l}P \\
M \\
G\end{array}$ & $\begin{array}{l}13,00 \\
17,00 \\
20,00\end{array}$ & $\begin{array}{l}13,647 \\
13,839 \\
12,793\end{array}$ & $\begin{array}{l}0,625 \\
0,647 \\
0,655\end{array}$ & $\begin{array}{l}0,917 \\
1,008 \\
1,034\end{array}$ & $\begin{array}{l}15,500 \\
16,167 \\
16,000\end{array}$ & $\begin{array}{l}, 333 \\
6,500 \\
5,500\end{array}$ & $\begin{array}{l}4,083 \\
4,833 \\
5,250\end{array}$ \\
\hline
\end{tabular}

Tabela 4. Parâmetros de qualidade da madeira analisados para os 3 clones de $E$. urophylla, pertencentes ao grupo fenotípico 4. 
A análise da variância para os parâmetros de qualidade da madeira, entre e dentro de grupos fenotípicos, expressa pelos valores de quadrado médio, é apresentada na Tabela 5. Foram verificadas diferenças significativas, ao nivel de $1 \%$ de probabilidade, entre grupos fenotípicos para a densidade básica da madeira, comprimento e diâmetro do lume das fibras. Diferenças significativas entre os clones dentro dos grupos fenotípicos foram, também, observadas para densidade básica da madeira, percentagem de casca, comprimento, diâmetro do lume e espessura da parede das fibras.

Tabela 5. Análise da variância (teste F) para os parâmetros de qualidade da madeira: dados de valores do quadrado médio.

\begin{tabular}{|c|c|c|c|c|c|c|c|}
\hline C.V & G.L & & & $\overline{\mathbf{Q}}$ & A. & & $=$ \\
\hline 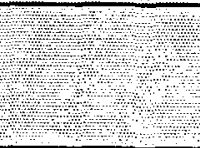 & $=$ & $\begin{array}{c}\text { Dens. } \\
\text { Básica }\end{array}$ & $\begin{array}{l}\text { Perc. } \\
\text { Casca }\end{array}$ & $\begin{array}{c}\text { Compr. } \\
\text { Fibra }\end{array}$ & $\begin{array}{l}\text { Larg. } \\
\text { Fibra }\end{array}$ & $\begin{array}{l}\text { Diam. } \\
\text { Lume }\end{array}$ & $\begin{array}{c}\text { Espessura } \\
\text { Parede }\end{array}$ \\
\hline Grupo & 3 & $0.0044^{\star \star}$ & 7.33 & $0.0093^{\star \star}$ & 0.6086 & $1.3826^{\star \star}$ & 0.1266 \\
\hline Clone (Gr) & 8 & $0.0020^{\text {*t }}$ & $13.05^{\star \star}$ & $0.0028^{* *}$ & 0.5359 & $0.8715^{\star *}$ & $0.3013^{\star \star *}$ \\
\hline Resíduo & 24 & 0.0032 & 2.98 & 0.0011 & 0.2894 & 0.1836 & 0.0522 \\
\hline Total & 35 & & & & & & \\
\hline C.V (\%) & & 2.85 & 12.30 & 3.23 & $\overline{3.25}$ & 5.92 & 4.93 \\
\hline
\end{tabular}

* significativo a $1 \%$ de probabilidade

* significativo a $5 \%$ de probabilidade

n.s. não significativo ao nivel de $5 \%$ de probabilidade 


\subsection{Teste de comparação de médias entre grupos fenotípicos}

Os testes de comparação de médias, entre grupos fenotípicos, para a densidade básica da madeira, percentagem de casca, comprimento, largura, diâmetro do lume e espessura da parede da fibras são apresentadas nas Tabela 6,8 e 9 respectivamente.

Tabela 6. Resultados do teste de Tukey para parâmetros de qualidade da madeira: densidade básica.

\begin{tabular}{|cccccc|}
\hline $\begin{array}{c}\text { Dens. básica } \\
\text { média } \\
\left(\mathbf{g} / \mathbf{c m}^{3}\right)\end{array}$ & $\begin{array}{c}\text { Grupo } \\
\text { fenotípico }\end{array}$ & 1 & 2 & 3 & 4 \\
\hline 0.64 & 1 &. & $0.0014^{\text {}}$ & 0.1204 & $0.0017^{\text {}}$ \\
0.61 & 2 &. &. & $0.0001^{\text {}}$ & 0.9341 \\
0.65 & 3 &. &. &. & $0.0001^{\text {}}$ \\
0.61 & 4 &. &. &. &. \\
\hline
\end{tabular}

* significativo a $1 \%$ de probabilidade

* significativo a $5 \%$ de probabilidade

Pela análise da Tabela 6 verifica-se que, pelos valores de densidade básica média da madeira, os grupos fenotípicos podem ser agrupados. Os grupos fenotípicos 1 e 3 apresentaram valores de densidade básica da madeira mais elevados do que os grupos fenotípicos 2 e 4.

Para este parâmetro observam-se diferenças significativas entre as médias dos grupos fenotípicos 1 e 2,1 e 4, 2 e 3 , e 3 e 4 .

Esses resultados indicam que a classificação dos 4 grupos através das características fenotípicas dos clones não se estende, ou não se aplica totalmente para o parâmetro densidade básica média da madeira. Essas informações são importantes na 
aplicação de métodos de seleção de clones quando deve-se considerar conjuntamente grupo fenotípico e densidade básica da madeira. Para sua comprovação, foi conduzido um estudo de correlação entre a densidade básica média da madeira e as caracteristícas fenotípicas quantitativas (Anexo I) estudadas por LOPEZ (1992), não tendo sido encontrada nenhuma tendência significativa pelos baixos valores dos coeficientes de correlação $\left(r^{2}\right)$ (Tabela 7).

Tabela 7. Correlação entre parâmetros de qualidade da madeira e características fenotípicas quantitativas de clones de E. urophylla, segundo Lopez (1992).

\begin{tabular}{|c|c|c|c|c|c|c|}
\hline & $\begin{array}{c}\text { Volume } \\
\text { (m3) }\end{array}$ & $\begin{array}{l}\text { C/L das } \\
\text { folhas }\end{array}$ & $\begin{array}{l}\text { Comp. } \\
\text { peciolo }\end{array}$ & $\begin{array}{l}\text { Diâm. } \\
\text { Cálice }\end{array}$ & $\begin{array}{l}\text { Comp. } \\
\text { cálice }\end{array}$ & $\begin{array}{c}\text { Comp. } \\
\text { pedicelo }\end{array}$ \\
\hline $\begin{array}{l}\text { D. Básica } \\
\text { (g/cm3) }\end{array}$ & $\begin{array}{l}a=0.60589 \\
b=0.08440 \\
r^{2}=0.034 \\
F=0.353 \mathrm{~ns}\end{array}$ & $\begin{array}{l}a=0.58048 \\
b=0.01019 \\
r^{2}=0.039 \\
F=0.409 n s\end{array}$ & $\begin{array}{l}a=0.49235 \\
b=0.05900 \\
r^{2}=0.487 \\
F=9.508 \text { * }\end{array}$ & $\begin{array}{l}a=0.58468 \\
b=0.05142 \\
r^{2}=0.051 \\
F=0.542 n s\end{array}$ & $\begin{array}{l}a=0.62257 \\
b=0.00438 \\
r^{2}=0.0002 \\
F=0.002 n s\end{array}$ & $\begin{array}{l}a=0.62024 \\
b=0.01330 \\
r^{2}=0.008 \\
F=0.084 n s\end{array}$ \\
\hline$\%$ Casca (vol.) & $\begin{array}{l}a=17.0395 \\
b=-12.273 \\
r^{2}=0.171 \\
F=2.074 n s\end{array}$ & $\begin{array}{l}a=16.2181 \\
b=-0.4725 \\
r^{2}=0.020 \\
F=0.205 n s\end{array}$ & $\begin{array}{l}a=12.6933 \\
b=0.6224 \\
r^{2}=0.012 \\
F=0.131 \mathrm{~ns}\end{array}$ & $\begin{array}{l}a=5.7356 \\
b=10.3956 \\
r^{2}=0.500 \\
F=10.025\end{array}$ & $\begin{array}{l}a=14.2788 \\
b=-0.2180 \\
r^{2}=0.0001 \\
F=0.001 n s\end{array}$ & $\begin{array}{l}a=15.2137 \\
b=-2.5265 \\
r^{2}=0.071 \\
F=0.773 \mathrm{~ns}\end{array}$ \\
\hline $\begin{array}{l}\text { Comp. Fib. } \\
\text { (mm) }\end{array}$ & $\begin{array}{l}a=0.94045 \\
b=0.27753 \\
r=0.212 \\
F=2.701 n s\end{array}$ & $\begin{array}{l}a=0.96165 \\
b=0.01009 \\
r^{2}=0.022 \\
F=0.228 n s\end{array}$ & $\begin{array}{l}a=1.00163 \\
b=0.00229 \\
r=0.0004 \\
F=0.004 n s\end{array}$ & $\begin{array}{l}a=1.03013 \\
b=-0.0289 \\
r^{2}=0.009 \\
F=0.095 \mathrm{~ns}\end{array}$ & $\begin{array}{l}a=1.05697 \\
b=-0.0626 \\
r^{2}=0.027 \\
F=0.282 \mathrm{~ns}\end{array}$ & $\begin{array}{l}a=0.98007 \\
b=0.06094 \\
r^{2}=0.101 \\
F=1.124 \mathrm{~ns}\end{array}$ \\
\hline $\begin{array}{l}\text { Esp. Parede } \\
(\mu \mathrm{m})\end{array}$ & $\begin{array}{l}a=4.21483 \\
b=1.72614 \\
r^{2}=0.149 \\
F=1.758 n s\end{array}$ & $\begin{array}{l}a=3.76226 \\
b=0.19345 \\
r^{2}=0.148 \\
F=1.743 n s\end{array}$ & $\begin{array}{l}a=3.92848 \\
b=0.30846 \\
r=0.139 \\
F=1.625 n s\end{array}$ & $\begin{array}{l}a=4.79987 \\
b=-0.2139 \\
r^{2}=0.009 \\
F=0.094 n s\end{array}$ & $\begin{array}{l}a=4.9477 \\
b=-0.3547 \\
r^{2}=0.016 \\
F=0.163 n s\end{array}$ & $\begin{array}{l}a=4.62020 \\
b=0.01698 \\
r^{2}=0.0001 \\
F=0.001 n s\end{array}$ \\
\hline
\end{tabular}


Os valores de densidade básica média da madeira dos clones de $E$. urophylla obtidos no presente trabalho, foram comparados aos encontrados por BRASIL (1983), para a mesma espécie e origem, porém em árvores com 3 anos de idade, os mesmos apresentaram valores superiores ao valor médio $\left(0,45 \mathrm{~g} / \mathrm{cm}^{3}\right)$ obtido pelo autora, que relata que a procedência de Flores apresentou valor de densidade básica média da madeira maior que a de Timor.

Da mesma forma FERREIRA (1994) relata para procedência de E. urophylla, valores de de densidade básica $\left(0,44 \mathrm{~g} / \mathrm{cm}^{3}\right)$ tratando-se, entretanto, de árvores mais jovens, com 4 anos de idade. É sabido que valores de densidade básica da madeira tende a aumentar com relação a idade das árvores.

O mesmo relatam GOUVÉA et alii (1997), onde os valores encontrados para densidade básica da madeira para $E$ urophylla variaram de 0,550 a $0,577 \mathrm{~g} / \mathrm{cm}^{3}$, para árvores de 6 anos de idade, ou seja, da mesma idade.

Com relação à percentagem de casca a análise da variância dos dados médios dos grupos fenotípicos não mostrou diferenças significativas; a não significância para esse parâmetro pode ser resultado da seleção ter sido direcionada para os clones que apresentavam "casca lisa", conforme descrito na metodologia. (Ítem 3.1.1.).

Entre os grupos fenotípicos os valores de percentagem de casca foram de 13.2, $13.5,14.8$ e $14.9 \%$ para os grupos fenotípicos 1, 2,3 e 4, respectivamente.

Com relação aos valores de percentagem de casca obtidos para os clones de $E$. urophylla, verifica-se que são próximos aos relatados na literatura para a espécie. Dessa forma, GOUVEA et alli (1997) e OLIVEIRA (1998), verificam valores de 12,75 a 15,59 \%.

Com relação ao comprimento das fibras, na Tabela 8 são apresentados os valores médios desse parâmetro para cada grupo fenotípico e os testes de comparação de médias. 
Tabela 8. Resultados do Teste de Tukey para parâmetros de qualidade da madeira: comprimento das fibras

\begin{tabular}{|cccccc|}
\hline $\begin{array}{c}\text { Comp. } \\
\text { médio das } \\
\text { fibras (mm) }\end{array}$ & $\begin{array}{c}\text { Grupo } \\
\text { fenotipico }\end{array}$ & 1 & 2 & 3 & 4 \\
\hline 1.00 & 1 &. & 0.0521 & 0.2868 & $0.0001^{\star \star}$ \\
1.00 & 2 &. &. & 0.3495 & $0.0088^{\star \star}$ \\
1.02 & 3 &. &. &. & $0.0009^{\star \star}$ \\
0.96 & 4 &. &. &. &. \\
\hline
\end{tabular}

** significativo a $1 \%$ de probabilidade

* significativo a $5 \%$ de probabilidade

Pela análise da Tabela 8 verifica-se que os valores médios de comprimento das fibras mostraram que os grupos fenotípicos 1,2 e 3 podem ser agrupados, em relação ao grupo fenotípico 4, com valores de 1.00, 1.00, 1.02, e $0.96 \mathrm{~mm}$, respectivamente.

Para esse parâmetro observam-se diferenças significativas entre as médias dos grupos fenotípicos 4 e 1,4 e 2 e 4 e 3.

A exemplo da densidade básica da madeira esses resultados indicam que a classificação dos 4 grupos fenotípicos através das características fenotipicas dos clones, não se extende ou se aplica para esse parâmetro, com implicações na seleção de clones.

$\mathrm{Na}$ Tabela 7 os baixos valores de coeficiente de correlação $\left(r^{2}\right)$ comprovam que não existe nenhuma tendência significativa entre os grupos fenotípicos com o parâmetro analisado.

Com relação aos valores de comprimento das fibras obtidos para os clones de $E$. urophylla, verifica-se que são próximos aos relatados na literatura para a espécie. Dessa forma, OLIVEIRA (1998) verifica valores médio de 1,05 mm. 
Segundo TOMAZELLO FILHO (1985), quando considera-se o comprimento médio das fibras, observam-se pequenas variações entre espécies, com valores em torno de 1,0 $\mathrm{mm}$. Entretanto a maior percentagem de fibras encontram-se entre as dimensões 0,60 a $1,40 \mathrm{~mm}$.

Com relação à largura das fibras a análise da variância dos dados médios dos grupos fenotípicos não mostrou diferenças significativas (Tabela 5). Entre os grupos fenotípicos os valores médios de largura das fibras foram de 16.5, 16.15, 16.57 e 16.13 $\mu \mathrm{m}$, para os grupos fenotípicos 1, 2, 3 e 4, respectivamente.

Com relação aos valores de largura das fibras obtidos para os clones de $E$. urophylla, verifica-se que são próximos aos relatados na literatura para a espécie. Dessa forma, FERREIRA (1994), FERREIRA \& SANTOS (1995) e OLIVEIRA (1998) verificam valores de 15,6 A 20,10 $\mu \mathrm{m}$

Com relação ao diâmetro do lume das fibras, na Tabela 9 são apresentados os valores médios desse parâmetro para cada grupo fenotípico e teste de comparação de médias.

Tabela 9. Resultados do Teste de Tukey para parâmetros de qualidade da madeira: diâmetro do lume das fibras.

\begin{tabular}{|cccccc|}
\hline $\begin{array}{c}\text { Diâmetro } \\
\text { médio do } \\
\text { lume }(\mu \mathrm{m})\end{array}$ & $\begin{array}{c}\text { Grupos } \\
\text { fenotípicos }\end{array}$ & 1 & 2 & 3 & 4 \\
\hline 7.03 & 1 &. & $0.0011^{\text {** }}$ & 0.2694 & 0.4704 \\
7.77 & 2 &. &. & $0.0169^{\star}$ & $0.0002^{\star *}$ \\
7.26 & 3 &. &. &. & 0.0746 \\
6.88 & 4 &. &. &. &. \\
\hline
\end{tabular}

\footnotetext{
** significativo a $1 \%$ de probabilidade
}

* significativo a $5 \%$ de probabilidade 
Pela análise da Tabela 9 verifica-se que os valores médios de diâmetro do lume das fibras mostraram que os grupos fenotípicos 1, 3 e 4 podem ser agrupados, em relação ao grupo fenotípico 2, com valores de 7.03, 7.26, 6.18 e $7.7 \mu \mathrm{m}$, respectivamente.

Para esse parâmetro observam-se diferenças significativas entre as médias dos grupos fenotípicos 1 e 2, 2 e 3, 2 e 4.

A exemplo da densidade básica da madeira e comprimento médio das fibras, esse resultado indica que a classificação dos 4 grupos fenotípicos não se estende ou se aplica para esse parâmetro, com implicações na seleção de clones.

$\mathrm{Na}$ Tabela 7 os baixos valores de coeficiente de correlação $\left(r^{2}\right)$ comprovam que não existe nenhuma tendência significativa entre os grupos fenotípicos com o parâmetro analisado.

Com relação aos valores de diâmetro do lume das fibras obtidos para os clones de E. urophylla, verifica-se que são inferiores aos relatados na literatura para a espécie. Dessa forma, FERREIRA (1994), FERREIRA \& SANTOS (1995) e OLIVEIRA (1998) verificam valores de 9,80 a 11,40 $\mu \mathrm{m}$.

Com relação à espessura da parede das fibras, a análise de variância dos dados médios dos grupos fenotípicos não mostrou diferenças significativas (Tabela 5).

Entre os grupos fenotípicos os valores médios de espessura de parede das fibras foram 4.77, 4.48, 4.61 e $4.62 \mu \mathrm{m}$, para os grupos fenotípicos 1, 2, 3 e 4, respectivamente.

$\mathrm{Na}$ Tabela 7 os valores baixos de coeficiente de correlação $\left(r^{2}\right)$ comprovam que não existe nenhuma tendência significativa entre os grupos fenotípicos (1 a 4), com o parâmetro espessura da parede.

Comparando-se os valores de espessura média da parede da fibra dos clones de E. urophylla obtidos no presente trabalho, com os relatados na literatura para a espécie, verifica-se que são próximos. Desta forma FERREIRA (1994), FERREIRA \& SANTOS (1995) e OLIVEIRA (1998) verificaram valores de 4,05 a 4,80 $\mu \mathrm{m}$. 


\subsection{Teste de comparação de médias dentro de grupos fenotípicos}

Os testes de comparação de médias entre os clones dentro de cada grupo fenotípico para os parâmetros densidade básica da madeira, percentagem de casca, comprimento, diâmetro do lume e espessura da parede das fibras são apresentados nas Tabelas 10 a 14, respectivamente.

Tabela 10. Resultados do Teste de Tukey para parâmetros de qualidade da madeira: densidade básica da madeira.

\begin{tabular}{|c|c|c|c|c|c|c|c|c|c|c|c|c|c|}
\hline & & \multicolumn{3}{|c|}{ GR 1} & \multicolumn{3}{|c|}{ GR 2} & \multicolumn{3}{|c|}{ GR 3} & \multicolumn{3}{|c|}{ GR 4} \\
\hline MÉD & CLO & 26 & 28 & 46 & 12 & 18 & 40 & 11 & 32 & 36 & 23 & 34 & 43 \\
\hline 0.681 & 26 & . & 00003 & 00001 & 0.0001 & 0.0001 & 0.0003 & 0.0440 & 0.2207 & 0.0135 & 0.0001 & 0.0001 & 0,0037 \\
\hline 0.619 & 28 & . & $\cdot$ & 0.7517 & 0.8153 & 00499 & 0.9759 & 0.0433 & 00062 & 0.1243 & 0.8094 & 0.0064 & 0.3069 \\
\hline 0.614 & 46 & $\cdot$ & . & . & 0.9339 & 0.0938 & 0.7746 & 0.0218 & 0,0029 & 0.0678 & 0.9399 & 0.0136 & 0.1852 \\
\hline 0.615 & 12 & $\cdot$ & . & . & 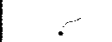 & 0.0799 & 0.8387 & 0.0262 & 0.0035 & 0.0799 & 0.9940 & 0.0115 & 0.2127 \\
\hline 0.588 & 18 & . & . & . & . & . & 0.0531 & 0.0003 & 0.0001 & 0.0012 & 0.0810 & 0.3657 & 0.0048 \\
\hline 0.618 & 40 & · & - & - & - & - & . & 0.0406 & 0.0057 & 0.1176 & 0.8328 & 00069 & 0.2933 \\
\hline 0.650 & 11 & . & . & . & . & . & . & . & 0.3936 & 0.5934 & 0.0257 & 00001 & 0.2866 \\
\hline 0.662 & 32 & . & - & . & . &. & . & . & . & 0.1714 & 000034 & 0.0001 & 0.0619 \\
\hline 0.642 & 36 & $\cdot$ & . & . & . & ${ }^{\circ}$ & . & $\cdot$ & . & $\cdot$ & 0.0787 & 0.0001 & 0.5883 \\
\hline 0.615 & 23 & . & . & . & . & . & . & . & . & . & - & 0.0116 & 0.2101 \\
\hline 0.575 & 34 & . & . & 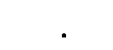 & . & 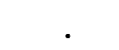 & . & . & . & . & . & . & 0.0005 \\
\hline 0.634 & 43 & . & . & . & . & . & . & . & . & . & & & \\
\hline
\end{tabular}

Significativo a $5 \%$ de probabilidade

Para a densidade básica da madeira, dentro do grupo fenotípico 1, verificou-se que 0 clone 26 apresentou maior densidade $\left(0,68 \mathrm{~g} / \mathrm{cm}^{3}\right)$, diferenciando-se significativamente do clone $28\left(0,62 \mathrm{~g} / \mathrm{cm}^{3}\right)$ e do clone $46\left(0.61 \mathrm{~g} / \mathrm{cm}^{3}\right) .0$ grupo mostra variações pequenas em relação à densidade básica da madeira (Tabela 10).

Para o grupo fenotípico 2, a maior densidade básica média da madeira foi encontrada para o clone $40\left(0,62 \mathrm{~g} / \mathrm{cm}^{3}\right)$, seguido pelo clone $12\left(0,61 \mathrm{~g} / \mathrm{cm}^{3}\right)$ e clone 18 $\left(0,59 \mathrm{~g} / \mathrm{cm}^{3}\right)$, porém, não se encontrando diferenças significativas entre os mesmos. 
Para o grupo fenotípico 3, as médias da densidade básica da madeira dos clones tiveram pequena variação, sendo de 0,64 (clone 36), 0,65 (clone 11) e 0,66 g/cm (clone 32), e não apresentam diferenças significativas ao nivel de $5 \%$ de probabilidade.

Para o grupo fenotípico 4, o clone 34 apresentou a menor densidade básica média da madeira $\left(0,57 \mathrm{~g} / \mathrm{cm}^{3}\right)$ diferenciando-se estatisticamente do clone $23(0,62$ $\left.\mathrm{g} / \mathrm{cm}^{3}\right)$ e do clone $43\left(0,63 \mathrm{~g} / \mathrm{cm}^{3}\right)$, que não diferenciaram entre si. Em função do valor do clone 34, podemos dizer que a variação individual neste grupo é ampla para esta característica.

A amplitude de variação para os valores de densidade básica da madeira dentro dos grupos fenotípicos foi de: $0,61-0,69 ; 0,60-0,68,0,54-0,65 \mathrm{~g} / \mathrm{cm}^{3}$, para os grupos fenotípicos 1, 2, 3 e 4 respectivamente.

Tabela 11. Resultados do Teste de Tukey para parâmetros de qualidade da madeira: percentagem de casca.

\begin{tabular}{|c|c|c|c|c|c|c|c|c|c|c|c|c|c|}
\hline & & \multicolumn{3}{|c|}{ GR 1} & \multicolumn{3}{|c|}{ GR 2} & \multicolumn{3}{|c|}{ GR 3} & \multicolumn{3}{|c|}{ GR 4} \\
\hline MED & CLO & 26 & 28 & 46 & 12 & 18 & 40 & 11 & 32 & 36 & 23 & 34 & 43 \\
\hline 14.37 & 26 & & 0.0051 & 0.5848 & 0.8262 & 0.2020 & 0.5330 & 0.0263 & 0.1301 & 0.9436 & 0.5482 & 0.3906 & 0.4378 \\
\hline 10.02 & 28 & . & . & $0.000 \mathrm{~B}$ & 0.0086 & 0.0888 & 0.0218 & 0.0001 & 0.1420 & 0.0043 & 10.0207 & 00006 & 0.0007 \\
\hline 15.15 & 46 & & . & . & 0.4454 & 0.0744 & 0.2471 & 0.0824 & 0.0444 & 0.6338 & 0.2563 & 0.7514 & 0.8160 \\
\hline 14.06 & 12 & • & - & . & . & 0.2866 & 0.6850 & 0.0161 & 0.1911 & 0.7717 & 0.7021 & 0.2838 & 0.3221 \\
\hline 12.52 & 18 & . & . & $\cdot$ & $\cdot$ & $\cdot$ & 0.5035 & 0.0012 & 0.8004 & 0.1793 & 0.4890 & 0.0388 & 0.0468 \\
\hline 13.48 & 40 & $\cdot$ & . & • & . & . & . & 0.0062 & 0.3592 & 0.4882 & 0.9815 & 0.1449 & 0.1680 \\
\hline 17.71 & 11 & . & . & & $\cdot$ & . & . & 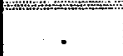 & 0.0006 & Q.6.108 & 10.0066 & 0.1486 & 0.1277 \\
\hline 12.16 & 32 & • & 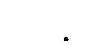 & & . & . & • & - & & 0.1143 & 0.3475 & 0.0224 & $=0027$ \\
\hline 14.47 & 36 & ${ }^{\circ}$ & 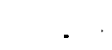 & & . & 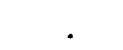 & . & . & 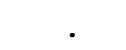 & 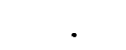 & 0.5027 & 0.4299 & 0.4799 \\
\hline 13.51 & 23 & $\cdot$ & $\cdot$ & . & . & . & $\cdot$ & . & - & . & . & 0.1510 & 0.1749 \\
\hline 15.60 & 34 & . & $\cdot$ & & . & . & . & $\cdot$ & . & . & $\cdot$ & . & 0.9327 \\
\hline 15.48 & 43 & & & & 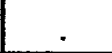 & 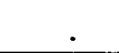 & & 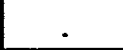 & . & 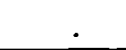 & 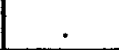 & . & \\
\hline
\end{tabular}

\section{Significativo a $5 \%$ de probabilidade}

Para a percentagem de casca, no grupo fenotípico 1 o clone 28 apresentou o menor valor (10,02\%), diferenciando-se significativamente ao nível de $5 \%$ de 
probabilidade do clone $26(14,37 \%)$ e do clone 46 (15,15\%), que não apresentaram diferenças significativas entre si (Tabela 11).

Para o grupo fenotípico 2 a maior percentagem média de casca foi encontrada para o clone 12 (14,06\%), seguido pelo clone 40 (13,48\%) e clone 18 (12,52\%). Porém, não foram encontradas diferenças estatísticas significativas entre os mesmos.

Para o grupo fenotípico 3 o clone 11 com 17,71\% diferenciou-se ao nivel de 5\% de probabilidade do clone $32(12,16 \%)$ e do clone $36(14,47 \%)$, sendo que estes não diferenciaram entre si.

Para o grupo fenotípico 4 não houve diferença significativa entre os clones, sendo que a maior média foi a do clone $34(15,60 \%)$ e a menor a do clone $23(13,51 \%)$.

A amplitude de variação para os valores de percentagem da casca da madeira dentro dos grupos fenotípicos foram 10,00 -15,15; 12,52 - 14,06; 12,16 - 17,71; 13,51 $15,60 \%$ para os grupos fenotípico 1, 2, 3 e 4 respectivamente.

Tabela 12. Resultados do Teste de Tukey para parâmetros de qualidade da madeira: comprimento da fibra.

\begin{tabular}{|c|c|c|c|c|c|c|c|c|c|c|c|c|c|}
\hline & & \multicolumn{3}{|c|}{ GR 1} & \multicolumn{3}{|c|}{ GR 2} & \multicolumn{3}{|c|}{ GR 3} & \multicolumn{3}{|c|}{ GR 4} \\
\hline MÉD & CLO & 26 & 28 & 46 & 12 & 18 & 40 & 11 & 32 & 36 & 23 & 34 & 43 \\
\hline 1.005 & 26 & & 0.0033 & 0.6854 & 0.4914 & 0.8815 & 0.3333 & 0.4538 & 0.1905 & 0.7532 & 0.0268 & 0.1031 & 0.4636 \\
\hline 1.092 & 28 & & . & 00087 & 0.0006 & 0.0023 & 0.0318 & 0.0194 & 0.0668 & 0.0015 & 0.0001 & 0.0001 & 0,000 \\
\hline 1.016 & 46 & . & . & . & 0.2785 & 0.5802 & 0.5690 & 0.7283 & 0.3580 & 0.4736 & 0.0106 & 0.0460 & 0.2595 \\
\hline 0.986 & 12 & . & . & . &. & 0.5887 & 0.1047 & 0.1572 & 0.0519 & 0.7067 & 0.1097 & 0.3293 & 0.9637 \\
\hline 1.001 & 18 & . & $\theta^{\prime}$ & . & . & . & 0.2663 & 0.3708 & 0.1472 & 0.8685 & 0,0370 & 0.1357 & 0.5580 \\
\hline 1.032 & 40 & . & . & . & . & . & . & 0.8232 & 0.7221 & 0.2041 & 000027 & 8.0130 & 0.0961 \\
\hline 1.025 & 11 & . & . & . &. & . & . & . & 0.5635 & 0.2911 & W00016 & 0.9217 & 0.1450 \\
\hline 1.041 & 32 &. & . & . & . & . & . & . & . & 0.1089 & (0.0011 & 0.0056 & $=0.047$ \\
\hline 0.997 & 36 & . & . & . & . & . & . & $10^{\circ}$ & . & . & 0.0523 & 0.1814 & 0.6733 \\
\hline 0.942 & 23 & . & . & . & . & . & . & . & . & . & . & 0.5122 & 0.1194 \\
\hline 0.960 & 34 & . & . & . & . & . & . & . & . & . & . & . & 0.3517 \\
\hline 0.985 & 43 & . & . & . &. & . & . & & . & . & & . & . \\
\hline
\end{tabular}

Significativo a $5 \%$ de probabilidade 
Para o comprimento das fibras dentro do grupo fenotípico 1,0 clone 28 apresentou o maior valor de comprimento $(1,09 \mathrm{~mm})$, diferenciando-se significativamente ao nivel de $5 \%$ de probabilidade do clone $46(1,02 \mathrm{~mm})$ e do clone $26(1,00 \mathrm{~mm})$, que não apresentaram diferenças entre si (Tabela 12).

Para o grupo fenotípico 2 os clones apresentaram as seguintes médias de comprimento de fibras: clone $12(0,98 \mu \mathrm{m})$, clone $18(1,00 \mu \mathrm{m})$ e clone $40(1,03 \mu \mathrm{m})$ não apresentando diferenças significativas ao nivel de $5 \%$ de probabilidade.

Para o grupo fenotípico 3, as médias dos clones variaram de 0,99 (clone 36) para $1,04 \mu \mathrm{m}$ (clone 32), não apresentando diferenças significativas ao nivel de $5 \%$ de probabilidade entre os clones estudados.

Para o grupo fenotípico 4, as médias de comprimento das fibras variaram de 0,94 (clone 23) para $0.98 \mu \mathrm{m}$ (clone 43), não apresentando diferenças significativas ao nivel de $5 \%$ de probabilidade entre os clones estudados.

A amplitude de variação para os valores de comprimento das fibras dentro dos grupos fenotípicos foram: $1,00-1,09 ; 0,98-1,03 ; 1,00-1,04 ; 0,94-0,98 \mu \mathrm{m}$, para os grupos fenoípicos 1, 2, 3 e 4, respectivamente.

Com relação aos valores de largura das fibras, dentro de grupos fenotípicos, os clones não apresentaram diferenças significativas na análise da variância dos dados (Tabela 5).

Sendo que para cada grupo encontrou-se a seguinte amplitude de variação para os valores de largura de fibra de madeira 16,31 - 16,96; 16,30 - 17,07; 15,90 - 17,09; $15,88-16,33 \mu \mathrm{m}$, para os grupos fenotípicos 1, 2, 3 e 4, respectivamente. 
Tabela 13. Resultados do Teste de Tukey para parâmetros de qualidade da madeira: diâmetro do lume das fibras

\begin{tabular}{|c|c|c|c|c|c|c|c|c|c|c|c|c|c|}
\hline \multirow[b]{2}{*}{ MÉD } & \multirow[b]{2}{*}{ CLO } & \multicolumn{3}{|c|}{ GR 1} & \multicolumn{3}{|c|}{ GR 2} & \multicolumn{3}{|c|}{ GR 3} & \multicolumn{3}{|c|}{ GR 4} \\
\hline & & 26 & 28 & 46 & 12 & 18 & 40 & 11 & 32 & 36 & 23 & 34 & 43 \\
\hline 7.074 & 26 & . & 0.9992 & 0.7135 & 0.0936 & 0.0013 & 0.5318 & 0.0321 & 0.4343 & 0.9169 & 0.0447 & 0.0689 & 0.1658 \\
\hline 7.073 & 28 & & . & 0.7142 & 0.0934 & $0,0 \mathrm{~min}$ & 0.5311 & 00320 & 0.4348 & 0.9162 & 0.0448 & 0.0688 & 0.1661 \\
\hline 6.944 & 46 & 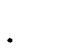 & . & . & 0.0448 & 0.0005 & 0.3244 & 0.0141 & 0.6756 & 0.6377 & 0.0935 & 0.0321 & 0.3007 \\
\hline 7.685 & 12 & . & . & . &. & 0.0689 & 0.2774 & 0.6014 & 0,0179 & 0.1139 & 0.0007 & 0.8754 & 0.0041 \\
\hline 8.351 & 18 & 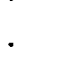 & . & . & . & . & 0.0060 & 0.1817 & 0,0002 & 0.0016 & 0.0001 & 0.0935 & 0,0001 \\
\hline 7.296 & 40 & $\cdot$ & . & 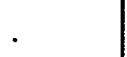 & . & . & . & 0.1139 & 0.1657 & 0.6016 & 00111 & 0.2163 & 0.0500 \\
\hline 7.870 & 11 & . & . & $\cdot$ & . & . & . & & 0.0052 & 0.0401 & 0.0002 & 0.7139 & 0.0011 \\
\hline 6.796 & 32 & . & . & - & . & . & . &. & . & 0.3767 & 0.1984 & 0.0125 & 0.5320 \\
\hline 7.111 & 36 & . & . & . &. & . & . &. & . & . & 0.0359 & 0.0846 & 0.1379 \\
\hline 6.333 & 23 & . & . & . &. & . & . & . & . & $\theta^{\circ}$ & 1. & 0,0005 & 0.4977 \\
\hline 7.741 & 34 & . & . & 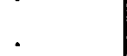 &. & . & . &. & . & 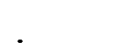 &. & . & 0.0028 \\
\hline 6.574 & 43 & 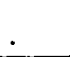 & 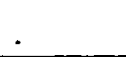 & & $\cdot$ & . & - & & 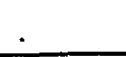 & & 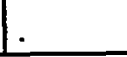 & & \\
\hline
\end{tabular}

\section{Significativo a $5 \%$ de probabilidade}

Para o diâmetro do lume das fibras, dentro do grupo fenotípico 1, os clones não apresentam variaçōes significativas, com valores de 7,07, 7,07 e 6,94 $\mu \mathrm{m}$, para os clones 26, 28 e 46, respectivamente (Tabela 13).

Para o grupo fenotípico 2, o clone $18(8,35 \mu \mathrm{m})$ diferenciou-se significativamente do clone $40(7,30 \mu \mathrm{m})$ e $12(7,69 \mu \mathrm{m})$ para o diâmetro do lume das fibras.

Para o grupo fenotípico 3, apenas o clone $11(7,87 \mu \mathrm{m})$, diferenciou-se ao nível de $5 \%$ de probabilidade do clone $32(6,80 \mu \mathrm{m})$ e clone $36(7,11 \mu \mathrm{m})$.

Para o grupo fenotípico 4, o clone 34 apresentou diâmetro do lume médio das fibras $(7,74 \mu \mathrm{m})$ diferenciando-se estatisticamente do clone $23(6,33 \mu \mathrm{m})$ e do clone 43 $(6,57 \mu \mathrm{m})$, que não variaram entre si. 
A amplitude de variação para os valores de diâmetro do lume dentro dos grupos fenotípicos foram: $6,94-7,07 ; 7,30-8,35 ; 6,80-7,87 ; 6,33-7,74 \mu \mathrm{m}$, para os grupos fenotipicos 1, 2, 3 e 4 respectivamente.

Tabela 14: Resultados do Teste de Tukey para parâmetros de qualidade da madeira: espessura da parede das fibras.

\begin{tabular}{|c|c|c|c|c|c|c|c|c|c|c|c|c|c|}
\hline & & \multicolumn{3}{|c|}{ GR 1} & \multicolumn{3}{|c|}{ GR 2} & \multicolumn{3}{|c|}{ GR 3} & \multicolumn{3}{|c|}{ GR 4} \\
\hline MÉD & CLO & 26 & 28 & 46 & 12 & 18 & 40 & 11 & 32 & 36 & 23 & 34 & 43 \\
\hline 4.972 & 26 & . & 0.1145 & 0.1370 & 0.0529 & 0,0032 & 0.0183 & 0,0001 & 0.9610 & 0.6242 & 0.3072 & 0.0014 & 0.4352 \\
\hline 4.666 & 28 & 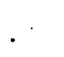 & . & 0.9216 & 0.6941 & 0.1142 & 0.3800 & 0,0020 & 0.1253 & 0.2649 & 0.5576 & 0.0585 & 0.4068 \\
\hline 4.685 & 46 & 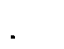 & . & . & 0.6234 & 0.0949 & 0.3302 & 0.0015 & 0.1495 & 0.3077 & 0.6250 & 0.0478 & 0.4636 \\
\hline 4.592 & 12 & . & . & . & & 0.2266 & 0.6242 & 00052 & 0.0585 & 0.1367 & 0.3308 & 0.1253 & 0.2261 \\
\hline 4.361 & 18 & ${ }^{\circ}$ & ${ }^{\circ}$ & 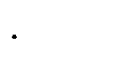 & $10^{\circ}$ & $\cdot$ & 0.4636 & 0.0786 & 0.0036 & 0.0104 & 0.0351 & 0.7313 & 0.0204 \\
\hline 4.499 & 40 & . & . & . &. & . & 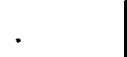 & 0.0164 & 0.0204 & 0.0529 & 0.1495 & 0.2856 & 0.0949 \\
\hline 4.018 & 11 & 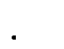 & . & $v^{\circ}$ & 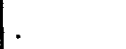 & . & . & & 0.0001 & 0.0001 & 0.0004 & 0.1494 & 0.0002 \\
\hline 4.963 & 32 & $\theta^{\circ}$ & . & r. & $10^{\circ}$ & . & . &. & . & 0.6590 & 0.3302 & 0.0015 & 0.4640 \\
\hline 4.879 & 36 & . & . & . & . & . & . & 1. & . & - & 0.5894 & 0.0046 & 0.7688 \\
\hline 4.777 & 23 & . & . & . & . & . & . & . & . & . & . & 0.0164 & 0.8050 \\
\hline 4.296 & 34 & $\sigma^{\circ}$ & . & . & . & . & . & . & . & . & . & . & 0.0092 \\
\hline 4.824 & 43 & & . & . & & . & . & & . & . & . & . & 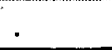 \\
\hline
\end{tabular}

\section{Significativo a $5 \%$ de probabilidade}

Para a espessura da parede das fibras no grupo fenotípico 1, por esse parâmetro não houve variação entre os clones com valores de 4,97, 4,66 e 4,68 $\mu \mathrm{m}$, para os valores 26,28 e $46 \mu \mathrm{m}$, respectivamente (Tabela 14).

Para o grupo fenotípico 2, da mesma forma, as médias dos clones para espessura da parede das fibras não mostraram diferenças estatísticas significativas com valores de 4,59, 4,36 e 4,49 $\mu \mathrm{m}$, para os clones 12,18 , e 40, respectivamente

No grupo fenotípico 3, a espessura da parede das fibras, correlacionadas com 0 resultado do diâmetro do lume, apresentou diferenças significativas entre os clones $11 \mathrm{e}$ 32 e entre os clones 11 e 36 . O clone 11 apresentou a menor espessura de parede, com $4,02 \mu \mathrm{m}$, seguido pelo clone $36(4,88 \mu \mathrm{m})$ e clone $32(4,96 \mu \mathrm{m})$. 
Para o grupo fenotípico 4, a espessura da parede da fibra, apresentou diferença significativa entre as médias dos clones, acompanhando a diferença apresentada para a densidade básica da madeira e diâmetro do lume. Podemos, assim, concluir uma possivel relação de comportamento entre essas características para os clones estudados.

A maior média foi apresentada pelo clone $43(4,82 \mu \mathrm{m})$, seguida pelos clones 23 $(4,77 \mu \mathrm{m})$ e $34(4,30 \mu \mathrm{m})$.

A amplitude de variação para os valores de espessura da parede das fibras dentro dos grupos fenotípicos foram: 4,66 - 4,97; 4,36-4,60; 4,02 - 4,96; 4,30-4,82 $\mu \mathrm{m}$, para os grupos feno típicos 1, 2, 3 e 4 respectivamente.

Com base nos resultados obtidos para clones $E$. urophylla dentro dos grupos fenotípicos 1 a 4, referentes aos parâmetros de qualidade da madeira analisadas, podese concluir que:

i. O grupo fenotípico 1 apresenta-se homogêneo para as características diâmetro do lume, largura e espessura das paredes das fibras, com pequenas variações individuais para a densidade básica da madeira, percentagem de casca e comprimento das fibras.

ii. O grupo fenotípico 2 é o mais homogêneo, não apresentando diferenças estatísticas para a maioria das características estudadas.

iii. O grupo fenotípico 3 apresentou significancia para espessura da parede das fibras não explicada pelos valores da densidade básica da madeira.

iv. O grupo fenotípico 4 apresentou maior variação da densidade básica da madeira, correlacionada com a espessura da parede das fibras.

Com base nas amplitudes, nota-se maior variação dentro dos grupos do que a apresentada entre grupos. Sendo assim, a seleção individual dentro dos grupos apresentam-se mais efetiva. 
Os parâmetros fenotípicos utilizados por Lopez (1992), para a classificação dos grupos fenotípicos 1 a 4 na população clonal de $E$. urophylla, instalada na Champion, não apresentam correlação com os parâmetros de qualidade da madeira analisados neste trabalho. Esses resultados indicam que as características de tronco, casca, folhas e frutos (Anexo 1) na população clonal de E.urophylla, não estão relacionados com a densidade da madeira, \% de casca e comprimento, largura, espessura e diâmetro do lume das fibras.

Dessa forma é fundamental nos processos de seleção incluir conjuntamente os parâmetros fenotípicos e de qualidade da madeira. Dentre os parâmetro de qualidade da madeira incluidos nos programas de melhoramento genético destaca-se a densidade básica, por ser uma característica fortemente herdável, utilizada por autores como FERNANDES et alii (1989), ALMEIDA et alii (1981) e OLIVEIRA (1981) conforme citado na revisão bibliográfica. 


\subsection{Variação dos parâmetros tecnológicos dentro de clones}

As variações dos valores de densidade básica da madeira, percentagem de casca, comprimento, largura, diâmetro do lume e espessura da parede das fibras são apresentados nas Tabelas 15 a 20 e Figuras de 2 a 7.

Tabela 15. Densidade básica média da madeira dos clones de $E$. urophylla e respectivo desvio padrão.

\begin{tabular}{|cccc|}
\hline GRUPO & CLONE & $\begin{array}{c}\text { MEDDIA } \\
\left(\mathbf{g}^{3} \mathbf{c m}^{3}\right)\end{array}$ & $\begin{array}{c}\text { DESVIO } \\
\text { PADRĀO }\end{array}$ \\
\hline \multirow{2}{*}{1} & 26 & $0,681^{\star}$ & $0,016^{\star \star}$ \\
& 28 & 0,619 & 0,013 \\
& 46 & 0,614 & 0,016 \\
\hline \multirow{2}{*}{2} & 12 & 0,615 & 0,021 \\
& 18 & 0,588 & 0,011 \\
& 40 & 0,618 & 0,035 \\
\hline \multirow{2}{*}{3} & 11 & 0,650 & 0,016 \\
& 32 & 0,662 & 0,010 \\
& 36 & 0,642 & 0,031 \\
\hline \multirow{2}{*}{4} & 23 & 0,615 & 0,008 \\
& 34 & 0,575 & 0,037 \\
& 43 & 0,634 & 0,028 \\
\hline
\end{tabular}

* valor médio de 3 repetições com 3 estacas por repetição.

** valor do desvio padrão da densidade básica entre estacas 


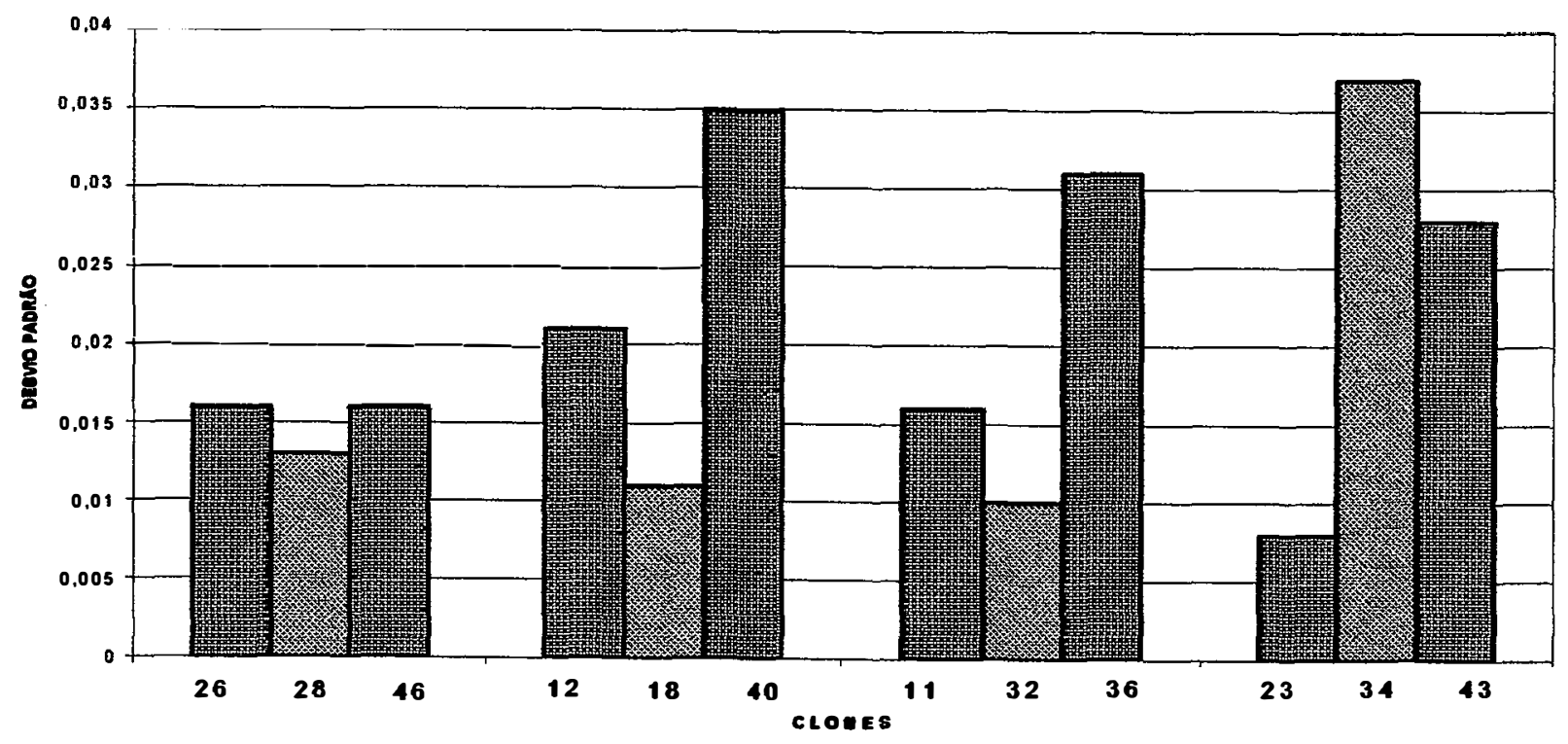

Figura 2. Desvio padrão da densidade básica da madeira para grupos fenotípicos e clones de E. urophylla

Com relação à densidade básica da madeira (Tabela 15, Figura 2), os clones de número 34, 36, 40 e 43 foram os que apresentaram maiores valores de desvio padrão, no que se refere a variação intraclonal para este parâmetro. Dentre os grupos fenotípicos, o de número 1 foi o que apresentou menor variação entre os valores de desvio padrão dos seus clones, sendo desta forma, o grupo com menor variação interclonal. Verifica-se também, de uma forma geral, que o grupo fenotípico 1 apresentou valores de desvio padrão menores de que os dos demais grupos. 
Tabela 16. Percentagem de casca média da madeira dos clones de E. urophylla e respectivo desvio padrão.

\begin{tabular}{|c|c|c|c|}
\hline GRUPO & CLONE & $\begin{array}{l}\text { MÉDIA } \\
(\%)\end{array}$ & $\begin{array}{l}\text { DESVYOO } \\
\text { PADRÄO }\end{array}$ \\
\hline \multirow{3}{*}{1} & 26 & $14,37^{*}$ & $1,45^{* *}$ \\
\hline & 28 & 10,02 & 0,65 \\
\hline & 46 & 15,15 & 4,19 \\
\hline \multirow{3}{*}{2} & 12 & 14,06 & 1,46 \\
\hline & 18 & 12,52 & 0,72 \\
\hline & 40 & 13,48 & 1,64 \\
\hline \multirow{3}{*}{3} & 11 & 17,17 & 1,49 \\
\hline & 32 & 12,16 & 0,75 \\
\hline & 36 & 14,47 & 3,98 \\
\hline \multirow{3}{*}{4} & 23 & 13,51 & 0,97 \\
\hline & 34 & 15,66 & 1,70 \\
\hline & 43 & 15,49 & 1,77 \\
\hline
\end{tabular}

* valor médio de 3 repetições com 3 estacas por repetição.

** valor do desvio padrão da densidade básica entre estacas

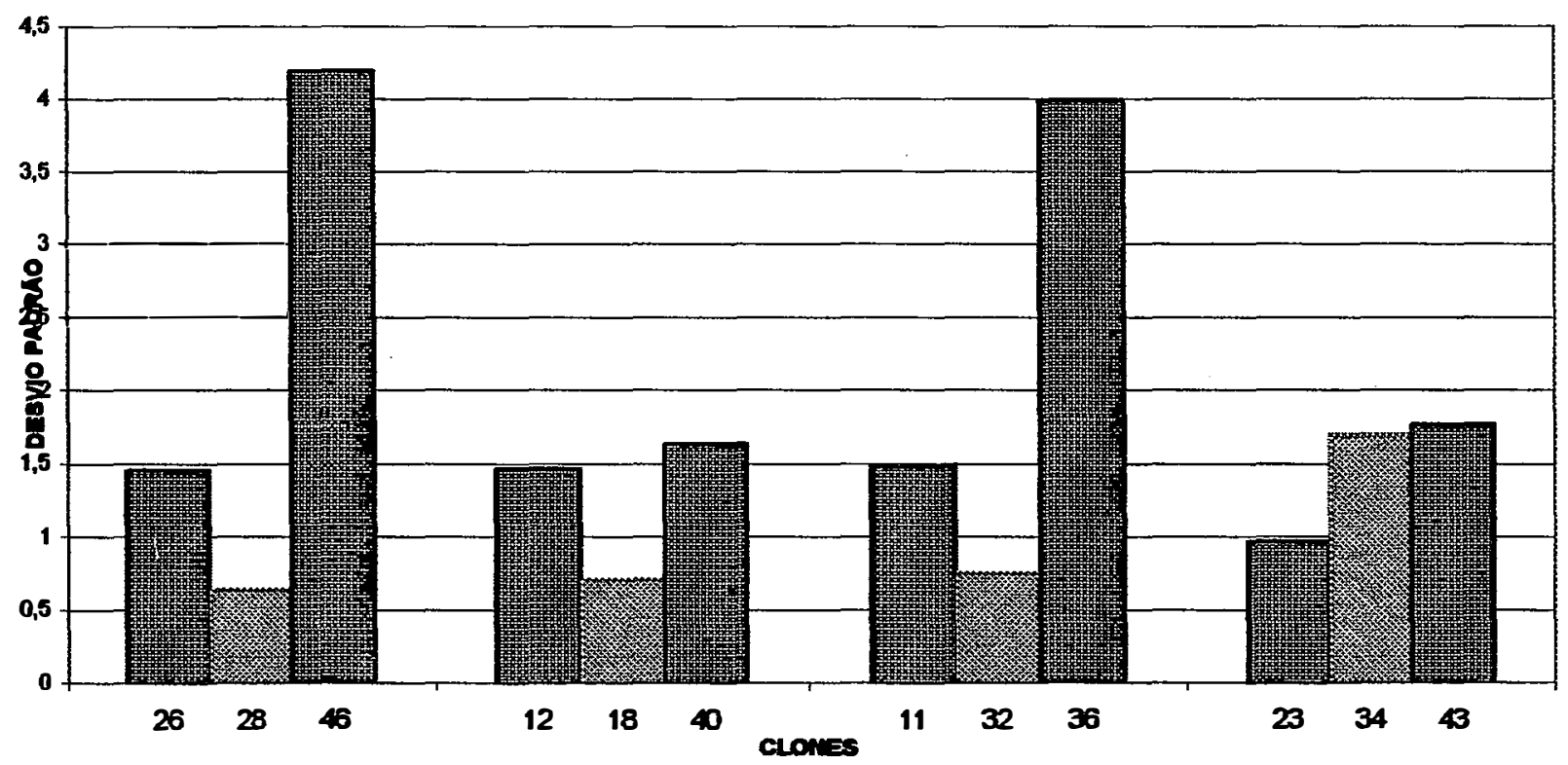

Figura 3. Desvio padrão da percentagem de casca para grupos fenotípicos e clones de E. urophylla 
Com relação à percentagem de casca (Tabela 16, Figura 3), os clones de número 36 e 46 foram os que apresentaram maiores valores de desvio padrão, no que se refere a variação intraclonal desse parâmetro. Dentre os grupos fenotípicos, os grupos 2 e 4 foram os que apresentaram menor variação entre os valores de desvio padrão dos seus clones. Sendo desta forma, os grupos com menor variação interclonal. Verifica-se também, de uma forma geral, que os mesmos apresentam valores de desvio padrão menores do que os demais grupos.

Tabela 17. Comprimento da fibra médio da madeira dos clones de E. urophylla e respectivo desvio padrão.

\begin{tabular}{|cccc|}
\hline GRUPO & CLONE & $\begin{array}{c}\text { MÉDIA } \\
(\mathbf{m m})\end{array}$ & $\begin{array}{c}\text { DESVIO } \\
\text { PADRÄO }\end{array}$ \\
\hline \multirow{2}{*}{1} & 26 & $1,00^{*}$ & $0,043^{\star *}$ \\
& 28 & 1,09 & 0,047 \\
& 46 & 1,02 & 0,055 \\
\hline \multirow{2}{*}{2} & 12 & 0,98 & 0,062 \\
& 18 & 1,00 & 0,031 \\
\multirow{2}{*}{3} & 40 & 1,03 & 0,053 \\
& 11 & 1,02 & 0,047 \\
& 32 & 1,04 & 0,070 \\
\multirow{2}{*}{4} & 36 & 0,99 & 0,042 \\
& 23 & 0,94 & 0,041 \\
& 34 & 0,96 & 0,047 \\
& 43 & 0,98 & 0,048 \\
\hline
\end{tabular}

* valor médio de 3 repetições com 3 estacas por repetição.

** valor do desvio padrão da densidade básica entre estacas 


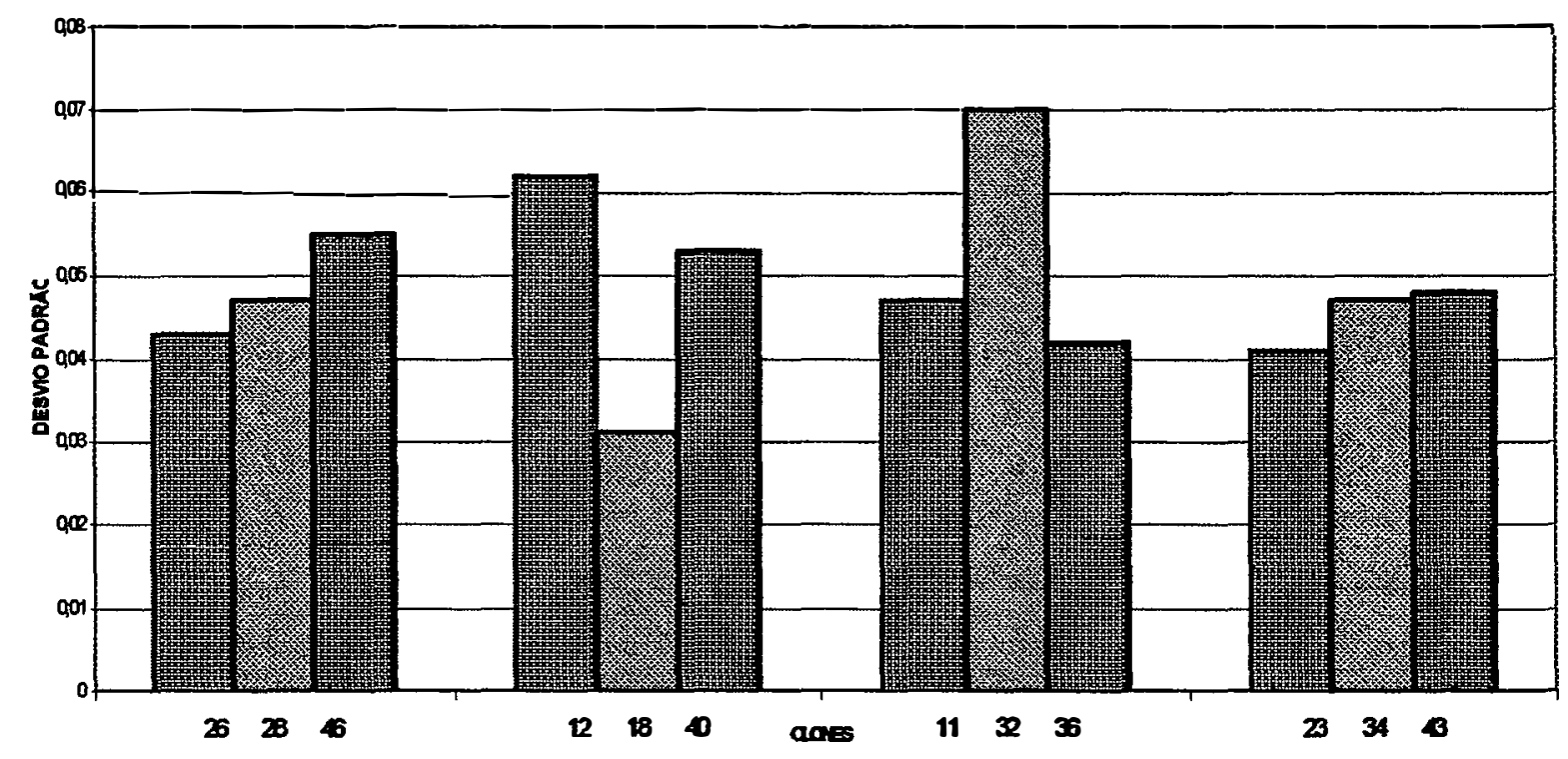

Figura 4. Desvio padrão do comprimento das fibras para grupos fenotípicos e clones de $E$. urophylla.

Com relação ao comprimento das fibras (Tabela 17, Figura 4), os clones de números 12, 32, 40 e 46 foram os que apresentaram maiores valores de desvio padrão, no que se refere a variação intraclonal desse parâmetro. Dentre os grupos fenotípicos, o de número 4 foi o que apresentou menor variação entre os valores de desvio padrão dos seus clones, sendo dessa forma, o grupo com menor variação interclonal. Verifica-se também, de uma forma geral, que o grupo fenotípico 4 apresentou valores de desvio padrão menores do que os dos demais grupos.

Com relação a largura das fibras (tabela 18, Figura 5), os clones de número 26, 28,32 e 46 foram os que apresentaram maiores valores de desvio intraclonal desse parâmetro. Dentre os grupos fenotípicos, os de número 2 e 4 foram os que apresentaram menor variação entre os valores de desvio padrão dos seus clones, sendo dessa forma, os grupos fenotípicos com menor variação interclonal. No entanto, o grupo fenotípico 4 apresentou valores de desvio padrão menores em relação ao grupo 2 . 
Tabela 18. Largura da fibra média da madeira dos clones de $E$. urophylla e respectivo desvio padrão.

\begin{tabular}{|c|c|c|c|}
\hline GRUPO & CLONE & $\begin{array}{l}\text { MEDDAA } \\
(\mu \mathrm{m})\end{array}$ & $\begin{array}{l}\text { DESVIO } \\
\text { PADRÄO }\end{array}$ \\
\hline \multirow{3}{*}{1} & 26 & $16,96^{*}$ & $1,142^{* *}$ \\
\hline & 28 & 1641 & 1,408 \\
\hline & 46 & 16,32 & 1,223 \\
\hline \multirow{3}{*}{2} & 12 & 16,93 & 0,894 \\
\hline & 18 & 17,07 & 0,993 \\
\hline & 40 & 16,30 & 0,985 \\
\hline \multirow{3}{*}{3} & 11 & 15,91 & 1,143 \\
\hline & 32 & 16,72 & 1,037 \\
\hline & 36 & 17,09 & 0,958 \\
\hline \multirow{3}{*}{4} & 23 & 15,89 & 0,492 \\
\hline & 34 & 16,33 & 0,464 \\
\hline & 43 & 16,22 & 0,547 \\
\hline
\end{tabular}

* valor médio de 3 repetições com 3 estacas por repetição.

* valor do desvio padrão da densidade básica entre estacas

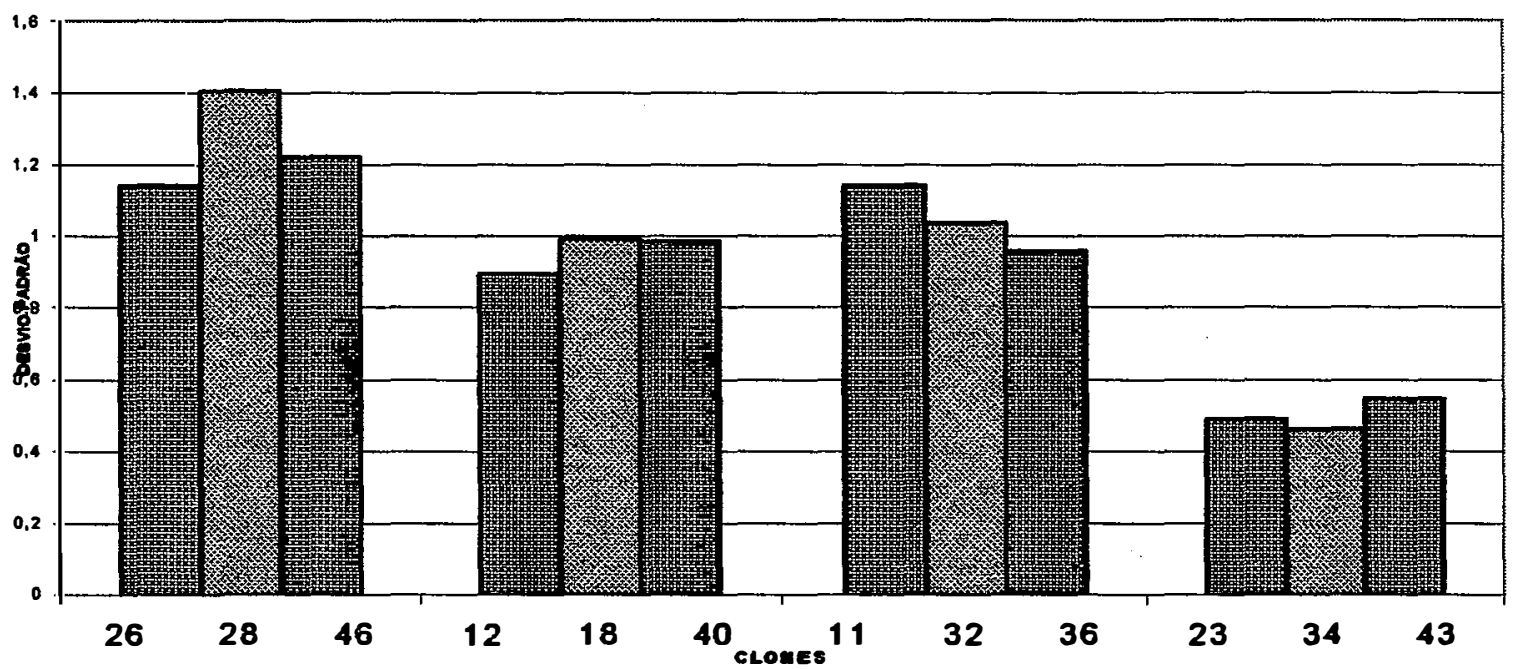

Figura 5. Desvio padrão da largura das fibras para grupos fenotípicos e clones de E. urophylla. 
Tabela 19. Diâmetro do lume da fibra médio da madeira dos clones de $E$. urophylla e respectivo desvio padrão.

\begin{tabular}{|c|c|c|c|}
\hline GRUPO & CLONE & $\begin{array}{l}\text { MEDIA } \\
(\mathrm{um})\end{array}$ & $\begin{array}{l}\text { DESVOO } \\
\text { PADRÄO }\end{array}$ \\
\hline \multirow{3}{*}{1} & 26 & $7,07^{*}$ & $0,773^{* *}$ \\
\hline & 28 & 7,07 & 1,071 \\
\hline & 46 & 6,94 & 1,140 \\
\hline \multirow{3}{*}{2} & 12 & 7,68 & 0,643 \\
\hline & 18 & 8,35 & 0,467 \\
\hline & 40 & 7,29 & 0,726 \\
\hline \multirow{3}{*}{3} & 11 & 7,86 & 1,115 \\
\hline & 32 & 6,79 & 0,899 \\
\hline & 36 & 7,10 & 0,550 \\
\hline \multirow{3}{*}{4} & 23 & 6,32 & 0,540 \\
\hline & 34 & 7,74 & 0,457 \\
\hline & 43 & 6,57 & 0,833 \\
\hline
\end{tabular}

* valor médio de 3 repetições com 3 estacas por repetição.

** valor do desvio padrão da densidade básica entre estacas

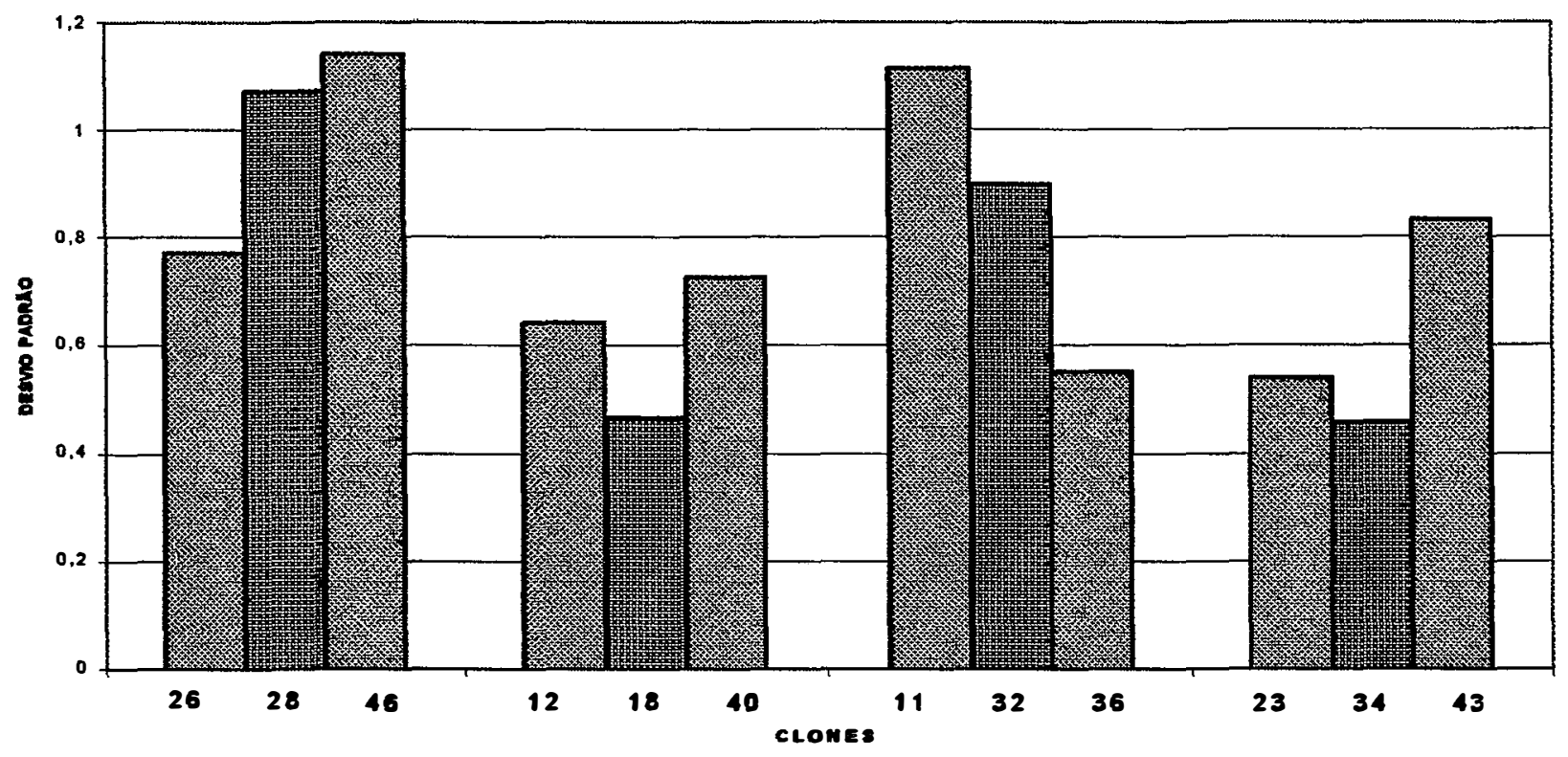

Figura 6. Desvio padrão do diâmetro do lume das fibras para grupos fenotípicos e clones de $E$. urophylla. 
Com relação ao diâmetro do lume das fibras (Tabela 19, Figura 6), os clones de número $11,26,28,32,43$ e 46, foram os que apresentaram maiores valores de desvio padrão, no que se refere à variação intraclonal desse parânetro. Dentre os grupos fenotípicos os de número 1, 2 e 4 foram os que apresentaram menor variação entre os valores de desvio padrão de seus clones. Sendo dessa forma, os grupos com menor variação intraclonal. Verifica-se também, de uma forma geral, que o grupo fenotípico 2 apresentou valores de desvio menor que os demais grupos.

Tabela 20. Espessura da parede da fibra média da madeira dos clones de $E$. urophylla e respectivo desvio padrão.

\begin{tabular}{|cccc|}
\hline GRUPO & CLONE & $\begin{array}{c}\text { MÉDIA } \\
(\mu \mathrm{m})\end{array}$ & $\begin{array}{c}\text { DESVIO } \\
\text { PADRĀO }\end{array}$ \\
\hline \multirow{2}{*}{1} & 26 & $4,97^{*}$ & $0,439^{\star \star}$ \\
& 28 & 4,66 & 0,326 \\
& 46 & 4,68 & 0,281 \\
\hline \multirow{2}{*}{2} & 12 & 4,59 & 0,531 \\
& 18 & 4,36 & 0,345 \\
& 40 & 4,49 & 0,295 \\
\hline \multirow{3}{*}{3} & 11 & 4,01 & 0,547 \\
& 32 & 4,96 & 0,315 \\
& 36 & 4,88 & 0,407 \\
\hline \multirow{2}{*}{4} & 23 & 4,77 & 0,332 \\
& 34 & 4,29 & 0,351 \\
& 43 & 4,82 & 0,435 \\
\hline
\end{tabular}

* valor médio de 3 repetições com 3 estacas por repetição.

* valor do desvio padrão da densidade básica entre estacas. 


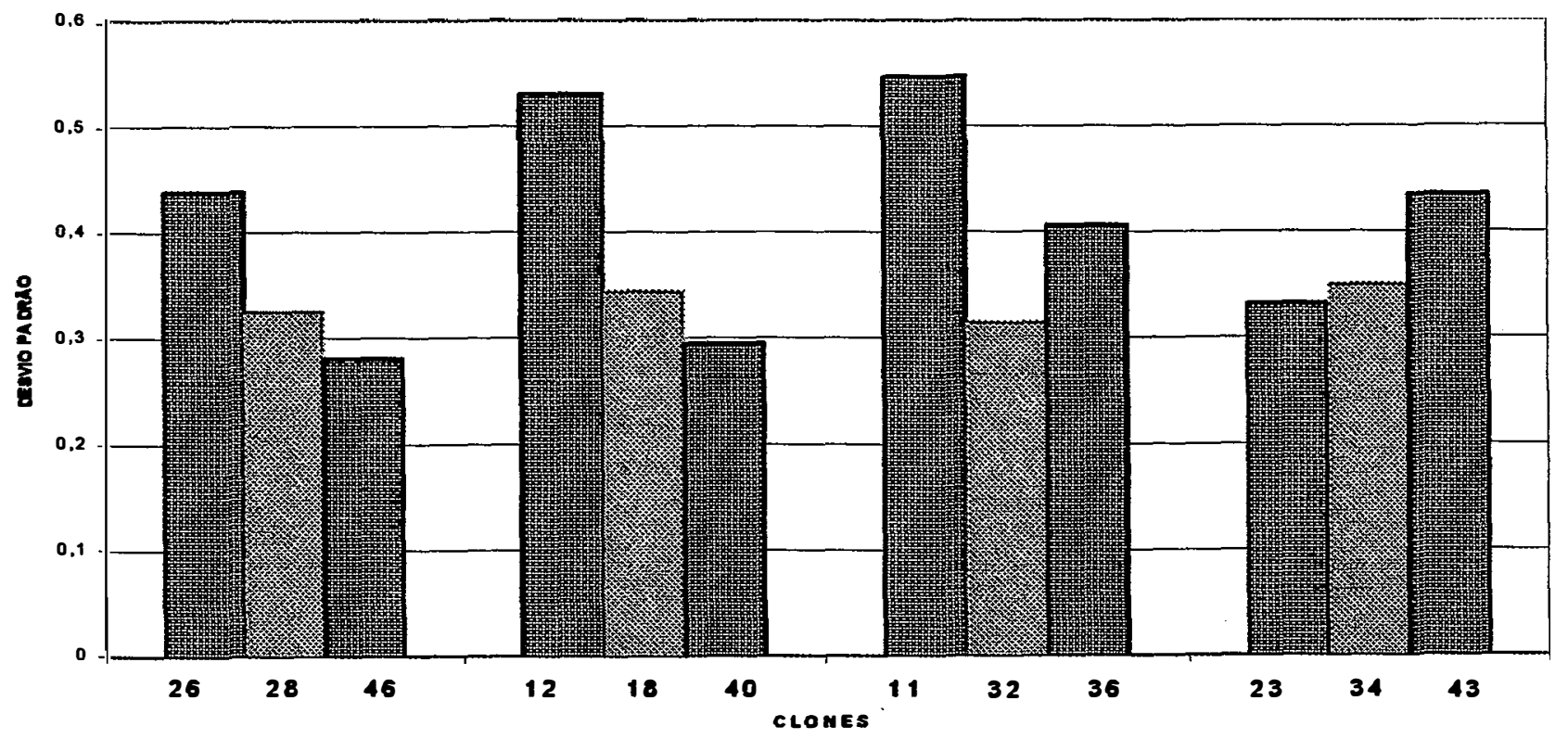

Figura 7, Desvio padrão da espessura da parede das fibras para grupos fenotípicos e clones de E. urophylla.

Com relação à espessura da parede das fibras ( Tabela 20, Figura 7), os clones de número $11,12,26,36$ e 43 foram os que apresentaram maiores valores de desvio padrão, no que se refere à variação intraclonal desse parâmetro. Dentre os grupos fenotípicos, os de número 1 e 4 foram os que apresentaram menor variação entre valores de desvio padrão dos seus clones, sendo desta forma, os grupos com menores variações interclonais.

Com base nas variações encontradas, podemos concluir que para o parâmetro densidade básica da madeira, o grupo fenotípico 1 apresentou os menores valores de variação tanto intraclonal como interclonal. Para os demais parâmetros estudados, destaca-se o grupo fenotípico 4, que em média, apresentou os menores valores de variação, tanto intraclonal como inîerclonal. 


\section{CONCLUSĀO}

Com base nos resultados do presente trabalho pode-se concluir que:

- Foram verificadas diferenças com relação à produtividade das parcelas ( $\left.\mathrm{m}^{3} / \mathrm{há}\right)$ nos 4 grupos fenotípicos e entre/dentro de clones desses grupos;

- Foram verificadas diferenças significativas entre alguns grupos fenotípicos para os parâmetros densidade básica da madeira, comprimento e diâmetro do lume das fibras;

- Pelos valores de densidade básica da madeira, percentagem de casca, comprimento, diâmetro do lume e espessura das paredes das fibras, foram verificadas diferenças significativas entre alguns clones para os grupos fenotípicos;

- Foram verificados, dentro dos clones, dos 4 grupos fenotípicos, que os valores de desvio-padrão dos parâmetros de qualidade da madeira, não evidenciaram uma mesma tendência de variação;

- Nos ensaios de seleção de clones superiores de E. urophylla devem ser incluídos conjuntamente, parâmetros de qualidade da madeira e botânicos/silviculturais. 


\section{REFERÊNCIAS BIBLIOGRAFICAS}

ALMEIDA, C.M.V.C et alii. Estimativas de herdabilidade em progênies jovens de Eucalyptus citrodora Hool. Revista Árvore, Viçosa, v5, n2, pág. 250 a 268, 1981.

ANDRADE, M.C.S. Variação das características das fibras em função dadensidade básica de cavacos de madeira de Eucalyptus grandis Hill ex Maidem. (Tese de Mestrado - UNESP), Botucatu -SP,43 pág, 1987.

BARRICHELO, L.E.G. Estudo das características físicas, anatomicas e químicas da madeira de Pinus caribaea Mor var. hondurensis para a produção de celulose Kraft. (Tese de Livre Docência - ESALQ/USP), Piracicaba-SP, 167 pág, 1979.

BARRICHELO, L.E.G \& BRITO, J.O. A madeira das espécies de eucalipto como matériaprima para a indústria de celulose e papel. Prodepef, Série divulgação, Brasilia, n13, pág 1 a 145, 1976

BARRICHELO, L.E.G \& BRITO, J.O. Correlações entre características físicas e químicas da madeira e a produção de carvão 2: Densidade de madeira $\times$ Densidade do carvão. Revista IPEF, Piracicaba-SP, n20, pág. 212 a 126, 1980

BARRICHELO, L.E.G. \& FOELKEL, E.B. Processo nitríco- acético para a maceração de madeiras. Silvicultura SP, n8,v28 pág. 732 a 733, 1983.

BARRICHELO, L.E.G; BRITO, J.O \& MIGLIORINI, J.A. Estudo da variação longitudinal da densidade básica de Eucalyptus spp. Silvicultura, SP, n.8, v.28, pág. 726 a 731, 1983. 
BERTOLUCCI, F. de L. G. \& PENCHEL, R.M. Clonagem do eucalipto: Efeitos sobre a produtividade e a qualidade da madeira. Revista Ciência Hoje, Rio de Janeiro, V.16, n.19, suplemento, pág. 16 a 21, junho, 1993.

BRASIL, M.A.M. Variação da densidade básica da madeira entre e dentro de procedências de Eucalyptus urophylla S.T. Blake. (Tese de Livre DocênciaUNESP), Botucatu-SP, 95 pág., 1983.

BRASIL, M.A.M. et alii. Variação da densidade básica da madeira entre procedências de Eucalyptus urophylla S.T. Blake. In: CONGRESSO FLORESTAL BRASILEIRO, 5, Silvicultura SP, Olinda-PE, n41, pág 110-113, 1986.

BRITO, J. O \& BARRICHELO, L.E.G. Correlações entre características físicas e químicas da madeira e a produção de carvão vegetal: Densidade e teor de lignina da madeira de eucalipto. Revista IPEF, Piracicaba-SP, n. 14, pág., 9-20. 1977.

BUSNARDO, C.A. et alii. Em Busca da qualidade ideal da madeira do eucalipto para produção de celulose III. In: CONGRESSO LATINO AMERICANO DE CELULOSE E PAPEL, 6, São Paulo, pág. 55 a 72, 1983.

CAMPINHOS Jr. E \& CLAUDIO-DA-SILVA Jr. E. Desenvolvimento do Eucalyptus do futuro. In: CONGRESSO FLORESTAL BRASILEIRO, 6, Trabalho convidado, pág., 83 a 92, 1990.

CANEVA, R. A et alii. Atuação da Champion em Três Lagoas. Revista Silvicultura, SP, n.50, pág. 32 a 34 jul/ago, 1993. 
CAPITANI, R. L.; VIEIRA, F. S. \& MENDES, F. S. Eucalyptus urophylla da Indonésia no Vale do Rio Docê. Revista C.V.R.D, v 8, n.27, pág. 37 a 52, março, 1987.

CARPIM, M. A. et alii. Comparação das características da madeira de Eucalyptus grandis e Eucalyptus saligna de diferentes procedências. In: CONGRESSO ANUAL DA ABCP, São Paulo, pág. 57 a 68, 1985.

DAVIDSON, J. Varition, association and inheritance of morfhological and wood characteres in a improvment programe for Eucalyptus deglupta. (Thesis PhD), Australian University, 263 pág, 1972.

DEMUNER, B. J. \& BERTOLUCCI, F.L.G. Seleção Florestal: uma nova abordagem a partir de estimativas de parâmetros genéticos e fenotípicos para características de madeira e polpa de eucalipto.Revista O Papel, Sp, n.1, ABTCP, pág. 16 a 23, janeiro, 1994.

FERNANDES, P.S et alii. Tensões de crescimento em procedências de Eucalyptus grandis Hill ex-maiden e suas relações com as caracterísiticas das fibras e densidade básica. Revista do Instituto Florestal, SP, n1, v1, pág. 215 a 234, 1989.

FERREIRA, C. A; FREITAS, M; FERREIRA, M. Densidade básica da madeira de plantações comerciais de eucaliptos na região de Mogi-Guacú (SP). Revista IPEF, Piracicaba SP, n. 18, pág. 106 a 107, 1979.

FERREIRA, M. Estudo da Variação da densidade básica da madeira de Eucalyptus alba Reinw e Eucalyptus saligna Smith. (Tese de Doutorado - ESALQ/USP), Piracicaba, SP, 71 pág., 1968. 
FERREIRA, M. Melhoramento genético do Eucalyptus urophylla S.T. Blake direcionado para a formação de população base tipo casca lisa ("gun"), Piracicaba, SP, 10 pág., 1985, (não publicado)

FERREIRA, M. Melhoramento e Silvicultura intensiva clonal. Revista IPEF, Piracicaba SP, n.45, pág.22-30, 1992.

FERREIRA, M. Características da madeira de espécies/procedências/árvores superiores e clones de Eucalyptus. Revisão aplicada ao melhoramento para produção de pasta celulósica. Anais IPEF, Aracruz - ES, pág. 1 a 18, junho, 1994.

FERREIRA, M. Consulta pessoal. 1996

FERREIRA, $M$ et alii. Adaptações de Espécies/Procedências nas regiões de cerrado do Brasil central. In.: SIMPÓSIO ENERGIA DA BIOMASSA FLORESTAL. Relatório final. Convênio CESP/IPEF, São Paulo, pág. 193, 1983.

FERREIRA, M \& SANTOS, P.E.T. Eucalypts wood traits for species/provenances/plus tree and clones planted in Brazil. _ A Review Applied to Genetic Improvenemt for Pulp Production. CRCTHF - IUFRO. Eucalypt plantations: Improving Fibre Yield and Quality. Australia, pág. 258 a 260, 1995.

FOELKEL, C.E; MORA, E \& MENOCHELI, S. Densidade básica: sua verdadeira utilidade como índice de qualidade da madeira de eucalipto para produção de celulose. In.: CONGRESSO FLORESTAL BRASILEIRO, 6, Campos do Jordão, SP, v.3, pág. 719 a $728,1990$.

FONSECA, S. M. et alii. Seleção da árvore industrial. Revista Árvore, v.20, n.1, ViçosaMG, pág. 69 a 85, 1996. 
GOUVÊA, C.F. et alii. Seleção fenotípica por padrão de proporção de casca rugosa persistente em árvores de Eucalyptus urophylla S.T. BLAKE, visando formação de população base de melhoramento genético: Qualidade da madeira. CONFERÊNCIA IUFRO SOBRE SILVICULTURA E MELHORAMENTO DE EUCALIPTO. Salvador BA, Julho, 1997, pág. 355 a 360.

GOLFARI, L. Estudo atual dos plantios e resultados das introduções de espécies e origens de eucaliptos na estado de Minas Gerais. Boletim Técnico, SIF, Viçosa, MG, v.1, n.1, pág. 1 a $120,1982$.

GRIFFIN, A. R. \& RIVELLI, J. A comment on clonal eucalypt plantation. Eucalyptus improvement and silviculture, Davis, v.1, n.1, 1993.

HIGA, R. C. V. \& STURION, J. A. Avaliação de brotação de 13 espécies de Eucalyptus na região de Uberaba MG. Boletim de Pesquisa Florestal, n.22/23, pág. 79 a 86, 1991.

HILLIS, N. E. Wood quality and utilization. In.: Hillis N. E \& Brow A. G. Eucalyptus for wood production. Adelaide, C.S.I.R.O, pág. 259 a 289, 1978.

JUVILLAR, J. B. Tecnologia de transformação da madeira. In.: PENEDO W. R. - USO DA MADEIRA PARA FINS ENERGÉTICOS. Belo Horizonte, MG, CETEC/IPT, n.1, pág. 69a 82, 1980. 
LOPEZ, C.R. Variações fenotípicas e genéticas de Eucalyptus urophylla S.T. Blake da Ilha de Flores (Indonésia). (Tese de mestrado ESALQ/USP), Piracicaba, SP, 125 pág., 1992.

MARTIN, B. \& COSSALTER, C. Les Eucalyptus des lles de la sonde. Bois et Forêts des Tropiques., Nogent-Sur-Marne, n.163, pág. 3 a 25, set/out., n.164, pág 3 a 14, nov./dez., 1975.

ODA S. \& FERREIRA, M. Produção de híbridos interespecificos de eucalipto por polinização aberta. In.: CONGRESSO FLORESTAL BRASILEIRO, 4, Belo Horizonte MG, 1982, Anais, Silvicultura, n.28, pág. 407 a 408, 1983.

OLIVEIRA, R. J. D. P. Variação da densidade básica da madeira e capacidade de regeneração entre e dentro de origens de Eucalyptus grandis E. Hill ex-maiden. Viçosa, MG, 61 pág. (Tese de mestrado-UFV), 1981.

OLIVEIRA, T. da S., Caracterização da madeira de Eucalipto para construção civil. São Paulo, ( Tese- Doutorado) Escola Politécnica/USP, 1998.

PÁSZTOR, Y. P. C. Estudo comparativo do comportamento das espécies Eucalyptus alba Reinw e Eucalyptus decaisneana Blume, na região de São Paulo. Revista IPEF, Piracicaba, SP, n.11, pág. 1- 16, 1975.

PÁSZTOR, Y. P. C et alii. Testes internacional de procedências de Eucalyptus urophylla S. T. Blake. Revista do Instituto Florestal,SP, v.2, n.2, pág. 207 a 214, dez., 1990. 
PRODEPEF. As introduções de Espécies/Procedências de eucalyptus realizadas pela C.PF.R.C. Resultados iniciais. Prodepef, séire Divulgação, Brasília, n.11, pág. 1-75, 1976.

RIBEIRO, F. A. \& ZANI, F. J. Variação da densidade básica da madeira em espécies/procedências de Eucalyptus spp. Revista IPEF, Piracicaba SP, n.46, pág.76-85, 1983.

SANTOS, P.E.T et alii. Potêncial para programas de melhoramento, estimativas de parâmetros genéticos e interação progênie $X$ locais, em populações de Eucalyptus grandis S.Blake, Revista IPEF,Piracicaba SP, n.43, pág. 11 a 19, 1990.

SHYMOYAMA, V. R. de S. Variações da densidade básica e características anatômicas e químicas da madeira de Eucalyptus spp. Piracicaba, SP, 93 pág., (Tese de mestrado ESALQ/USP), 1990.

SHYMOYAMA, V. R. de S. \& BARRICHELO L. E. G. Densidade básica da madeira, melhoramento e manejo florestal. Série Técnica IPEF. v.6, n.20, pág.22, Agosto, 1989.

STURION, J. A; ALBINO, J. C \& MORITA, M. Variação da densidade básica da madeira em 12 espécies de Eucalyptus plantadas em Uberaba - MG, Boletin de Pesquisa Florestal, Curitiba PR, pág. 28 a 38, 1987.

TAPPI TEST METHODS, Atlanta, TAPPI PRESS, 1995 
TOMAZELLO FILHO, M. Variação radial da densidade básica e da estrutura anatômica da madeira do Eucalyptus saligna e E. grandis. IPEF, Piracicaba n. 29, pág. 37 a45, 1985.

VASCONCELOS DIAS, R. L. \& CLAUDIO DA SILVA, Jr. E. A. Influência da densidade básica da madeira de híbridos de Eucalyptus grandis em suas características químicas e propriedades de polpações e do papel. In.: CONGRESSO ANUAL ABCP, São Paulo, pág. 31 a 55, 1985.

VIEIRA, F. S. Procedência de Eucalyptus urophylla S.T. Blake. In.: SIMPÓSIO IUFRO EM MELHORAMENTO GENÉTICO E PRODUTIVIDADE DE ESPÉCIES FLORESTAIS DE RÁPIDO CRESCIMENTO, Águas de São Pedro, SP, Agosto, Anais Silvicultura, SP, v8, n.31, pág. 512 a 515, 1983.

VIEIRA, F. S \& BUCSAN, B. Ocorrências naturais do Eucalyptus urophylla na Indonésia. Silvicultura, SP, v.3, pág. 359 a 361, 1980.

VITAL, B. R \& DELLA LUCIA, R. M. Efeito do espaçamento na produção em peso e na qualidade da madeira de Eucalyptus grandis e Eucalyptus urophylla aos 52 meses de idade. Revista Árvore, Viçosa, MG, v.11, n.2, pág. 132 a 145, Dez.,1987.

ZANI, J. F. et alii. programa de melhoramento genético de Eucalyptus urophylla S.T. Blake, através de seleção precoce. In.: CONGRESSO FLORESTAL BRASILEIRO,6, v.3, ed.2, Campos do Jordão SP, 1990, pág. 468 a 471, 1983. 


\section{ANEXOS}

\section{ANEXO 01}

Listagem das variaveis utilizadas por Lopez 1992 em seu estudo de agrupamento:
a) Variáveis quantitativas:
1. Altura total das plantas $(\mathrm{m})$
2. Diâmetro do tronco das plantas a $1,30 \mathrm{~m}$ do solo $(\mathrm{cm})$
3. Relação comprimento/largura das folhas
4. Diâmetro do cálice do fruto $(\mathrm{mm})$
5. Comprimento do pecíolo das folhas $(\mathrm{mm})$
6. Comprimento do cálice do fruto $(\mathrm{mm})$
7. Comprimento do pedicelo do cálice do fruto $(\mathrm{mm})$
8. Sobrevivência das árvores (\%)

\begin{tabular}{|l|}
\hline b) Variáveis qualitativas nominais: \\
1. Cálice: -Tipo de disco \\
-Tipo de valvas \\
2. Tronco:-Bifurcação na base \\
-Bifurcação no topo \\
3.Forma do tronco: \\
-Perfeitamente reto \\
-Ligeira tortuosidade superior \\
-Ligeira tortuosidade superior e inferior \\
-Reto com ligeira tortuosidade na base \\
-Tortuosidade acentuada no topo \\
-Tortuosidade acentuada na base \\
-Ligeira tortuosidade em toda extenção \\
4.Forma do cálice: \\
- - Hênico \\
-Campanisférico
\end{tabular}


continuação

c) Variáveis qualitativas ordinais:

1.Tortuosidade geral do tronco: -nenhuma

-1 plano

-2 plano

2.Inclinação do tronco: -nenhuma

-leve

-média

-acentuada

3.Desrama: -grande

-média

-pouca

4.Comprimento da copa: -pequeno

-médio

-grande

5. Largura da copa: -estreita

-média

-ampla

6. Altura da casca fibrosa no tronco: $-^{-1}$ terço

$-2^{0}$ terço

7. Densidade da copa: -rala

$-3^{0}$ terço

$$
\text { -média }
$$

-densa

8.Textura da casca: -fina

-média

-grossa

9.Espessura do pedicelo do cálice: -fino

-intermédio

-grosso

10.Aspecto geral do clone: -muito bom

-bom

-médio

-ruim 


\section{ANEXO 02:}

Classificação dos grupos fenotípicos segundo Lopez (1992)

\begin{tabular}{|c|c|}
\hline $\begin{array}{c}\text { Grupos } \\
\text { Fenotipicos }\end{array}$ & \multicolumn{1}{|c|}{ Clones } \\
\hline I & $1,3,4,5,6,7,8,10,13,15,16,17,19,20,21$ \\
& $\begin{array}{c}22,26,27,28,38,39,41,45,46,48,51,53, \\
\end{array}$ \\
\hline II & $12,18,33,35,40$ \\
\hline III & $11,29,32,36,49,50,55$ \\
\hline IV & $23,43,34$ \\
\hline V & 2 \\
\hline
\end{tabular}


ANEXO 03:Delineamento estatístico do banco clonal e produtividade média dos clones.

\begin{tabular}{|c|c|c|c|c|c|c|c|c|c|c|c|c|c|c|c|c|c|}
\hline & & $=$ & $=$ & $=$ & $\overline{\mathbf{R}}$ & $\bar{E}$ & $\mathbf{P}$ & $\bar{E}$ & $\mathbf{T}$ & 1 & 6 & $\overline{0}$ & $\bar{E}$ & S & & 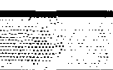 & MÉDIA \\
\hline $\mathrm{Gr}$ & CL & 1,0 & 2,0 & 3,0 & 4,0 & $\overline{5,0}$ & 6,0 & 7,0 & 8,0 & 9,0 & 10,0 & 11,0 & 12,0 & $\overline{13,0}$ & 14,0 & $\longdiv { 1 5 , 0 }$ & $\left(\mathrm{~m}^{3} / \mathrm{ha}\right)$ \\
\hline & 1 & 389,0 & 393,0 & \begin{tabular}{|l|l|}
482,1 \\
\end{tabular} & & & & & & & & & & & & & 421,3 \\
\hline & 3 & 339,0 & 384,3 & 245,4 & 229,6 & 311,7 & 231,5 & 239,3 & 208,9 & 441,9 & $|424,5|$ & & & & & & 305,6 \\
\hline & 4 & 469,4 & 335,7 & $\mid 347,1$ & 323,3 & 217,8 & 661,7 & 483,8 & $|985,7|$ & & & & & & & & 478,1 \\
\hline & 5 & 344,4 & 293,6 & $\mid 262,7$ & 566,6 & 534,5 & & & & & & & & & & & 400,3 \\
\hline & 6 & 313,4 & 211,3 & 380,2 & 389,3 & 456,9 & 623,8 & 503,1 & & & & & & & & & 411,1 \\
\hline & 7 & 467,9 & 375,9 & $|379,5|$ & 692,9 & & & & & & & & & & & & 479,0 \\
\hline & 8 & 221,9 & 556,6 & & & & & & & & & & & & & & 389,2 \\
\hline & 10 & 345,3 & 499,3 & 427,2 & & & & & & & & & & & & & 423,9 \\
\hline & 13 & 411,3 & 340,6 & 424,3 & $\mid 366,8$ & 494,5 & 719,0 & & & & & & & & & & 459,4 \\
\hline & 15 & 359,2 & 348,7 & $\mid 760,3$ & & & & & & & & & & & & & 489,4 \\
\hline & 16 & 216,3 & 503,2 & 545,6 & 705,8 & 728,4 & 465,8 & & & & & & & & & & 527,5 \\
\hline & 17 & 207,4 & 193,2 & 161,3 & 438,6 & 581,8 & 438,8 & & & & & & & & & & 336,8 \\
\hline & 19 & 204,7 & 214,4 & 116,6 & $\mid 181,7$ & 84,9 & 85,9 & 131,5 & $\mid 121,1$ & 385,4 & $\mid 401,7$ & 302,7 & & & & & 202,8 \\
\hline 1 & 20 & 421,5 & 226,1 & $|407,8|$ & 576,0 & 423,0 & & & & & & & & & & & 410,9 \\
\hline & 21 & 232,3 & 297,4 & 223,2 & 221,4 & 588,1 & & & & & & & & & & & 312,5 \\
\hline & 22 & 161,2 & 527,2 & 469,6 & 465,2 & 421,6 & & & & & & & & & & & 409,0 \\
\hline & 26 & 333,1 & 770,8 & 671,5 & & & & & & & & & & & & & 591,8 \\
\hline & 27 & 285,1 & 201,2 & 292,0 & 409,0 & 0,0 & & & & & & & & & & & 296,8 \\
\hline & 28 & 599,5 & 586,4 & 609,0 & 494,8 & 550,1 & \begin{tabular}{|l|}
$\mid 473,7$ \\
\end{tabular} & 557,2 & $\mid 496,6$ & 510,5 & 541,3 & 792,1 & 736,0 & 677,1 & 933,8 & 1059,4 & 641,2 \\
\hline & 38 & 277,3 & 409,2 & & & & & & & & & & & & & & 343,2 \\
\hline & 39 & 386,2 & 317,2 & 347,3 & 286,7 & 258,2 & 315,9 & 400,9 & 780,9 & 664,3 & & & & & & & 417,5 \\
\hline & 41 & 180,2 & & & & & & & & & & & & & & & 180,2 \\
\hline & 45 & 247,9 & 242,9 & $\mid 290,2$ & 596,3 & 488,4 & & & & & & & & & & & 373,1 \\
\hline & 46 & 335,2 & 660,1 & | 613,7 & & & & & & & & & & & & & 536,3 \\
\hline & 48 & 127,4 & $\mid$\begin{tabular}{|l}
196,2 \\
\end{tabular} & $\mid 183,4$ & 248,9 & 254,6 & 621,5 & & & & & & & & & & 272,0 \\
\hline & 51 & 483,7 & 391,8 & 397,2 & 521,3 & & & & & & & & & & & & 448,5 \\
\hline & 53 & 333,0 & 518,1 & $\mid 466,1$ & & & & & & & & & & & & & 439,1 \\
\hline & 54 & 252,3 & & & & & & & & & & & & & & & 252,3 \\
\hline & \begin{tabular}{|l|}
12 \\
\end{tabular} & 365,5 & 628,8 & 3703,1 & 655,4 & & & & & & & & & & & & 588,2 \\
\hline & 18 & 438,8 & 704,0 & 689,3 & 930,8 & 776,9 & 858,0 & 646,4 & 533,9 & & & & & & & & 697,3 \\
\hline 2 & 33 & 269,4 & 216,0 & $\mid 216,4$ & 230,7 & 243,5 & 342,2 & 215,1 & 497,2 & & & & & & & & 278,8 \\
\hline & 35 & 32,7 & 162,4 & 393,3 & & & & & & & & & & & & & 196,2 \\
\hline & 40 & 325,4 & 214,0 & $\mid 240,1$ & 489,6 & 369,5 & 276,5 & 240,9 & 606,2 & 577,6 & & & & & & & 331,1 \\
\hline
\end{tabular}


Cont'

\begin{tabular}{|c|c|c|c|c|c|c|c|c|c|c|c|c|c|c|c|c|c|}
\hline \multirow{2}{*}{\multicolumn{2}{|c|}{$\begin{array}{ll}1 \\
\end{array}$}} & \multicolumn{3}{|c|}{ Ifores } & \multicolumn{2}{|c|}{$\mathbf{R}-\mathbf{E}$} & \multirow{2}{*}{$\frac{P}{6,0}$} & \multirow{2}{*}{$\frac{E}{7,0}$} & \multirow{2}{*}{$\frac{T}{\mid 8,0}$} & \multicolumn{2}{|c|}{16} & \multirow{2}{*}{\multicolumn{2}{|c|}{$\begin{array}{cc}\bar{O} \quad E \\
11.0 \mid 12.0\end{array}$}} & \multicolumn{3}{|c|}{ 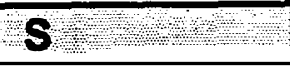 } & \multirow{2}{*}{$\begin{array}{l}\text { TMÉDIA } \\
\left(\mathrm{m}^{3} / \mathrm{mal}\right)\end{array}$} \\
\hline & Cl & 1,0 & 2,0 & 3,0 & 4,0 & 5,0 & & & & 9,0 & 10,0 & & & 13,0 & 14,0 & 15,0 & \\
\hline & 11 & $\overline{188,4}$ & 159,7 & 170,8 & & & & & & & & & & & & & 172,9 \\
\hline & 29 & 247,8 & & & & & & & & & & & & & & & 247,8 \\
\hline & 32 & 496,4 & 278,5 & 627,1 & 551,0 & $|752,0|$ & & & & & & & & & & & 541,0 \\
\hline 3 & 36 & 142,0 & 150,3 & 446,2 & 527,2 & $|362,1|$ & 573,9 & 313,3 & & & & & & & & & 359,3 \\
\hline & 49 & 358,7 & & & & & & & & & & & & & & & 358,7 \\
\hline & 50 & 208,9 & & & & & & & & & & & & & & & 208,9 \\
\hline & 55 & 1126,7 & & & & & & & & & & & & & & & 1129,7 \\
\hline & 23 & 215,1 & 217,5 & 320,0 & & & & & & & & & & & & & 250,8 \\
\hline 4 & 43 & 178,3 & 198,8 & 404,7 & 485,2 & & & & & & & & & & & & 316,7 \\
\hline & 34 & 421,5 & 242,2 & 231,5 & 248,0 & 357,6 & & & & & & & & & & & 300,2 \\
\hline 5 & 2 & $\overline{152,9}$ & $\overline{143,6}$ & $\overline{102,5}$ & 177,8 & \begin{tabular}{|l|}
173,5 \\
\end{tabular} & 250,5 & 285,1 & 271,3 & 492,8 & & & & & & & 227,8 \\
\hline
\end{tabular}




\section{ANEXO 04:}

Amostragem das repetições com base na produtividade individual de cada repetição

TABELA DOS CLONES E PARCELAS AMOSTRADAS

\begin{tabular}{|c|c|c|c|c|c|}
\hline Clones & $\begin{array}{c}\text { Grupos } \\
\text { Fenotípicos }\end{array}$ & $\begin{array}{c}\text { Produção } \\
\text { (m3/ha) }\end{array}$ & $\begin{array}{c}\text { Repetição } \\
1\end{array}$ & $\frac{\text { Repetição }}{2}$ & $\begin{array}{c}\text { Repetiçăo } \\
3\end{array}$ \\
\hline 28 & $T$ & 0 & (11) 792,1 & (14) 933,8 & (15) 1059,4 \\
\hline 26 & I & 591 & (1) 333,0 & (2) 770,7 & (3) 671,5 \\
\hline 46 & 1 & 536.30 & (1) 335,2 & (2) 660,1 & (3) 613,7 \\
\hline 18 & II & 697.30 & (4) 703,9 & (5) 930,7 & (6) 858,0 \\
\hline 12 & II & 588 & (2) 628,7 & (3) 703,0 & (4) 6 \\
\hline 40 & II & 371. & (4) 489,6 & (8) 606,2 & (9) 577,57 \\
\hline 32 & III & 541.00 & (3) 627,1 & (4) 551,0 & (5) 752,0 \\
\hline 36 & III & 359.30 & (3) 446,2 & (4) 52 & 3,9 \\
\hline 11 & III & 172.90 & (1) 188,4 & (2) 159,6 & (3) 170,7 \\
\hline 43 & IV & 316.70 & (2) 198,7 & (3) 404,6 & (4) 485,2 \\
\hline 34 & IV & 300.20 & (1) 421,5 & (4) 2 & (5) 357,6 \\
\hline 23 & IV & 250.80 & (1) 215,0 & (2) 217,4 & (3) 320,0 \\
\hline
\end{tabular}

